\title{
Ubudoda abukhulelwa : the development and testing of a peer-led STI, HIV and AIDS prevention intervention for male prison inmates in South Africa
}

Citation for published version (APA):

Sifunda, S. (2006). Ubudoda abukhulelwa : the development and testing of a peer-led STI, HIV and AIDS prevention intervention for male prison inmates in South Africa. [Doctoral Thesis, Maastricht University]. Universiteit Maastricht. https://doi.org/10.26481/dis.20060317ss

Document status and date:

Published: 01/01/2006

DOI:

10.26481/dis.20060317ss

Document Version:

Publisher's PDF, also known as Version of record

Please check the document version of this publication:

- A submitted manuscript is the version of the article upon submission and before peer-review. There can be important differences between the submitted version and the official published version of record.

People interested in the research are advised to contact the author for the final version of the publication, or visit the DOI to the publisher's website.

- The final author version and the galley proof are versions of the publication after peer review.

- The final published version features the final layout of the paper including the volume, issue and page numbers.

Link to publication

\footnotetext{
General rights rights.

- You may freely distribute the URL identifying the publication in the public portal. please follow below link for the End User Agreement:

www.umlib.nl/taverne-license

Take down policy

If you believe that this document breaches copyright please contact us at:

repository@maastrichtuniversity.nl

providing details and we will investigate your claim.
}

Copyright and moral rights for the publications made accessible in the public portal are retained by the authors and/or other copyright owners and it is a condition of accessing publications that users recognise and abide by the legal requirements associated with these

- Users may download and print one copy of any publication from the public portal for the purpose of private study or research.

- You may not further distribute the material or use it for any profit-making activity or commercial gain

If the publication is distributed under the terms of Article $25 \mathrm{fa}$ of the Dutch Copyright Act, indicated by the "Taverne" license above, 


\section{Ubudoda Abukhulelwa}

The development and testing of a peer-led STI, HIV and AIDS prevention intervention for male prison inmates in South Africa

Sibusiso Sifunda 



\section{Ubudoda Abukhulelwa}

The development and testing of a peer-led STI, HIV and AIDS prevention intervention for male prison inmates in South Africa

\section{PROEFSCHRIFT}

ter verkrijging van de graad van doctor aan de Universiteit Maastricht, op gezag van de Rector Magnificus Prof.dr. G.P.M.F. Mols, volgens het besluit van het College van Decanen, in het openbaar te verdedigen op vrijdag

17 Maart 2006 om 14.00 uur

Sibusiso Sifunda 


\section{Promotores:}

Prof dr. H. W. van den Borne

Prof. dr. S. P. Reddy (MRC, South Africa)

\section{Co-promotor:}

Dr R. A. C. Ruiter

\section{Beoordelingscommissie:}

Prof. dr. G. I. Kok (Voorzitter)

Dr. A. Krumeich

Prof. A. D. Mbewu (MRC, South Africa)

Prof. M. F. Ramashala (MRC, South Africa)

Prof. dr. N. K de Vries

Cover graptic: Mulindi Grimwond

From desigin to print-feady: Muthdni Grimwood

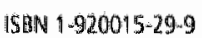

The studies presented in this thesis were conducted by the National health Promotion Research and Development Group, Medical Research Coundl, South Africa in collaboration with Enory Unwersity, Atlanta, United States of Anmerica amo the National Department of Correctional Services, Pretoria, South Africa.

This research was supported by the National Institutes for Drug Abusen NDA (Griant w-101-DA-12331-01A1). 


\section{Contents}

Chapter 1 page 7

Introduction

Chapter 2 page 17

Access Point Analysis on the State of Health Care Services in South African Prisons: A qualitative exploration of Correctional Health Care Workers and Inmates' Perspectives in KwazuluNatal and Mpumalanga.

Chapter 3 page 33

Social construction and cultural meanings of STI/HIV related terminology amongst Nguni speaking inmates and warders in four South African correctional facilities

Chapter 4 page 47

Psychosocial Determinants of Risky Sexual Behaviour amongst South African Prison Inmates

Chapter 5 page 65

The Relationship between Alcohol and Drug Use and Sexual Behaviour amongst Prison Inmates in Developing Countries: The Case of South Africa

Chapter 6 page 81

The Effectiveness of a Peer-led HIV/AIDS and ST7 Health Education Intervention for Prison Inmates in South Africa

Chapter 7 page 99

General discussion and conclusion

References page 113

Summary . page 118

Samenvatting page 121

Acknowledgements page 125

Curriculum Vitae page 126 

Chapter 1

Introduction 


\section{Introduction}

It has been reported that most inmates will have sex within the first few days of getting released from prison (Mahon, 1996; Seal, Margolis, Sosman, Kacanek, Binson Er Project Start 2003). One reported determinant of this behaviour is the pressure on men coming out of prison to immediately prove that serving time in prison hasn't taken away their 'manhood' (Seal et al., 2003). This reality poses a situation whereby inmates expose themselves to the potential of being infected with STIs including HIV and AIDS, and on the other hand expose the general community to getting infections from inmates who already had STls prior to or while they were in prison. This stark reality makes it cruciall for correctional authorities and public health practitioners to join hands towards designing programs that address the transitional period between prison life and reintegration into the community.

This thesis outlines the process of the development of the first ever large scale collaborative partnership between the South African Department of Correctional Services (DCS) and the Medical Research Council (MRC) of South Africa. This partnership was aimed at forging a relationship towards the scientific exploration of health care services in correctional facilities and leading, amongst other things, to the systematic development of a HIV, AIDS and STI health education intervention for soon to be released inmates. 


\section{Prison health issues}

Globally on any given day the number of people serving time for various offenses varies between 30 and 50 million and is seemingly on an upward trend (Levy, 1997). The most significant observation to be made about the prison population is the fact that most people are incarcerated for a very brief period which implies that there is a very huge turnover of people who come in and out of the prison system in any given year. The prison system is essentially a highly regulated but not closed system such that health problems are continuously moving between the two sides of the prison walls in a seemingly chaotic fashion (Glasser \& Greifinger, 1993).

HIV/AIDS and STDs remains the biggest health challenge facing prisoners globally. For example, whereas the AIDS incidence rate in the total US population in 1994 was 31 cases per 100,000, the corresponding aggregate rate across state and federal adult systems in the same year was 518 per 100,000 (Braithwaite, Hammett \& Mayberry, 1996). Furthermore, screening and blinded studies of inmates in countries such as Australia and Ireland have revealed that most correctional systems have HIV sero-prevalence rates between 1\% and 4\% (Dolan, Wodak \& Penny, 1995; Bellis, Weild, Mutton, Beeching $\&$ Syed, 1997). The general trend in almost every country shows that inmate populations show HIV sero-prevalence rates ranging between five to ten times those seen in the general populations (Dolan et al, 1995; Grinstead, Zack \& Faigeles, 2001). In Sub-Saharan Africa, when one considers the reported HIV prevalence rates in the general population, this problem is likely to be even bigger than what has been documented in available literature.

Surveys conducted in correctional facilities in other countries such as Australia and Nigeria (Dolan et al., 1995, Idemudia \& Reddy, 2002) have shown that between six and $12 \%$ of male inmates admit to having sex while in prison, and in Brazil up to $70 \%$ of inmates reported being sexually active while in prison (Foreman, 1999). However, sexual practices amongst inmates while incarcerated are usually underreported due to the secrecy that is attached to such practices as well as the contradictory policies on homosexuality and sodomy in prisons. It is due to these reasons that sexual risk reduction programmes need to reach a balance of addressing risk behaviour for all potential sexual encounters without focusing entirely on prison specific scenarios.

Correctional facilities provide a captive audience, which is predominantly constituted by members of the general population who usually do not receive adequate health care outside of prison due to poverty, unemployment, violence and poor access to public health services (Glaser \& Greifinger, 1993; Watson, Stimpson \& Hostick, 2004). While serving time in correctional facilities this group of people can be captured for health promotion programs, which can result in a spill over effect when they finally get released back into their communities. Furthermore, prison populations tend to be very dynamic as inmates are constantly transferred between facilities and also coming in and out of prison at a very fast rate. This constant movement within prison and between the 'inside' and 
'outside' of prison provides a perfect mechanism for the transmission of diseases at a very high rate, but conversely if prisoners are recruited into properly designed intervention programmes they can provide a valuable mechanism of information and skills dissemination.

\section{Prison based Health Education interventions and Health Promotion programmes}

Health promotion is a planned activity based on careful needs assessments that are sensitive to the experiences of, and risks faced by target populations (Schaalma, Abraham, Gilmore \& Kok, 2004). Many health education programmes are usually inadequately or inappropriately planned and executed, usually resulting in ineffective health education interventions (Reddy, Van den Borne \& Yach, 1995). Health promotion programmes have been found to be the most effective when developed and implemented in a systematic manner following a proper planning and evaluation model (see Figure 1).

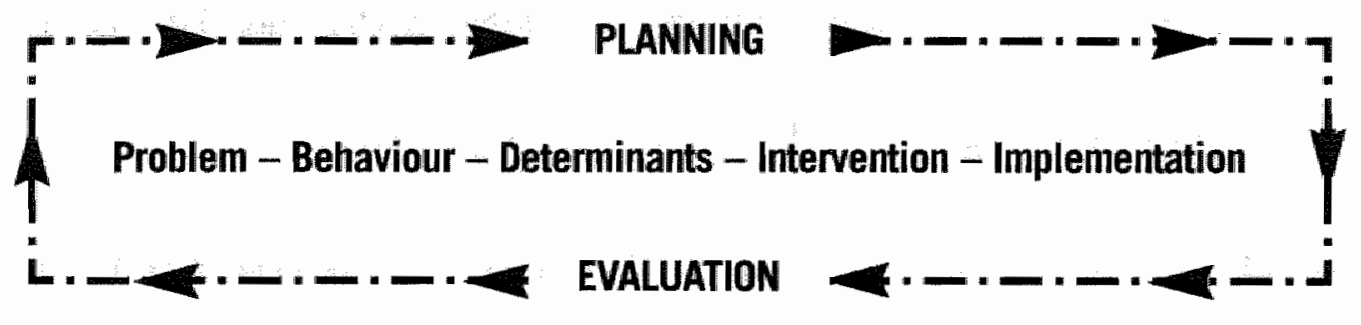

Figure 1. Model for Planning and Evaluation of Health Education Interventions; adapted from Reddy, Van Den Borne \& Yach, 1995. With permission.

This model follows a systematic approach whereby the first phase entails identifying the health problem. This is followed by identifying the behaviour that causes the problem, and in the case of inmates several behaviours such as substance use and risky sexual behaviour are identified to be responsible for causing health problems. Subsequently, the determinants leading to these behaviours are identified and this thesis explored these determinants that were specific to inmates related health behaviour. This included the socio-cultural as well as environmental determinants that are faced by inmates both within prison as well as outside of prison. The next phase is then intervention development which is designed and guided by the behavioural targets (see also Bartholomew, Parcel, Kok, \& Gottilieb, 2001). This stage involves the identification of the most effective strategies for delivering the programme. 
The next phase is the actual implementation where decisions have to be made about the timing and channels used to deliver the intervention. This stage also has to take into account the logistics and security issues within the prison as well as the follow up interviews with participants after the intervention. The evaluation process according to this framework is a continuous process throughout the various phases and proceeds in a cyclicall manner.

Systematically developed programmes have been applied extensively and successfully in STI, HIV and AIDS prevention over a large range of subpopulation groups such as high school students (Kirby \& DiClemente, 1994, James, Reddy, Ruiter, et al., 2005), college students (Bryan, Schindeldecker \& Aiken, 2001), injecting drug users (Van Empelen et al 2001), men who have sex with men (Hospers, Dewets, Ross, \& Kok, 1999) and others. Most of these studies have utilised with varying success traditional theories and constructs that are applied in HIV and AIDS prevention such as the Aids risk reduction model (ARRM) (Fisher \& Fisher, 1992), social cognitive theory (SCT) (Bandura, 1986), theory of planned behaviour (TPB) (Ajzen, 1991), health belief model (HBM) (Becker, 1974) and a host of other emerging theories. One important observation has been the realisation that interventions no matter how effective cannot be implemented indiscriminately across different population groups and be expected to achieve the same results. The evidence shows that the most effective interventions will be those that are specifically designed and targeted for a particular subpopulation. So, an intervention that works well with high school students will not necessarily achieve the same results when implemented in an incarcerated juvenile population, which might even be the same age as high school going kids.

In a groundbreaking study by Sheeran, Abraham and Orbell (1999), a large scale systematic meta-analysis was conducted to review the psychosocial correlates of condom use amongst heterosexual males. Out of a total of 121 interventions that were included in the study they did not find even a single study that had been done amongst inmates as a subpopulation. Condom use has been shown to be a very effective form of AIDS prevention amongst heterosexual men and is reported to even work better than sexual partner reduction and most theories have been demonstrated in many studies to be very effective in modifying condom use behaviour (Albarracin, Johnson, Fishbein \& Muerleile 2001).

However, amongst correctional populations this has been lacking as traditionally prison based health programmes have tended to be responsive to specific outbreaks and incidence of certain disease and was highly biased towards the biomedical curative model rather than long term prevention of diseases (Dolan et al., 1995; Jacob \& Stover, 2000). It is only recently that there has been an emergence of the first few research projects engaged in systematical exploration of prison specific health behaviour determinants. This body of work has led to the identification of new constructs of health related behaviour that are specific to inmates such as optimism about the future, self esteem and other 
constructs (Bryan, Aiken \& West, 2004). In addition to this traditional health behaviour theories such as the TPB and ARRM have been tested for their applicability on inmates' targeted health interventions (Bryan, Ruiz \& O'Neill, 2003, Clark et al., 2000)

The use of peer educators has been used extensively in the delivery of health education interventions amongst different subpopulation groups. Although widely used for targeting a number of settings they have been shown to be particularly effective when utilised amongst groups that are viewed to be disadvantaged such as inner city school kids (Fisher, Fisher, Bryan \& Misovich, 2002), and prison inmates (Devilly, Sorbello, Eccleston \& Ward, 2005), amongst others. According to Turner and Shepard (1999) the rationale to utilise peer educators has been justified amongst other reasons because of the following potential strengths:

- It is usually more cost effective than other methods

- Peers are considered to be a highly credible source of information.

- Peers are more successful than professionals in passing on information because people identify with their peers

- Peer educators aiso act as role models

- Peer education can also be beneficial to those involved in providing it

- Peer education can be used effectively to educate those who are hard to reach through conventional methods

Most of these observations can be seen to hold very true for inmate populations and thus really made a strong point for utilising former inmates as instructors of choice when delivering health promotion programmes in prison populations. The issue of instructor credibility is usually more crucial amongst inmates as they are generally suspicious of other people who do not have the experience of spending some time on the inside.

\section{The South African prison system}

The South African prison system is made up of about 241 prisons which house on average a total of about 180000 inmates (DCS, 2001). The prison population is made up of both sentenced and awaiting trial prisoners who are both accommodated within the corrections system. This situation provides many potential problems in terms of overcrowding and other health threatening problems. Research studies conducted in other countries indicate a high level of risky sexual behaviour and substance abuse amongst prison populations (Bellis et al., 1997; Braithwaite et al., 1996). As most of the data comes from western countries where the lifestyles are different to the local ones, this project was aimed at bringing some light on these issues in the South African context. This was extremely necessary as no previous research had been conducted in South African prisons due to the closed policies of the past, where there was a lot of secrecy on how the prison system used to function.

Prisons in South Africa are predominantly populated by African Black males who come from extremely disadvantaged and depressed backgrounds (DCS, 2001). Men 
make up almost $98 \%$ of the total prison population and the majority of them $(60 \%)$ are under the age of 30 years. This is a historic reality based on the legacy of our past, but the trend has continued into present times due to a host of prevaling socio-economic conditions in the country. The added factor of lower literacy rates and higher tendency to engage in risky behaviours amongst offenders makes them an even more vulnerable group than males in the general population. The department has a well-established program whereby inmates can acquire useful skills such as farming, brick laying or even get high school qualifications. Therefore the time spent in prison can be further utilised as an access point for imparting HIV/AIDS and STI prevention information more especially in preparation for release back into the community.

This study is the first extensive research enquiry into the South African correctional system after the advent of the new democratic era. Following the 1994 first democratic elections a philosophical change was seen in the correctional services where a more rehabilitative approach was adopted in the management of offenders. One classic example of this policy shift was the launch and adoption of an extensive campaign known as "Gearing Towards Rehabilitation" (DCS, 2003). This study emanated after a series of discussions and consultations between the National Department of Correctional Services and the participating research institutions to obtain evidence-based information that will inform policy formulation within the department. The development and testing of a health education intervention is the first step in the application of systematically developed interventions targeting prison populations in South Africa.

\section{Outline of the thesis}

Chapter 2 of this study report on an access point analysis, which aimed at identifying the prevailing health care service issues in the correctional setting in South Africa. This study was quite important firstly due to the previous insular policies of the department during the Apartheid regime, which resulted in a complete block out of information between the outside world and the prison. Secondly, this study allowed the research team to explore what inmates and prison health workers experienced both as providers and users of the prison health care system. This also served as preparation and planning for the development and implementation of the intervention and this aspect provided useful information into the content and logistical issues that are involved in delivering programmes to inmates in a prison.

Chapter 3 describes a qualitative study conducted to explore the socio-cultural and linguistic issues that needed to be taken into consideration when designing a health education intervention for Nguni speaking inmates who were generally poorly educated and therefore necessitated the delivery of the programme to be done in a Nguni language. As most of the concepts involved were largely western-based biomedical and psychosocial terminology this study explored the linguistic issues around adaptation of these concepts into Nguni teaching materials that were contextually relevant to our target 
population.

Chapter 4 presents a determinants study exploring the applicability of traditional theories of behaviour mainly the SCT and the TPB on their applicability on the prediction of health risk reduction behaviour amongst inmates who were soon to be released from prison. This chapter also served to explore if there were other additional prison specific determinants that are related to sexual behaviour amongst inmate population in the study area.

Chapter 5 then explored the impact of alcohol and other substance use on risky sexual behaviour amongst inmates as well as the drug use patterns amongst the inmates in the correctional settings in South Africa. These were explored because of evidence from research in other areas indicating that alcohol use and drugs use might mitigate unsafe sexual behaviour (Malow, Devieux, Jennings, Lucenko, \& Kalichman, 2001; Wingwood G DiClemente, 1998).

Chapter 6 reports on the evaluation of the intervention that was subsequently developed and administered to soon-to-be-released prison inmates in four prison facilities in the provinces of KwaZulu-Natal and Mpumalanga in South Africa. The intervention was implemented in four prisons using a nested randomised design whereby each prison had both a control and an experimental group. This chapter presents the findings of the short-term effects of the intervention immediately after the intervention while participants were still in prison as well as the long-term effects at community follow-up measured 3 6 months after participants had been released from prison

Finally, a general discussion of the whole research project as well as policy recommendations and future avenues in prison health research are presented in chapter 7. 


\section{Chapter 2}

Access point analysis on the state of Health Care services in South African prisons: A qualitative exploration of correctional Health Care Workers and Inmates' perspectives in Kwazulu-Natal and Mpumalanga.

Sifunda, S., Reddy, S.P., Braithwaite, R.B., Stephens, T., Bhengu, S., Ruiter, R.A.C., \& Van den Borne, B. (2005)

Access Point Analysis on the State of Health Care Services in South African Prisons: A qualitative exploration of Correctional Health Care Workers and Inmates' Perspectives in Kwazulu-Natal and Mpumalanga 


\section{ABSTRACT}

This paper explores inmates and prison health care workers perceptions on the state of health care services in four correctional facilities in South Africa. Structural and organisational issues are explored on how they impact the delivery and provision of health care to inmates within correctional facilities. Additionally the study forms an access point analysis of prisons as a health care setting as part of the development and testing of a SII/HIV health education intervention for soon to be released inmates. Focus groups discussions (6-8 participants per group) were conducted with inmates in four facilities. Individual face to face interviews were conducted with eight health personnel. We explored the experiences and insights from both staff and inmates to get a view from both providers and end users of health care in correctional settings. Data was analysed thematically. We found strong evidence of prison being a strategic point to increase access to health services for offenders. Curative services within prisons were well established and running despite the presence of certain challenges varying across institutions. Prevention programmes emerged as an area that requires stronger emphasis to facilitate imparting skills and promoting safer practices for inmates upon release. Peer led health education programmes might be seen as an important aspect of preparation for release and community reintegration amongst inmates. 


\section{Introduction}

Historically health and welfare services for inmates within the South African correctional facilities were provided by the Department of Correctional Services (DCS) independently from the services provided by the National Department of Health, which caters for the health of the general population (Van Heerden, 1995). Although the health care system in South Africa is usually documented as a dual health system comprising of both the private and the public health sector, the DCS health system currently operates possibly as the third major service provider of health care in the country providing care to over 180000 inmates (DCS, 2001).

However the fact that health service delivery is not a core business in this department necessitates the need to engage in studies that would explore the system in order to formulate programs that are informed by the prevailing circumstances within correctional facilities. Staff members within correctional facilities also operate under a unique chain of command system whereby a health worker is graded professionally according to qualifications, as well as along a hierarchical grading that is used in the organisational structure of the department. The prevailing organisational structure within the correctional facility, therefore presents a situation where health service delivery in terms of medical referrals and authorisations operate differently from those found in the general public health sector. Unlike in the general population where ill-health usually leads to an individual seeking attention from a health practitioner, in the correctional facility the first point of consultation is usually a non-health worker who is typically a prison warder, who may or may not permit the inmate to go to the clinic as it involves a long line of consultation and security arrangements. The route to care in correctional facility is controlled by custody policies, routines and spur of the moment decisions, which are primarily guided by policies and practices. These procedures can create significant delays, roadblocks and detours on the way to receiving medical attention (Stoller, 2003).

Since the democratic elections in 1994 the South African Correctional Services had a major paradigm shift in terms of their philosophies where they adopted a more humane and problem solving approach to their service delivery with rehabilitation as a central focus. Recent initiatives such as the 'Gearing Towards Rehabilitation' (DCS, 2003) campaign have been launched in order to improve the conditions and status of correctional populations. While any change is likely to bring some difference to an institution that was previously insular and pro punitive in its approach, a more systematic long term problem solving strategy is required especially in the critical area of health care provision and disease prevention. Given the change in orientation of the department of correctional service they have recently embarked on a process of creating research partnerships with external research organisations. Such initiatives were unheard of in the past due to the secrecy that was prevailing in this department during the days of Apartheid. The present study was conducted as part of a collaborative partnership forged with the Medical Research Council of South Africa and other international role players in prison health research. 
To get an in-depth view into prison health services, constructs from the theories of organisational dynamics were used in trying to gain insight into how staff members as part of the organisation as well as inmates who are end users of health services perceived health service deliveries in the correctional facility. There are many approaches to understanding how organisations function ranging from the most basic to the advanced that can be employed to explore the dynamics of operations in any organised structure such as a correctional facility. Mintzberg (1993) states that every organised human activity boils down to two fundamental requirements, which are the division of labour into various tasks to be performed and the coordination of these tasks to accomplish activities. In a usual health care facility this is generally a straight forward process based on the size of the facility and the hierarchy of the health care workers and levels of seniority, for instance a doctor normally issuing orders to the nurses (Reddy, Meyer-Weitz, Van den Borne, Kok \& Weijts, 1998). For health facilities operating within the correctional system the way tasks are structured, divided and coordinated differs with the management and coordination of health activities weighed together with other core activities in the prison such as safety, security and other inmates' welfare issues. The conflict between health and welfare needs of inmates and safety concerns and protocols is a common feature in correctional health care delivery in most countries (Stoller, 2003; Watson, Stimpson, \& Hostick, 2004).

Organisations have been shown to select structured organisational styles that are perceived to have an internal consistency to their situational environment, size and other concerns (Cummings \& Worley 1997). In correctional facilities the issue of safety and security is usually viewed as a high priority and therefore most decisions on staff allocations and rotations are made to ensure that security takes the highest priority. In this type of organisation it is highly likely that certain rights and privileges can be waived based on how management views the perceived security risk situation. Inmates who maybe classified as violent maybe denied or delayed from accessing medical attention if there is no escort staff member available to accompany them across the correctional facility.

The settings approach to health promotion design and planning provided a good framework for exploring the state of thealth care services in South African correctional facility (Poland, Green, \& Rootman, 2001). The correctional facility as a new setting for an envisaged health education intervention needed to be explored fully as part of the conceptualisation and planning of an appropriate intervention addressing health problems that affect inmate populations. The prison setting also provides a challenge to health services due to the informal power structures within the inmates themselves, where there is the existence of informal trading systems for supplies (Foreman 1999; Mahon 1996). This bartering is done amongst inmates and sometimes involving staff members, for items, such as food, drugs and most likely medical supplies from the prison infirmary. This has serious implications in terms of regulating and structuring of health care delivery and practices within the prison environment.

This study comprised of a qualitative enquiry into the health care services and health 
education programs being provided by the correctional system. The aim of the study was to explore the structural and organisational dynamics of providing care and delivering an inmate life skills program within the correctional facility for soon to be released inmates. A prerequisite for designing such an intervention is to gain a clear understanding of the perceptions and experiences of both health care workers and inmates.

\section{Method}

\section{Study setting and sampling}

The study sites consisted of 4 prisons in the provinces of KwaZulu-Natal (KZN) and Mpumalanga (MP) provinces. The selected prisons were classified as medium-sized, medium security facilities housing between 500 to 1000 inmates per facility. Four focus group discussions (FGDs) were conducted with inmates in the four selected facilities. All the selected prisons were either located in a small town or in a semi-rural area which is the characteristic of most prisons in the country. Each focus group consisted of between 6-8 inmates with ages ranging from 18 to 35 years of age. The FGDs were conducted using pre determined semi-structured discussion guides that had been designed and pre tested in one prison found in one of these two provinces. Additionally in-depth interviews were conducted with nine health care workers from the same facilities to gain their perspective on the health services provided. Of the nine participants 4 were registered nurses, 4 were social workers and 1 was a nursing assistant.

\section{Interview schedule}

The focus group discussions were conducted with inmates using a semi- structured preprepared discussion guide, which had been developed based on the available literature on current issues on health services provided by correctional facilities. Individual face-toface in-depth interviews were conducted with health workers utilising semi-structured interview schedules. Most of the themes explored in the discussion guides were chosen specifically to ensure that discussions elicited would provide meaningful information on correctional health issues and thus enable the team to design the research tools required for further studies in correctional facilities. The major themes focused on access to health care services for inmates while in correctional facilities. Furthermore we explored themes on staffing issues, standard protocols on admission procedures in relation to health, management of sexually transmitted infections, other infectious diseases and chronic conditions. Additionally the themes explored health care seeking behaviour, referral systems and provision of facility based health interventions targeting inmates.

\section{Data collection}

The focus group discussions with inmates and in-depth interviews with health workers were tape recorded and then transcribed verbatim (Patton, 2002). Facilitators also kept 
field notes during the discussions for additional data gathering. All focus group discussions were conducted in isiZulu by a team of trained isiZulu speaking facilitators who were also responsible for the overall data management. The discussions were then transcribed by the same team and then translated into Enilish. To ensure accuracy the transcripts were back translated into isiZulu by another team of isiZulu Speaking research assistants, originally from the areas where the research was being conducted, and therefore familiar with local dialects. All interviews with health care workers were conducted in English.

\section{Data analysis}

The qualitative data management software Kwalitan version 5 (Peters, 2000) was utilised for coding the collected data. The discussion guides had been prepared with a list of predetermined themes in order to focus the discussions on a specific area of content. Based on the pre-determined tree of themes from the focus group discussion guides and interview schedules the data was then coded into major themes with new emerging themes and patterns continuously added during coding. At first level the data was analysed to explore findings arnongst the inmates' focus group and staff members independently. The next stage was to explore themes that were highlighted in both inmates and staff generated data. The findings from both inmates and health care workers were reported in an integrated manner as supportive information rather than being reported individually as contrasting opinion.

\section{Results}

\section{Admission procedures}

Health care workers explained that department protocol stipulates that all inmates get a full medical check up usually conducted by nurses immediately, upon admission into prison.

"upon admission all prisoners come to clinic for check up, we ash them If they was on chronic treatment and what type of a treatment you were getting. If he knows the name of the treatment, we continue with that treatment. We then open a medical file for them." (health worker respondent).

Inmate participants on the other hand did not seem to recall having any medical check up on admission except for a few participants who mentioned that "they put you on a scale" when they get into prison, which is likely to be during medical check-up on admission.

\section{Health care seeking procedures}

Most participants gave an account of a protracted process of seeking health care which started very early in the morning when they woke up. Participants reported having to go through a series of consultations and approvals within the different operating structures and lock up zones in the prison before reaching the clinic. 
"You first start with the person in charge of the section and explain to him that you want

to see the doctor. So in the morning before they open for us they uswally ask if there is

anyone with a prablem... they come by every day to check" (inmate respondent).

Due to the restriction of movement within correctional facilities; health care seeking was reported to be one of the means that inmates try to utilise in order to move from one section to another through faking sickness.

"It's the way of getting out of the section (cells) and come to the hospital and do their own things on the way, like smuggling things like dagga (marijuana)" (health worker). Both inmates and prison health care workers explained that fake illness reports was a serious problem as genuinely sick people could be declined access to health care due to being suspected of feigning illness.

There are those who are really sick and then there are those who are just bing... a person will just think right now what's wrong with him and say I'm suffering from this" (inmate participant).

Clinic consultation visits were also reported by participants to be widely used to avoid participating in everyday chores such as going to the farms or cleaning the sections.

"Some prisoners really feigns sickness, they really not sick. You examine him and you can't find any syndrome. Just ask one question, don't you want to go to work? and then the truth comes up" (health worker respondent).

\section{Access to health care services by inmates}

Health care workers felt that inmates usually received better health care within the prison than they would otherwise get if they were outside.

"It happened so many times someone came in very sick and they get much better(in prison, when they go out they sometimes come back in worse state. From my point of view I think they get more well in prison"(health worker respondent).

The perception of better access to health care in prison was also confirmed by some of the inmate participants as reported by one prisoner who said,

"... when I entered prison, I was sich suffering from TB. It's better now, when I came here

in jail I told them I was sick and they gave me the pills" (inmate participant).

One correctional health worker strongly believed that the health and welfare of inmates may sometimes get worse after leaving the prison and mentioned situations where postponement of release was applied just to safeguard the health of the inmates.

"....if a person has a little bit of life span left, we will think twice before releasing him to circumstances like nural areas where there is no health care system. Sometimes you know circumstances on the "outside' is worse than 'inside" (health worker respondent)."

\section{Management of chronic conditions}

Health staff reported that in most instances medications for inmates with chronic diseases such as diabetes are administered under staff supervision in the prison clinic area. 
They don't want the prisoners to have a pill or a capsule in their possession. If he comes in the morning and say he must get it 3 times a day, we gave him his dose for the morning, 12 o'clock he must report again and in the afternoon to get his dose. The policy says they must get it in front of us" (health worker respondent).

Health workers reported that some of the rules regarding health and safety were largely due to the risky practices that inmates engage in such as tattooing and violence.

"...usually in the prison we heep it with ourselves, because we can't give needlles to a prisomer in the section other prisoners will maybe steal the syringes and use it for other purposes...They can make tattoos with needles"(health worker respondent).

Staff participants explained that they were able to make some discretion and give some level of autonomy to people with long term conditions such as Diabetes as they have to self manage the conditions even when they get out of prison.

"Diabetes more often because they test themselves everyday we let them to test themselves because if they go outside they must be accustomed on how to do it" thealth worker respondent)

\section{Management of sexually transmitted infections including HIV and AIDS}

Nursing staff all reported a moderately high presence of sexually transmitted infections amongst inmates in their facilities. They explained that there were established protocols in prison on how to manage STls, HIV and AIDS within their health facilities which included treatment, counselling as well as collecting specimens for screening.

"I do the pre-test counselling then we take blood, take it to the provincial (hospitall and

when the result come back we do the post-test counselling" (health worker respondent).

Health workers explained that there was no standardised protocal on partner notification as well as referral to outside facilities when inmates got discharged. They reported that inmates were encouraged to inform their partners if they were found to have STls but there was no monitoring on whether inmates actually followed through with the advice.

"It's difficult because they are in prison, but we encourage them to inform partners, during visiting hours they must discuss with their partners and ask them to go to the clinic" (health worker respondent).

Voluntary testing and counselling was reported by both inmates and health workers to be a freely available service in line with the national policies on the comprehensive management of HIV and AIDS.

"the counsellor tell them about the disease itself, preparing them for the outcome of the HIV test. And they must give permission for that. It is important to get information about disease. It is important to know what their status is" "health worker respondent.

Participants explained that a positive HIV test posed potential stigmatisation as inmates would immediately have to start receiving a special diet of extra fruits, which are collected daily from health workers. This special treatment was also confirmed by inmate participants who referred to the 'AIDS diet' that some people get in the clinic. 
"We give post test counselling and from there we give him special diet, fresh fruit. I see all my HIV positive patients at least once a day. I'm dishing the fruit out myself, me and my colleagues. By that means we are actually seeing them and can ask how are you? It's actually working very well" (health worker respondent).

Despite voluntary counselling and testing (VCT) availability in all the correctional facilities participants reported very low uptake of the service as observed by one inmate who said

"I know that they do conduct tests if you want. But I think it must be compulsory. When a person enters prison he must get tested because he is coming from the outside maybe he has this thing and it comes out when he is now inside" (inmate participant).

Mixed views were expressed around the issue of implementing compulsory HIV testing for all inmates in prisons, as some participants were strongly opposed to the idea.

"I don't think it must be compulsory because a person must do something out of his own will... just because I'm in jail I now have to take a blood test by force, even 'autside' they don't force a person to take a blood test" (inmate participant).

There was also a large portion of participants who strongly supported the introduction of such a policy as they viewed it as an opportunity to discover their status and thus be able to access the necessary treatment.

"I think that testing everyone would be very good, so that a person knows the circumstances he is living under, because as we are sitting here you may find out that I do have it but I don't know" (inmate participant).

\section{Capacity of correctional health care system}

The general feeling amongst health workers was that most correctional health facilities were overstretched as staff had to see a very high number of patients.

"T think it really has a big influence on the service because you know we are supposed to work with 600 prisoners. At this stage it's approximately 1300 prisoners. So we really struggle to meet the needs of the prisoners" (health worker respondent).

Additionally health workers were usually deployed to operate alone in the institutions especially in smaller prisons where there would only be one nurse who was responsible for the entire prison. A participant reported instances where a non-health worker ended up taking over the responsibility of providing health care services to inmates when the nurse was not on duty.

"If I have to attend courses and there is no registered nurse to administer medicines and help the prisoners... I have got a disciplined (staff) member who is working with me as a clerk, so he gives the mediane" (health worker respondent).

Health workers explained that they had to make curative services a priority and that preventive and health promotion programmes as a consequence usually received little or no attention at all.

"... there is no moving (progress) in this health promotion for all the health education that must be given... it is impossible to conduct health education and I really think there is 
not enough staff" thealth worker respondent).

Larger prisons were reported to be better staffed than smaller facilities as they had more personnel in their teams and therefore had more space to provide better services.

"Here there are seven staff members. We are five registered nurses, and two nursing assistants, but this two assistants, the prison utilise them anywhere they like, because nursing assistants are not classified as health staff" (health worker respondent).

Participants reported that most staff members received continuous professional training and thus have to leave their duty stations in order to attend training.

"..I always go to attend courses if people in head office says you must do so" (health worker respondent).

\section{Medical referral services}

The referral system in correctional facilities was reported to operate at two levells. Firstly prisons were reported to refer to local government hospitals for inmates who require specialised medical attention and diagnostic tests.

If someone requires an $X$-Ray, because we don't have an $X$-Ray machine... we refer

him to the general hospital where they X-Ray him" (health worker respondent).

The other reported referral procedure applied in the case of inmates who require long term hospitalisation. The standard practice was then to transfer them to a bigger correctional facility where they usually have a bigger health care facility that operates 24 hours a day providing comprehensive medical attention for inmates.

"When prisoners are too sick we start liaison with the provincial office, then they arrange for - (prison) which is a 24- hour institution" (health worker respondent).

\section{Access to traditional medicine}

All the participants explained widespread use of traditional remedies within the correctional facilities. This practice was perceived to be complicated by the existence of policies in the prisons that prohibited access to traditional medicines for inmates.

"No they are not allowed. Because we won"t know whether this muti (herbs) is for STD or poison. So muti is not allowed in the prison at all" (health worker respondent).

Participants reported that the prohibition has led to other inmates who are not trained to be traditional healers, to start providing the service to other inmates within the prison.

"What I know is there are nyangas (traditional healers) inside... In fact we usually go and" work outside, so a traditional healer knows the kinds of plants he needs so he digs them up and smuggles them inside, he then mixes them" (inmate participant).

Traditional herbs and potions were also reported to have the ability to provide magic that can lead to inmates getting acquittals or reduced prison sentences.

".I also think certain prisoners use muti to get reduced sentences I think mainly people you'll find with muti are those awaiting trial prisoners for discharge when they go to court, so when they go to court they won't be found guilty..." (health worker respondent). 


\section{Health Education programmes for inmates}

When asked about the availability of health education programmes in prison there were varied responses depending on the facilities.

"We've gor a video machine and TV. There are always videos available, the prisoners actually have to look at the video and ask questions. I think the information we give is best. We have posters, we get some pamphlets or flyers" (health worker respondent).

In facilities where they had a peer educator programme participants reported that the common strategy was the use of audio-visual based materials which also double functioned as some form of entertainment and break in the monotony of prison life.

"There are workshops that are conducted against HIV/AIDS in the sections. There are even cassettes (videos) that are available" (Inmate participant).

Some participants reported that health education sessions happened infrequently, more on commemorative occasions as opposed to routine programming.

"It happens once a year, maybe during the celebration of the AIDS day, whereby they bring condoms. Maybe they will show us how to use them" (inmate participant).

it should happen at least once a month then it can stay in your mind. So now if they only come once a year by the time they come back we would have forgotten about this thing a long time ago" (inmate participant).

Inmates also indicated strong support for a pre release intervention focusing on HIV prevention as something that would make life easier for them when they get outside.

"I only started to hear about it (HIV/AIDS) inside here in jail, therefore I don't know

what to do once I'm outside in order to protect myself from AIDS" (inmate participant).

\section{Barriers to delivering Health Education interventions in prison}

Security concerns and movement restrictions were reported to be the main barriers hindering effective implementation of health education programmes.

"What I would like to see is intercom system or network in all the cells because most of the cells have got TVs. Then everyday for a short time in the evening say for 10 minutes to put on a health program for everyone to watch "(health worker respondent).

Participants explained that due to the different security risk grading some inmates who were considered high risk did not qualify to access the sections where the sessions were conducted and this led to selective access to information and preventive skills.

"We have got three sections and ther you find out that they give higher positions to one section and nothing to ather sections. Like for me, I' $m$ hearing for the first time that there are counsellors (peer educators) inside here" (inmate participant).

\section{Access to condoms in prisons}

All the health workers reported that the department policy is that all prisons should make condoms available to all inmates. Despite the existence of this protocol, sodomy was still 
regarded as a punishable offence in prisons and therefore inmates were not keen on collecting condoms, as it was seen as an admission of having sex with other men in the prison.

"Sodomy is there, depends whether it is a consented sodomy or not, because if they agreed to it, it won't come to our knowledge, it is very common because we can give the condoms on the passages. There they are getting finished. Where are they used if its not sodomy" (hedth worker respondent.

Some inmates reported that "other people" use the available condoms and therefore were in support of the policy of having the condoms available in prison.

What I can say is that they don't take them if there is somebody looking, but wey check if there is nobody watching and take them (inmate participant).

"...in order for those who want to take these things (condoms), they must make them available inside the rooms where people sleep and be next to them (inmate participant).

\section{Discussion}

This study aimed to gain insight into the state of health care services including prevention interventions provided by correctional facilities in South Africa. This information is significant especially in the context of a paradigm shift in the post-Apartheid correctional services. The results highlight a number of key issues that are unique to health care delivery in the context of serving an incarcerated population. The study was one of the steps to ensure that change in health care and prevention practice was guided by evidence as opposed to popular or political opinion, more especially since prisons were highly politicised during apartheid. Gaining information from both inmates and prison staff as key informants was expected to increase the validity of the findings through obtaining views on the experiences and perceptions on health care from both provider and recipient.

A key observation that clearly emerged from this study expressed by both inmates and health care workers, was the fact that prisons may serve as a first point of contact with proper medical attention for a number of inmates. Most inmates are likely to come from disadvantaged backgrounds and adding their involvement in criminal activities is likely to make health care seeking a very low priority while outside of prison (Sifunda et al. $2005 \mathrm{c}$. These lindings are in line with findings from a number of industrialised countries where the health care system is supposed to be more developed and probably more efficient (Hammett, Gaiter \& Crawford, 1998; Watson et al 2004). This in turn means that even their families and communities are likely to fall in a sector of society that is underserved by the public health system. This is clearly highlighted by one of the health workers who strongly felt that health education for the inmates before they get released, was likely to provide information even for their partners and families when they get back to their communities with newly acquired preventive health information and skills.

Prison custodial warders who have no health training reportedly act as the first point 
of consultation that then approves and grants permission for inmates to see health workers. This clearly results in the subjectivity of the initial point of gaining permission to proceed to the health section and receive appropriate care as mentioned by the inmate participants. However it is important to highlight the admission by inmates themselves, of the fact that a large proportion of people used health-seeking procedures as means to go out and conduct their own business, which more often than not are illegal such as smuggling drugs and other prohibited items into the cells. As correctional staff are clearly aware of these practices, the situation poses a challenge and most likely reduces the trust and transparency on how the approval to seek health care in the clinic is granted in the prison.

Placing sick inmates on directly observed therapeutic programmes (DOTS) is an inevitable reality of delivering care in prison, due to all the restrictions and safety concerns that go with issuing medications to inmates. $A$ very effective practice in the management of TB cases can potentially bring problems to daily prison operations when applied across the board for all long term management of diseases due to intensive staff inwolvement. There are obvious increases in workloads for custodial staff, as inmates then require daily escorts to different points within the prison to collect their medication, sometimes several times daily. Due to the reported shortage of staff within the facilities and movement restrictions involved in getting permission to go through the system, inmates can easily become victims of subjective and selective preferences on the part of prison warders. It is encouraging though to hear that in some institutions chronic cases do get special wavers on some of these restrictions especially considering that they have to go through the clinic procedures every day of their lives while under incarceration. The prison culture also provides a dilemma in the dual scenario of providing proper nutrition to inmates while at the same time trying not to stigmatise patients as evident in the ability for inmates to clearly differentiate from the normal food, Diabetic diet and the so called "AIDS diel". As this study was conducted before the national roll-out of anti retroviral therapy in South Africa $(\mathrm{DOH}, 2004)$ it is very likely that the implementation of this policy, will obviously have an added pressure on prison resources and will obviously lead to many changes on the day to day operations of correctional health facilities

There is an obvious struggle between a western-based medical system and traditional health care, and this is more evident in the prison system due to the lack of free movement that inmates face when they are in custody. This struggle largely reflects on issues that the broader society is graspling with in trying to forge a peaceful co-existence between the two systems. In the case of prisons it poses problems for inmates as the prohibitions exposes people to the situation of seeking remedies from less qualified people masquerading as healers inside prison. This is clearly not a straight-forward issue but dealing with it through resistance and prohibition is unlikely to lead to solutions that are satisfactory to all the concerned parties. The use of traditional medical remedies is a commonly expressed need amongst most inmates (Sifunda et al., 2005b) and 
unfortunately cannot just be ignored or wished away by correctional authorities.

The study shows that health promotion through the provision of appropriate health interventions for inmates appears to be a challenge. While there are policies in place for health education, due to a shortage of staff there appears to be limited infrastructure for specific life skills interventions. As a consequence most interventions rely on individual initiatives of each team in their prison and thus the variations in the availability between facilities. As a result there seemed to be no proper training program in place, or the necessary support required to enable health care workers to implement any programs for inmates: This is clearly demonstrated by the differences in the little health education provided where some facilities even conducted these as annual events on "World AIDS Day". This clearly presents a missed opportunity which can be better exploited and utilised to equip inmates with crucial prevention information which can protect them from getting infected or infecting their partners when they leave prison.

The availability of condoms within the system is unlikely to lead to much benefit especially if not backed up by comprehensive programmes that impart skills on inmates and thus enable them to change their behaviour both inside the prison as well as when they get released and return to their communities. This issue is further confounded by the conflicting policy of sodomy being a criminal offence inside prison while condoms are freely available to inmates. As a result sexual activity becomes a secretive topic as inmates are generally afraid to be associated with engaging in sex lest they be charged by officials for practising 'sodomy'.

To the best of our knowledge this was the first comprehensive study that explored the health care system in the South African Correctional setting. The findings of this study clearly highlighted some of the prevailing issues that are hindering the effective provision of health care services in the correctional facilities in South Africa. More importantly the information was largely used to inform the content and design of a subsequent large-scale system-wide survey covering all correctional facilities in the country, which is currently ongoing. It is the findings of such a large-scale quantitative exploration of the system that will give even better insight into the issues of correctional healthcare delivery. 



\section{ABSTRACT}

Cultural sensitivity is increasingly recognised as a means to enhance the effectiveness of health promotion programmes all over the world. Sociocultural meanings and terminology of diseases are important in understanding how different groups perceive and interpret illness. This study formed part of the process of developing and adapting an STI/HIV peer led health education intervention for soon to be released inmates who were predominantly Nguni speakers in South Africa. Focus group discussions were conducted with prison inmates in four facilities. Additionally four more focus groups were conducted with non-health trained (custodial) personnel in the prisons who are Nguni speakers from the same community. The data reveals unique terminology and meanings attached to several biomedically defined STls. These socio-cultural constructions are not just confined to inmates as findings from warders' discussions showed a similar picture. Moreover we find the existence of a number of traditional "folk" STls and culture-specific prevention methods. This is reflected in health seeking behaviour, where dual consultation of traditional healers and biomedical remedies is widely practiced. The research has biopsychological as well as cultural implications for the development and adaptation of interventions that will be contextually relevant in indigenous populations. 


\section{Introduction}

Cultural sensitivity can be defined as the extent to which ethnic/cultural (and linguistic) characteristics, experiences, norms, values, behavioural patterns and beliefs of a selected population as well as relevant historical, environmental and social forces are incorporated in the design, delivery and evaluation of targeted health promotion materials and programmes (Resnicow, Soler, Braithwaite, Ahluwalia, \& Butler, 2000). Kagawa-Singer \& Kassim-Lakka (2003) outline this issue appropriately by saying, "every culture defines what health is for its members, determines the aetiology of disease, establishes the parameters within which distress is defined and signalled, and prescribes the appropriate means to treat the disorder both medically and socially" (p.578). This observation cannot be more relevant in sexually related conditions and behaviour change programmes where the complex issue of sexuality and long term expectations of adopting certain behaviours brings extra dynamics into the cultural and language issues.

There appears to be an uncomfortable co-existence of western defined diseases and the so-called folk illnesses, which are found in most non-western societies. Folk illnesses have been defined as "syndromes from which members of a particular group claim to suffer and for which their culture provides an aetiology, diagnosis, preventative measures and regiments of healing" (Helman, 2001, p. 86). These so called descriptions of illness draw largely from the repertoire of language, idioms, metaphors, imagery and myths from that cultural context. The differences in illness representations among different cultural groups have been widely documented in the interpretation and description of symptoms and illness in psychiatric conditions (Kleinman, 1987, Kleinman, 1988). There are distinct cultural-based, learnt patterns and interpretations of how individuals experience and explain illness which ultimatelly dictates how they manage them. (Radley, 1994). It is through this realisation that there have been continued calls for a shift from a strict biomedical model in psychiatric care to an integrated approach that takes all these dynamics into consideration.

In the case of the Nguni speaking people in South Africa there is a unique vocabulary that is used by communities to describe Sexually Transmitted Infections (STls). Among Nguni speakers a number of other illnesses have been described as sexually transmitted infections and in some instances some of them are viewed as being more serious than the biomedically defined STIs. These definitions have evolved over time through cultural experiences and observations. A similar pattern was observed in Mozambique where they found two distinct categories of STls with one corresponding to Western biomedicine and the other category based on unique cultural specific conditions also linked to sexually related presentations (Green, Zokwe, \& Dupree, 1995). Understanding the interrelationship between these terminologies and their interaction with the broader biomedical definitions of illness is important in providing an insight into the reality as perceived by the population and can go a long way in informing the development of appropriate and contextually relevant health education interventions. 
The subject of culture and local meanings attributed to sexual behaviour and sexual unfections was largely ignored in early HIV/AIDS research due to the almost exclusive focus on descriptive data which was often viewed as high priority information that could lead to quick preventative measures (Parker, 1995). The tendency not to focus on the socio-cultural and linguistic factors that shape sexual experience has been detrimental in the long term management of sexually transmitted infections and HIV/AIDS (MeyerWeitz, Reddy, Weiits, Van den Borne, \& Kok, 1998). Additionally Parker 1995 emphasises that seeking more comprehensive measures should go beyond the frequency of certain behaviours to include the "subjective and interjective" social, cultural and linguistic meaning associated with sexually transmitted diseases. It is therefore essential to engage in an in-depth exploration of these issues in order to contribute to the development of targeted HIV/STI interventions which are culturally sensitive, linguistically appropriate and appealing (Toroyan \& Reddy, 1998a, 1998b).

This paper reports on data gathered from a qualitative study, conducted as one of the components of the expanded study which was to develop, implement and evaluate a health education intervention targeting soon to be released inmates. An in-depth exploration of the contextual issues would enable the research team to ensure that the eventual health education intervention targeting inmates would convey all the deeper meanings and other culturally relevant issues, as opposed to conducting a superficial cross translation of English written and western based educational materials.

The study was carried out in the provinces of KwaZulu-Natal (KZN) and Mpumalanga (MP). These two provinces lie adjacent to each other and share a common heritage in terms of language and culture. The general population living in this area is mainly Nguni speaking (isiZulu, siSwati and isiNdebele). The research team comprised of indigenous Nguni speakers who were originally from these communities and therefore demonstrated both an understanding and sensitivity to the community being researched.

South Africa carries a large burden of sexually transmitted diseases where it has been reported that over $50 \%$ of antenatal clinic attendees are infected with at least one or more of the prevailing STIs in the country (Pham-Kanter, Steinberg, \& Ballard, 1996; Colvin, 1997; DOH, 2004). The risk of contracting HIV in people with untreated STIs is up to five times higher due to STls being a significant co-factor in the transmission of HIV (Wasserheit, 1992; Flemming \& Wasserheit, 1999). Prison populations worldwide have been known to have a high prevalence of STls as they are likely to engage in risky sexual behaviour, including alcohol and drug use, multiple sexual partners as well as engaging in transactional sex (Braithwaite, Hammet \& Mayberry, 1996; Adesanya Ohaeri, Ogunlesi, Adamson, \& Odejide, 1997). Furthermore most prisoners due to poor socio-economic conditions and constant trouble with law enforcement authorities are unlikely to receive medical attention even when they are outside of prison.

Prison facilities represent a microcosm of the community with almost every health problem in the "free world' experienced on an even larger scale on the inside (Rapposeli 
et al., 2002). This has been due largely to a number of factors but chief among them has been the historical lack of intervention and prevention programmes for inmates during and after incarceration. The time spent in prison has been identified as one of the few opportunities through which inmates can acquire skills and knowledge about health related information more especially programs on STI and HIV prevention (Braithwaite et al., 1996, Bryan et al., 2003). While the developing world follows this trend it is important to ensure that the programmes that they put in place, engage the challenges that face the participants of the intervention.

The prison environment in itself creates a special subculture which results in an added dynamic amongst inmates, one that might not exist in the general Nguni speaking population. There is a whole range of grammar and terminology that is only used and understood by people who have been in prison. While much of this study was not a direct exploration of a so called prison sub-culture, it was a very important part of formulating a properly designed health education intervention. This ethnomedical understanding and much of the emerging vocabulary was incorporated into the intervention.

\section{Methods}

\section{Setting}

The provinces of KZN and MP are 2 of the nine provinces, which make up the Republic of South Africa. Research conducted by the department of Health through the national Ante-Natal surveys have consistently indicated that the two provinces have the highest HIV sero-prevalence rates in the country, namely $30 \%$ for $\mathrm{KZN}$ and $28 \%$ in MP (DOH, 2002). It was therefore logical to explore the dynamics of risk behaviours in prisons in these two provinces as it was an opportunity to gain insight into a group of people that are transiently moving in and out of the general population under the prevailing HIV conditions. Prisoners being a sub-group who are generally exposed to higher sexual risk behaviours than the general population therefore warranted special enquiry as part of a comprehensive approach to HIV prevention in these provinces and the country as a whole.

\section{Sampling and data collection}

Two focus group discussions (FGDs) were conducted in each of the four selected prisons in KZN and MP. All the selected prisons were either located in a small town or a semi rural area which is the general characteristic of most prisons in the country. Each focus group consisted of between 6-8 African black male inmates ranging from 18 to 35 years of age. All the participants were first language Nguni speakers who had a low level of education with an average of about 3 years of formal education. This meant that they had extremely poor command of English in both written or spoken form. The FGDs were conducted using discussion guides containing themes and constructs that had been 
prepared based on a literature search as well as a pilot focus group conducted among inmates during the initial phase of the study.

An additional 4 focus group discussions were conducted with general custodial staff (non-health personnel) members in the same prisons, with one focus group per prison. All the general staff members who were selected for the focus groups were African black Nguni speaking males from the same communities as the inmates. Custodial staff are usually moderately educated individuals who have an average of grade 10 education. General staff members were chosen as key informants because they spend more time interacting with prisoners in their everyday life and they are involved in most decisions about and movements of inmates within the prison facility. As this aspect of the study was not targeting a prison specific phenomena, but rather an everyday cultural and linguistic meanings of life and living, the general staff members provided valuable information as most of them came from the communities around the prison that the study participants came from.

\section{Interview schedule}

Pre-prepared focus groups discussion guides were developed based on theories on sociocultural illness representation. Interviewer schedule consisted of detailed open - ended questions which explored themes such as knowledge of STIs including commonly used terminology and their meanings, causes of STls as well as transmission and prevention. Additional probes explored themes such as healthcare seeking behaviour as well as traditional culturally based prevention practices. The study instruments were pre-tested amongst prison inmates and staff members in one prison in KZN, prior to implementing it at the four study sites.

\section{Data collection procedures}

The focus group discussions were recorded on audio- tape and the facilitators also kept field notes during the discussions for additional data gathering. All focus group discussions were conducted in isizulu by a team of trained isiZulu speaking facilitators who were also responsible for the overall data management. The discussions were then transcribed by the same team and then translated into English. To ensure accuracy the transcripts were back translated into isiZulu by another team of isizulu speaking research assistants, originally from the areas where the research was being conducted, and therefore familiar with local dialects.

\section{Data analysis}

The qualitative data management software Kwalitan version 5 (Peters, 2000) was utilised for coding the collected data. The discussion guides had been prepared with a list of predetermined themes in order to focus the discussions into a specific area of content. Based on the pre-determined tree of themes from the focus discussion guides and 
interview schedules the data was then coded into major themes with new emerging themes and pattems continuously added during coding. The main themes explored included issues such as biomedical terminology and its meaning prevention and health care seeking behaviour. Additional themes that emerged encompassed cultural meanings and definitions of STI, traditional folk STls and other sex related conditions that are not necessarily acquired through sexual contact. Initially the data was analysed to explore findings amongst the inmates' focus group and staff focus groups independently. During the next stage themes that were common to both inmates' focus group discussions and staff focus group discussions were generated and examined. The emerging themes were then grouped into concepts that are derived from the theories of socio-cultural illness representation. (Helman, 2001; Kleinman, 1988)

\section{Results}

\section{Terminology and meaning of common sexually transmitted diseases}

The following words and phrases emerged during the discussion with both inmates and prison warder participants. " $i$ drop" - This is one of the most popular STI terminology used by Nguni speakers based on their observation of drops of discharge that the patient usually experiences in presentation of syphilis, In men they explain that this discharge forms 'drops" which exudes out of the penis. This presentation of symptoms has resulted in 'idrop' being seen as a male STI.

"I think drop is when the penis is leaking" (warder respondent).

"I think it is a disease like 'drop'. You get it when you sleep with a woman and you find" that you get injured in your manhood (private parts)" (inmate respondent).

Syphilis is also referred to as "ugcunsula" which is the indigenous term for the disease. The respondents explained that this word is not symptom related. Furthermore they clarified that 'ugcunsula' is widely understood across different age groups, and will therefore be commonly used as the diagnosis when consulting with traditional healers.

"Cauliflower" (genital warts). This is an English word that is used to describe another common type of STI. Again the terminology used to describe genital warts is derived from the actual changes that occur on the male sexual organ after an advanced progression of the disease. A prison warder upon probing described cauliflower as something like a tree, "a flesh tree'. This could indicate that men, wait until the formation of 'cauliflower-like swellings" which is an advanced disease stage, before they seek health care.

"Intwala zengulube",- This phrase translated into English literally means "pig lice" which could indicate the subtle existence of some belief that pubic lice could be spread by some contact with pigs as opposed to getting it through sexual contact with an infected person.

"You just have itching on your private parts. When you scratch you can pick them up or sometimes they run around to your face and head" (inmate respondent).

"Ukuvivuka kwezimbilapho", sometimes referred to simply as "imbilapho". The 
participants explained that swollen glands that usually accompany a number of sexually transmitted infections are regarded as an independent infection and that they did not associate it with other STls. This often means that the individual may be seeking remedies for the treatment of the swollen glands as the presenting diseases as opposed to finding the root cause of the symptoms, which is a sexually transmitted one.

"Ibuba" - known in the biomedical world as gonorrhoea, this was a unique finding as it was mentioned mainly by older participants in the focus groups, and younger participants were not familiar with it.

"Ingoulaza" This term together with a multitude of others is generally used to refer to both HIV and AIDS which creates the impression that it is perceived as being one and the same thing, even though few people try to differentiate by referring to HIV as "igciwane lengculaza" (AIDS virus). The terms " $Z 3$ " and "Amagama amathathu (three letters)" is another popular description that emerged, derived from the 3 letter abbreviation of HIV as opposed to AIDS but is widely used to refer to people who are considered to be sick and showing symptoms of the disease.

"Isipatsholo" This is the term widely used to describe herpes derived on the presentation of blisters that usually occur in the genitals when someone is infected with the disease. They explained that the blisters have to be visible on the outside of the organ to fit the description of this condition.

"Your private part gets swollen with itchy rash or blisters" (warder respondent).

\section{Popular beliefs about causes of sexually transmitted infections}

During the discussions it became evident that biological differences and gender dynamics play a very big role in understanding how diseases are spread and transmitted between sexual partners.

If a uoman loses her husband they take certain herbs, should you sleep with that woman you get a disease. This also happens when you sleep with a woman who has lost a young baby" (warder respondent).

Participants explained that they viewed women as having the ability to deliberately infect a partner with an STI either as a form of revenge for suspected infidelity or just to be spiteful to their partner.

"According to my understanding, I think if it is a 'drop', sometimes it's because lets say

you sleep with a woman and that woman put a cent (coin) under her tongue, you do get

a drop in that way" (inmate respondent).

Participants also viewed the female body as a powerful mystical entity, mostly attributed to the menstrual cycle, which is associated with 'bad blood or dirty blood'. This blood can be passed on if sexual activity takes place between a man and a woman during the menstrual period.

"I can say you can get a drop if you sleep with a menstruating woman" (inmate respondent. 
Generally accepted biomedical methods of family planning such as the birth control pill and the injection were also explained by the respondents as possible causes of sexually transmitted diseases.

These contraceptives for the women, injections can also cause some sickness, I can't

remember but it was on televisions..." (Warder respondent).

Participants mentioned that men have the ability to deliberately infect a woman with a STI, as punishment for suspected cheating so that any man who sleeps with her will get infected with the disease, a practice referred to as setting up a 'trap'.

"What I know of is umagazini/umanyazini (potassium per manganate), you (a man'

drink it and you go and sleep with your woman, the other person who will sleep with her

after you will eventually get a disease and it becomes a drop" (inmate respondent).

Some participants indicated that they believed that certain hygienic practices may lead to the transmission of STI between two partners, as the infections are generally associated with being 'dirty'.

"...I think the cause of the disease, if the female is not washing herself, her private parts,

then the disease can stay there and during sex you get it" (inmate respondent).

The participants explained that male partners can reduce their chance of getting infected after sleeping with a 'dirty girl' by making sure that they wash themselves after having sex.

"... when you sleep with a girl and you don't wash, the dirt is left inside you, that is why one suffers from these diseases" (inmate participant).

\section{Traditional or folk explanations of transmission and prevention of sexually transmitted infections}

Both inmates and warders elucidated explanations which resulted in a special category of sexually transmitted infections namely folk or traditional sexual illnesses. They explained that most traditional sexual illnesses were strongly linked to the issues of fidelity and prevention of potential and suspected cheating by a spouse or sexual partner.

"...certain inyangas (traditional healers) make use of a knife, so when you dose a knife you have closed a wife. So when you come to meet with my wife, you come strong, but when you want to enter her you become powerless, you won't enter her, you won't have a sexual intercourse with her" (warder respondent).

The participants outlined two conditions called llumbo and Ikhubalo. They explained that the two conditions are closely related and sometimes the names can be used interchangeably. Both these conditions were understood to affect people who have slept with a woman who had a 'trap' set by her husband to ensure that no other man is able to get intimate with her.

"..., like us men we set a trap in our wives so that she cannot sleep with other men. Some use muti (traditional potions) which turns into ilumbo inside a woman, and when someone else sleeps with her he catches it, then it destroys your blood and if you don't 
get traditional help you will die eventually" (inmate respondent).

The explanations given by inmates were also supported by prison warders in the groups who reported believing in and using most of these cultural practices

"...for example I have a wife and I am working far away, she is left at our home. In order to protect her not to sleep around you set some mut in her private parts so when she sleeps with another man they will be tied up until they will be taken to an inyanga.

III be doing that to catch them in the act" (warder participant).

During discussions it emerged that these conditions are viewed mainly as a deterrent to discourage partners from sleeping with other people.

"a person decides how he wants to set a trap on his wife, so ikhubalo will be this trap and whoever sleeps with my wife will be scared away by anything, others they make

ikhubalo to be a mamba (snake), so whenever you go to meet his wife you come across a mamba" (inmate participant).

Participants reported that these fidelity based prevention measures, can also be applied by females to ensure that their male partners do not engage in casual sex or extra marital relationships with other people.

"And even women too they use such things. If you're a man they know maybe you sleep around. They just put that "muti" in the bottle and lie it down (horizontal). You penis will be soff always. Then when she store it like this (upright), then you become strong (erect)" (warder participant).

In addition to those conditions that are seen as fidelity based, participants also reported the existence of other conditions that will affect their sexual organs and sexual performance through traditional witchcraft or some form of revenge from their enemies. Participants mentioned that local communities are able to identify the tell tale signs of 'trap spots' and thus avoid getting infected by walking around or avoiding the spot

"Sometimes in our cuilture we believe that you can get it on what we call a 'jump over' which is known as 'umego" (inmate participant).

\section{Health care seeking behaviour}

Most participants reported actively using the dual health system of traditional healers and clinics as a form of addressing presentations of STI related symptoms.

"You also have to go to traditional healers for treatment of these diseases to get something

to "spyt" (douche) with" (Irmate participant).

This was reaffirmed by the custodial prison workers who reported having to confiscate traditional medicines from visitors as this is viewed as contraband in correctional facilities.

"The department tried to make away (ban) with traditional mediane. We have bee sending herbs away when visitors bring them" (warder participant).

Inmates reported a number of ways to smuggle herbs and potions into the prison through relatives or through inmates who go outside to work in the prison farming sections. 
".there are nyangas (traditional healers) inside... In fact we usually go and" work outside, so a traditional healer knows the kinds of plants he needs so he digs them up and smuggles them inside" (inmate participant).

Despite the resistance and restriction of herbs and potions entering prison, participants explained they routinely use both biomedical treatments and traditional remedies while in prison as well as outside. On in-depth probing some warders indicated lower levels of objection to the traditional remedies especially on a personal level.

"The other thing is we don't know these herbs. Other people can practice witcharaft while others are real nyangas. So its better if we can hire members (staff) who know the difference between good herbs and bad ones to regulate their entry into prison" (warder respondent).

\section{Discussion}

This paper explored the socio-cultural dynamics and language construction of STI/HIV related information amongst male Nguni speaking inmates, who had relatively low levels of formal education and were between the ages of 18 to 35 . Additionally information was gathered from prison warders who were from a similar background and within the same age range as the inmates. By utilising focus group information from both inmates and warders we further explored whether these issues will only be specifically applicable to inmates or there was an overlap with non-incarcerated Nguni speaking men. Without attempting to claim an overall generalizability of these findings, this study highlights the existence of a broad spectrum of beliefs and interpretations of STI related information. This information is widely used in the interpretation of and coping with sexually transmitted infections amongst Nguni speaking young men.

The data from the study suggests that Nguni speaking inmates have a set of terminology, which forms part of their vocabulary when describing STIs and HIV. This information is a likely reflection of what exists in the larger population amongst speakers of these languages as confirmed by the focus group discussions held with prison warders: The study participants were able to describe a range of terms and words related to sexually transmitted infections. These included words like 'idrop' which is based on symptom identification to 'cauliflower', which describes physical changes to 'ibuba" which identifies an actual disease namely gonorrhoea. Significantly some indigenous terms showed generational differences whereby younger people were not familiar with words that older people used to describe certain conditions for example, ibuba referring to gonorrhoea. Other diseases such as syphilis is described and explained using the indigenous term 'ugcunsula'.

In the case of HIV and AIDS the complexity of both the infection and the disease is reflected by participants providing a multitude of words and terms. Ingculaza is a term which conflates both HIV and AIDS. They were however able to provide terms specifically for the AIDS virus, igciwane lengculaza. The seriousness of the virus is also 
located in specific Nguni terminology namely 'amagama amathathu' and ' $\mathrm{Z} 3$ ' implying differentiation between HIV and the terminal consequences of AIDS. This terminology also implies potential stigmatisation of individuals and fear of death. Interestingly not a single participant amongst inmates mentioned the words that are generally used in the biomedical model. Words that are generally skimmed over as colloquial words in most studies (Helman, 2001) were found to be predominantly used by study participants to derive meaning of STIs. It is important to emphasise that health workers and researchers should avoid the temptation to assume that one single local term can be used across the board to describe illness amongst non-Western language groups. The reality is that in most traditional descriptive based illness meanings, there are usually a number of words that are used to describe similar or the same conditions and most of this terminology is always evolving (Winch et al, 1996).

The findings of this study are similar to earlier findings on STI related descriptions in Sub-Saharan Africa (Green, Jurg, \& Dgedge, 1993) whereby it was found that local indigenous people have unique views and interpretations of sexually transmitted infections. In most cases diseases are not viewed on a simple causal route but more as a complex web of illness representations (Helman, 2001). The cause of certain diseases is viewed over a wide range of understandings including both the biological and spiritual level of illness presentations. Participants reported that engaging in sexual intercourse with widows and women who had lost a child can cause sexually transmitted infections. The reference to dirty blood and poor hygiene levels among women as causes of STls has demonstrated a certain level of misinformation and myths on the biological manifestations of diseases. However the association of the menstrual cycle with a potential transmission of sexual disease cannot be dismissed as a myth or lack of information, as it is strongly embedded in the social and cultural practices that are traditionally based and provide meaning within the Nguni community.

This study clearly shows the existence of traditional folk based sexually transmitted or sexually related illnesses, which are not recognised in biomedical definitions of STls. Conditions such as Ikhubalo and ilumbo lean strongly on a spiritual definition and interpretation of illness due to their links to the use of snakes and other animal imagery that are supposed to discourage infidelity amongst couples. There can be no denying of the fact that these diseases exist and are viewed with seriousness as indicated by the general agreement that proper consultation with traditional healers is required when you get 'infected' with these conditions.

The data demonstrate complex notions of prevention, which encompasses spiritual, physical and culturally bound mythological practices. These practices are wrapped in notions of fidelity in the context of cheating partners i.e. women having extra marital sexual relations. On careful observation most of these prevention strategies seem to be based on men taking control over 'their women' by applying certain herbs and potions obtained from traditional healers. These methods are perceived as providing 'traps' for the 
prevention of extra marital sex which they explained results in acquiring disease. Most of these preventive traps are based on a complex interaction of the spiritual, physical and mythological beliefs, which all operate at different levels of the prevention process and are deeply ingrained. These methods appear to present a situation whereby men can absolve any responsibility of active participation in preventive measures as long as they have applied the traditional methods that safe guards them and their sexual partners. In contrast mainstream preventive strategies rely and promote active engagement of individuals in the process of voluntary behaviour change and adopting preventive strategies such as condom use. This creates a potential conflict between traditional and mainstream prevention strategies due to the difference of one being more passive and the other relying on the active engagement of the individual in disease prevention. It is highly likely that traditional methods are perceived as being more efficacious and even easier to practice than mainstream methods such as taking personal responsibility for condom use. Discarding the traditional methods as cultural myths and taboos is likely to perpetuate conflict between the traditional ideas on prevention and the mainstream evidence based prevention approaches.

The study demonstrated that health care seeking behaviour amongst Nguni speakers almost always involve the consultation of the dual system of western based medicine and traditional healers who then provide herbal remedies, potions and spiritual counsel. It must be added that consultation involves both preventive and treatment practices. Even the adoption of prohibitive policies against traditional medicine in prisons has resulted in widespread smuggling of herbs and potions by inmates in order to address this need. As some illnesses are interpreted as being due to some contamination of the blood, the traditional methods will always be necessary as western medication is viewed as not being adequate to address these conditions holistically (Green, 1992). Striking a balance between the need for individuals to utilise these two systems is an issue that health workers and researchers should grapple with respectfully.

The aim of the study was to explore the socio-cultural meanings as a way to develop a health education intervention targeting male inmates. The issue of cultural dynamics is a much specialised subject and still requires more focused and in-depth exploration than was done in the present study. The use of focus groups from a limited subgroup of the society is likely to have limited the completeness of the unique cultural dynamics that exist amongst. Nguni speaking populations. Nonetheless it is extremely important for researchers to put more emphasis on eliciting and understanding local terminology as a criticall step towards developing effective health education interventions. The emerging differences such as divergent views on prevention highlight the need to avoid a 'carpet bomb' approach in the development of health education interventions and makes the case for tailoring interventions to account for variations in language and terminology of illness representations. This is one of the first few studies that critically address the issue of language and meaning in a manner, that seek to integrate ethnomedical dynamics in intervention development as an existing reality as opposed to myths that needs to be changed. 
46 


\section{Psychosocial determinants of risky sexual behaviour amongst South African prison inmates}

Submitted as:

Sifunda, S., Reddy, S.P., Braithwaite, R.B., Stephens, T., Bhengu, S., Ruiter, R.A.C., \& Van Den Borne, B. (2005). Psychosocial Determinants of Risky Sexual Betiaviour amongst South African Prison Inmates 


\section{ABSTRACT}

To inform future intervention programmes, this study explored the psychosocial and contextual determinants of intention to reduce risky sexual behaviour amongst inmates in South African prisons. A cross sectional study using interviewer administered questionnaires was conducted with 357 inmates across 4 prison facilities in South Africa that were involved in a pre-release health education intervention for parolees. About $65 \%$ of participants were first time offenders. Almost $50 \%$ were unemployed prior to arrest and $66 \%$ were married at time of incarceration. Self-efficacy, general life skills efficacy and sexual communication were the strongest predictors of intention to reduce risky behaviour upon release. High intenders were significantly different from low intenders in their self-efficacy, sexual communication, attitudes towards condom use and the perceived norm of sex being a non-utilitarian transaction. It is concluded that the exploration of subpopulation specific behavioural determinants is a critical step in the development of effective contextually-relevant health education interventions 


\section{Introduction}

Internationally it has been recognised that prison populations should have access to targeted systematically developed intervention programmes to prevent sexual transmitted infections (STls) and HIV infection inside and outside prison (WHO, 2000; Watson, Stimpson, \& Hostick, 2004; Bryan Ruiz, \& O'Neill, 2003). In fact, prison populations worldwide face a host of problems ranging from poor hygienic conditions, overcrowding, to the threat of sexual abuse either through coercion or more often by force, often in relation to drug abuse and other prison related dynamics (Braithwaite, Hammet \& Mayberry, 1996, Hammett, Maruschak, \& Harmon, 1999). These realities place inmates under high risk for STl and HIV infection. In addition, prison inmates are a highly mobile population who constantly move in and out of prison as well as within different prisons (Hammett, Harmon \& Rhodes, 2002). This means that people who commit offenses face a double risk of being infected both from within and outside prison.

Therefore, and because inmates may be difficult to reach after release due to unstable social and financial environments (e.g., lack of permanent residence, work), the time spent in prison provides an opportune moment for public health practitioners to explore ways of designing health interventions that empower offenders while in the captive audience state of prison life and in preparation of future life outside prison (Braithwaite et al., 1996; Grinstead, Zack, \& Faiggeles, 2001; Watson et al., 2004).

Sexual practices amongst inmates while incarcerated are usually underreported due to the secrecy that is attached to such practices as well as the contradictory policies on homosexuality and sodomy in prisons. Mahon (1996) mentions a so called 'code of silence' which inmates may take pledging not to discuss about sex either amongst themselves or to outsiders which can result in underreporting of the rate and range of sexual activities that take place in prisons. Prison programmes targeting soon to be released inmates are more favourable and likely to succeed than in-prison programmes due to the secrecy associated with prison based sexual activity. However, health interventions in prisons are rarely and hardly ever designed and evaluated in a scientifically sound process (Grinstead Zack, \& Faiggeles, 1999; Bryan et al., 2003).

In sub-Saharan Africa STI and AIDS prevention programmes in the prison setting are even non-existent let alone that no knowledge currently exists about the psychosocial determinants of risky sexual behaviour among prison inmates. As part of a long term study to develop and evaluate a peer-led intervention programme, the present study specifically aimed to estimate the psychological correlates of risky sexual behaviours in inmates that will be soon released. Following the process of planned behaviour change (Bartholomew, Parcel, Kok, \& Gottlieb, 2001; Reddy, Van den Borne, \& Yach, 1995), the identified correlates of risky sexual behaviour upon release, should then serve as target points for the intervention programme that aims to explore the advantages of using the final days of a prison sentence as a window of opportunity to present an HIV prevention intervention to offenders before they rejoin the community. 
The South African prison system is made up of about 238 prisons which house on average a total of about 180000 inmates (DCS, 2001). Both sentenced and awaiting trial inmates are accommodated within the corrections system. This situation provides many potential problems in terms of overcrowding and other health threatening problems due to the close proximity of inmates in their lock up areas. The current government inherited the Apartheid prison system which had closed off the prison facilities, making it impossible to conduct any type of research into the conditions and health status of prison inmates in South Africa prior to the 1994 first democratic dispensation. Research into the South African correctional system provides a new pool of information that pertains to sexual risk behaviour in inmate populations in Sub-Saharan Africa.

HIV/AIDS and STIs remain among the biggest challenges facing inmates globally and in Sub-Saharan Africa this problem is likely to be even bigger when one considers the documented AIDS projections in the general population UNAIDS, 2000\%. Few studies have been conducted in mostly western countries on HIV/AIDS related issues in prison populations. Screening and blinded studies of inmates in countries such as Australia and Ireland have revealed that most correctional systems have HIV sero-prevalence rates between $1 \%$ and $4 \%$ (Dolan, Wodak, \& Penny, 1995; Bellis, Weild, Mutton, Beeching, $\&$ Syed, 1997). The general trend in almost every country shows that inmate populations show HIV sero-prevalence rates ranging between five to ten times those seen in the general populations (Dolan et al., 1995; Grinstead et al, 2001). In the case of South Africa where the national sero-prevalence rate is estimated at over $10 \%$ (Shisana \& Simbayi 2002) this evidence projects a very gloomy picture for its prison population.

\section{The present study}

Most prison intervention programmes are the result of a direct response to prevalence data of specific problems such as injecting drug use and rape while in prison. A systematic approach towards programme development, including the use of health behaviour theories and supportive empirical research is thus largely missing. As conceptual framework for the present study we combined the theory of planned behaviour (Ajzen, 1991 ) and the social cognitive theory (Bandura, 1986). According to these theories, the key constructs guiding individual behaviour change are one's attitude towards the behavioural object (e.g., condom use), which is determined by individuals' beliefs about the perceived benefits of adopting the new behaviour and perceived barriers to modifying or changing the undesirable behaviour, one's perception of how significant others in their social circle think about engaging in the new behaviour, referred to as the subjective norm, and the estimation of one's ability to perform the particular behaviour, referred to as selfefficacy. The influence of these three psychosocial determinants on behaviour is mediated through an individual's behavioural motivation to engage in certain behaviour or change the behaviour, referred to as intention. These behavioural models (for recent overview and use in research, see Abraham, 2004; Kok \& Schaalma, 2004) emphasise the importance 
of outlining short term tangible benefits of changing behaviour or conversely the immediate negative effects of not changing, and the behaviour's feasibility that will then serve as target point for the intervention programme (Bartholomew et al, 2001).

Many studies have been conducted on psychosocial determinants of sexually related behaviour mostly amongst gays and MSM (Hospers \& Kok, 1995), the youth and young adults (Bosompra, 2001), and other high risk groups such as injecting drug users (Van Empelen, Schaalma, Kok, \& Jansen, 2001; Rees, Saitz, Horton \& Samet, 2001). The literature shows very little has been done with people who have a history of offending. Most of the studies conducted on prevention initiatives in prisons have been conducted in Western countries where the socio-cultural context is different to those of the developing world (Idemudia \& Reddy 2002). Furthermore, prison interventions have also tended to focus on the time spent in prison and overlooked the importance of imparting skills that are applicable to both 'inside' and 'outside' of prison life. This study therefore utilised traditional theoretical concepts that have been used in other groups to explore how they correlate with sexual risk behaviour in order to inform contextual and culturally relevant programmes in third world inmate populations.

\section{Method}

\section{Study design}

This cross-sectional descriptive study formed part of an ongoing bigger study that was aimed at developing health education intervention programmes for prison inmates in the KwaZulu-Natal (KZN) and Mpumalanga (MP) provinces of South Africa (reported elsewhere, Sifunda et al., 2005a, 2005b, 2005d). The data reported here formed the baseline information from the participating inmates prior to them receiving the health education intervention programme. The study received full. ethical approval from the South African Medical Association Research Ethics Committee (SAMAREC).

\section{Participants and study setting}

The study sites consisted of four prisons in the provinces of KwaZulu-Natal (KZN) and Mpumalanga (MP) provinces. Two prisons were selected in KZN and another two selected in MP. The selected prisons were classified as medium sized security facilities. The sites were selected after taking into account the logistics of having to follow up the participants after being released from prison to go back to their communities, as the intervention was a long-term 12 months cohort study. The four selected prisons were housing a total number of about 3022 inmates.

As the programme was designed for people who were about to leave prison, the inclusion criteria for participants was soon to be released inmates who were to get out of prison within 3 months after receiving the intervention programme. From the prison records of individuals who had been earmarked for release on parole or end of prison 
sentence, a total of 362 inmates were selected to participate in the intervention programme of which 357 consented to participating in the study and thus provided the information for the baseline questionnaire. The participants consisted mainly of African Black men who were Nguni language speakers. Most people who speak this group of languages are fluent in IsiZulu which is the most commonly spoken dialect of all the Nguni languages and also South Africa's most spoken language across all ethnic groups.

\section{Study instrument}

A questionnaire was designed based on the theory of planned behaviour (Ajzen, 1991) and the social cognitive theory (Bandura, 1986), and on information that was obtained through focus group interviews conducted during a preliminary qualitative study that was conducted in four prisons as a situational analysis of the South African prison health system and the social construction and cultural meanings of ST1 and HIV/AIDS related terminology (for a report on this data, see Sifunda et al, 2005a, 2005b). Following demographic variables such as province, age, ethnicity, level of education, employment history, marital status, the questionnaire measured the knowledge and beliefs about causes and transmission of STIs including HIV/AIDS, attitudes towards condom use and people living with HIV/AIDS, sexual communication, social norms about gender relations and sexual violence, self-efficacy and skills for practicing safer sex and health promoting practices in prison.

The questionnaire was prepared in English and translated from English to IsiZulu. To ensure the accuracy of the translations, the IsiZulu version of the questionnaire was back translated to English by a team of research assistants who were involved in the project as data collectors and health educators. The first author who is a first language IsiZulu speaker rechecked all the translations. The questionnaire was interviewer administered as most prison inmates had very low literacy levels.

\section{Measures}

Knowledge about spread and transmission of HIV/AIDS and other STIs. Inmates' knowledge about the spread and transmission of HIV and other STIs was measured using the averaged scores of nine items $(\alpha=91)$. Questions addressed issues such as: "You can get HIV by sharing needles", "You can get HIV by coming into contact with infected blood", "HIV/AIDS is caused by condoms", and "HIV/AIDS is caused by witcheraft". The items were measured using a scale with three possible options (true, false, I don't know) that were recoded into $1=$ incorrect, $2=$ unsure, and $3=$ correct.

Attitudes. Participant's attitude towards condom use in preventing HIV was assessed using three items $(\alpha=.76)$ with 5-point scales $(1=$ strongly disagree, $5=$ strongly agree) (e.g." It is important to use a condom every time you have sex", "Condoms work well to prevent HIV and other STls"; "it is important to use a condom every time you have sex"). Additionally attitude towards condom use in sexual encounters, which measured negative 
beliefs about using condoms, was assessed using five items $(\alpha=.68)$ with a 5 . point answering scale ( 1 = strongly disagree, $5=$ strongly agree). Questions asked addressed issues such as "condoms are embarrassing to use", and "a woman loses a man's respect if she asks him to use a condom". Participants' attitude towards people living with HIV/AIDS was assessed using eight items ( $\alpha=75)$ with answering scales that ranged from I U definitely would mind) to 5 (I definitely would not mind). Questioned covered issues like, "If your relative has HIV would you mind caring for them" and "Would you mind sharing a room with an HIV positive person".

Sexual Communication. Five items assessed sexual communication of participants with their sex partners $(\alpha=89$ ) on a scale from I (strongly disagree) to 5 (strongly agree). The questions addressed issues of negotiating condom use and being the first person to initiate discussion on safer sex practices (e.g., "It is okay for a woman to discuss HIV/AIDS issues with her partner", "A man should be able to discuss with his partner about safe sex").

Beliefs. Eight items assessed the bellief of sex as a utilitarian transaction $(\alpha=74)$ on a scale from 1 (strongly disagree) to 5 (strongly agree). Questions asked addressed beliefs such as "woman expect payment in return for sex", "I need to have sex with my partner in order not to lose them", and "it is okay for a man to demand sex from their partner.

Social Norms. Five items measured on a 5 -point scale $(1=$ strongly agree, $5=$ strongly disagree) the perceived social norms about males playing a controlling and dominant role in relationship (male control in relationships; $\alpha=67$ ). Questions were asking issues such as "a woman should never contradict or argue with her man in public", and "in a relationship woman are largely out to exploit a man". Two items using a 5-point scale $(1=$ strongly agree, $5=$ strongly disagree) assessed the perceived norms of condom use in different sexual relations (i.e., "Married couples should not use condoms when having sex" and "It is only important to use condoms with girlfriends and not with wives"; Pearson's correlation $=.47$ ).

Self-efficacy. Participant's general life shills efficacy was measured using eight items $l \alpha=91)$ with a scale ranging from 1 (not at all confident) to 5 (extremely confident). These items measured participants' confidence regarding maintaining a healthy balanced diet, seeking health care and consultation, as well as avoiding alcohol and other substances (e.g. "I am confident that I can always seek medical care when sick", "I arn confident that I can always eat the right food", "I am confident that I can always awoid drinking alcohol and getting drunk $\left.{ }^{\prime \prime}\right)$. Skills for practicing safer sex was assessed using nine items $(\alpha=.89)$ which measured participants' confidence in issues such as being able to put on a condom correctly, being able to put on a condom even if it is dark, being able to resist sexual intercourse without using a condom even if it someone you have slept with before. All these items were measured on 5-point scales ranging from 1 (surely not) to 5 (surely yes).

Intention. The intention to reduce risky sexual behaviour upon release from prison was measured using five items with a scale ranging from 1 (surely not) to 5 (surely yes). 
These items assessed participants" intentions to perform activities that result in reduced risk behaviour in particular using condoms and negotiating condom use with all sexual partners, asking sexual partners about past STI and sexual history, and asking partners about HIV status and testing, and lastly avoiding mixing sexual activity with substance use $(\alpha=82)$.

\section{Data analysis}

The data was analysed using the statistical software SPSS, version 12.0. Frequencies and descriptive statistics were calculated for each item in the questionnaire both at data cleaning and analysis stages. Hierarchical multiple regression analysis was used to analyse the relations between the psychosocial constructs and intention to reduce risky sexual behaviour upon release from prison. Furthermore, respondents were categorised into two groups of high intenders $(N=195)$ and low intenders $(N=149)$ based on a median split of the intention distribution. Multivariate analysis of variance (MANOVA) was used to explore the differences between those who demonstrate high intention to reduce risky behaviour and those who had low intention to reduce risky behaviour on the psychosocial constructs. The same analyses were repeated for those who were consistent $(N=63)$ and inconsistent $(N$ $=137$ ) condom users, combined to form a group of "ever condom users" $(N=200)$, versus "never condom users" ( $\mathrm{N}=153)$.

\section{Results}

\section{Demographic profile of participants}

The mean age of the participating inmates was 27 years with the youngest being 17 years old and the oldest 55 years old. Nguni speaking African Black men made up $96 \%$ of the selected participants. A few participants from other "racial" groups were included after demonstrating a good command of the language of instruction, which was isiZulu. Additional English copies of the material were also given to these participants as they had verbal skills but not reading and writing skills of the language. Table 1 shows that almost $8 \%$ of the participants had no formal education and $47 \%$ only had primary school education. A total of 50\% were unemployed at the time of arrest and $37 \%$ were holding jobs paying under $\mathrm{R} \| 0000(\$ 1300)$ per annum. A large proportion of the selected participants $(65 \%)$ were first time offenders serving a prison sentence for the first time.

\section{Correlates of intention to reduce risky sexual behaviour upon release}

Table 2 demonstrates the correlates, means and standard deviations for all the predictors. Attitude towards condom use in different sexual encounters, attitude towards people living with HIV/AIDS sexual communication, self-efficacy to practice safe sex and general life skills efficacy all had a positive correlation with the intention to reduce risky sexual behaviour upon release from prison, while the belief of sex as a utilitarian transaction was 
Table 1: Socio-demographic profile of secondary school learners

\begin{tabular}{|c|c|c|}
\hline Variables & Erequency $(\%)$ & Percentage: \\
\hline \multicolumn{3}{|l|}{ Race } \\
\hline Black & $343(96)$ & 96 \\
\hline White & $4(1)$ & 1 \\
\hline Indian & $2(1)$ & 1 \\
\hline Coloured & $7(2)$ & 2 \\
\hline \multicolumn{3}{|l|}{ Marital Status } \\
\hline Married & $231(66)$ & 66 \\
\hline Not Married & $118(34)$ & 34 \\
\hline \multicolumn{3}{|l|}{ Education level } \\
\hline No formal education & $27(8)$ & 7.6 \\
\hline Primary school & $166(47)$ & 46.5 \\
\hline Grade10 & $93(26)$ & 26.1 \\
\hline Grade 12 & $71(20)$ & 19.8 \\
\hline \multicolumn{3}{|l|}{ Employment history } \\
\hline Unemployed & $177(50)$ & 49.6 \\
\hline Under R10 000 & $132(37)$ & 37.0 \\
\hline R10 000-R19 999 & $35(10)$ & 9.8 \\
\hline$R 20000-R 29999$ & $13(3)$ & 3.4 \\
\hline \multicolumn{3}{|l|}{ Criminal History } \\
\hline 1st thime offender & $233(65)$ & 65.3 \\
\hline Repeat offender & $124(35)$ & 34.7 \\
\hline
\end{tabular}

$(n=357)$

negatively related to intention. The attitude towards condom use in HIV prevention, perceived social norm of male control in relationships, perceived social norm of condom use in different relationships, and knowledge were not significantly associated with the intention to reduce risky sexual behaviour.

Participants demonstrated high selfefficacy to practice safe sex as well as general life skills efficacy. However, $17 \%$ expressed that they would have difficulty saying no to sex with someone they have just met if they are sexually attracted to them. Sexual communication skills were also high amongst the participants, even though a small proportion (13\%) that felt that partners should not enquire about the other partner's previous sexual relationships.

The participants generally showed positive attitudes towards the use of condams. However, a substantial number of inmates' participants $(48 \%)$ felt that using condoms 
Table 2: Correlation of predictors of intention to reduce RSB upon release from prison

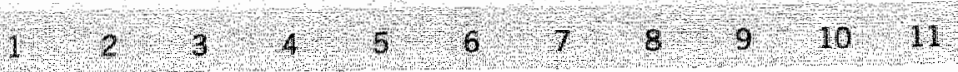

1. Interention 1

2. General life skills $49^{*} * 1$

setfoefficacy

3. Self-efficacy $\quad .47^{* *} \cdot 38^{* *} \quad 1$

towards shills for

practising siafer sex

4. Sexual $\quad 31^{* *} \cdot 32^{* *} \cdot 22^{* *} \quad 1$

communication

5. Atritude towards $\quad .06 \quad .06 \quad .05 \quad .06 \quad 1$ condom use in $\mathrm{HIV}$

prevention

6. Attitude towards $\quad 12^{*} \quad .04 \quad .06 \quad .19^{* *} \quad .43^{* *} \quad 1$

condom use in

sexual encounters

7. Attitude towards $.30^{* *} \quad .29^{* *} \quad .19^{* *} \quad .61^{* *} \quad .04 \quad .18^{* * *} \quad 1$

PLWHA

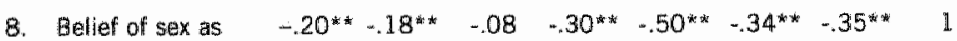

a ullilitarian:

transiaction

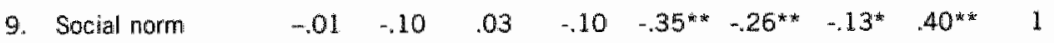

towards male

control in

relationships

10. Soritall norm

$\begin{array}{lllllllllll}.02 & .02 & .00 & -.02 & -.28 * * & -.19 * * & -.04 & .27 * * & .33^{* *} & 1\end{array}$

towards condiom

use in different

rations

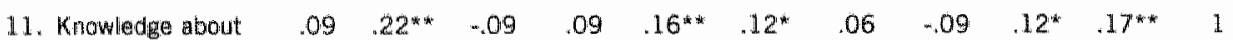
transtrisision:

Mean"

$\begin{array}{lllllllllll}4.63 & 4.26 & 4.13 & 4.36 & 3.77 & 3.85 & 4.38 & 1.79 & 2.91 & 2.93 & 2.45\end{array}$

Standard deviation

$\begin{array}{lllll}0.63 & .86 & .72 & .86 & .84\end{array}$

$\begin{array}{llll}.80 & .58 & .86 & 1.25\end{array} .56$

$* p<.05 ; * * 0 \%$ of

All inems are medsuned on a 5 proin scale, accept for knowledge, which is measured on a 3 point scale 
showed that you do not trust your partner. On the attitude towards the use of condoms in different sexual relationships more than half participants $(52 \%)$ felt that mamied couples did not need to use condoms and $38 \%$ said that it was only important to use condoms with girlfriends and not wives. Attitudes towards people living with HIV and AIDS was generally positive, but a large proportion of participants $(54 \%)$ felt that an HIV positive health worker should not be permitted to continue working in a clinic and another $26 \%$ felt that PLWHAs should not be allowed into public places.

On the belief of sex as a utilitarian transaction a large proportion $(41 \%)$ believed that women expected money in return for sex. On the perceived social norm of male control in sexual relationships almost $46 \%$ felt that a woman will. only respect a man who lays down the rules. Further on the use of condoms in different sexual relations almost $53 \%$ of the participants felt that married couples did not need to use condoms.

The knowledge of respondents on transmission of HIV was moderately high $(M=$ 2.47; $S D=53$ ). However, there seemed to be some confusion about non-sexual contact and risk of transmission of HIV where knowledge was low on items such as "A person can get HIV by sharing the same toilet with an infected person ( $35 \%$ in agreement) and "a person can get HIV by sharing the same room with an infected person $133.0 \%$ in agreement).

A hierarchical multiple regression analysis regressed intention to practice safer sex on the scales of knowledge, attitudes, sexual communication, social norms and self-efficacy (see Table 3). Skills to practice safe sex contributed $24 \%$ to the variance on intention. Entering general life skills efficacy while controlling for skills to practice safe sex added an additional $11 \%$ of explained variance. Sexual communication entered while controlling for the two self-efficacy variables contributed an additional $4 \%$ of the unique explained variance. The final equation, which included the measures of self-efficacy, sexual communication, attitude, belief of sex as a utilitarian transaction, social norms, and knowledge, explained $39 \%$ of the variance in intention $(F(10,332)=21.56, p<.001$, $\mathrm{R}^{2}=0.39$ ), with significant unique contributions of sexual communication, self-efficacy related to skills to practice safer sex, and general life skills efficacy. The measures of attitude, perceived social norms, belief of sex as a utilitarian transaction, and knowledge were non-significant predictors in the final equation.

\section{Differences between High Intenders and Low Intenders to reduce risky sexual behaviour upon release}

In order to explore the differences between the participants with a high intention and those with a low intention to reduce risky sexual behaviour upon release, the sample was divided into two groups using a median split of intention distribution (Median $=5.0$.) The mean intention score for the low intenders was $M=2.78(S D=.89)$ and for the high intenders $M=4.77(S D=.71), t(350)=20.92, p<001$. A MANOVA conducted on the indices of knowledge, attitude, sexual communication, perceived social norms and self- 


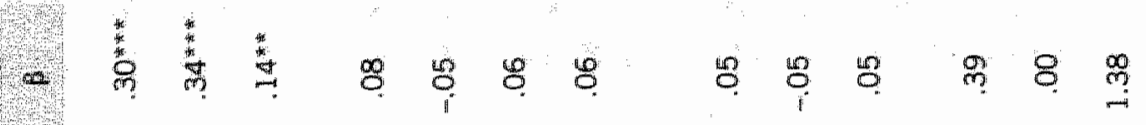

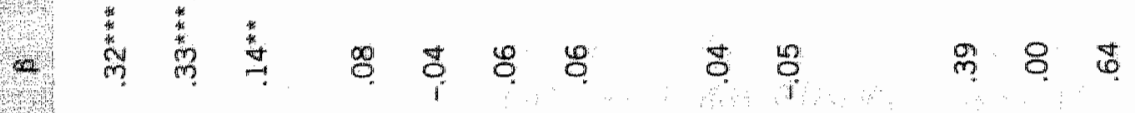

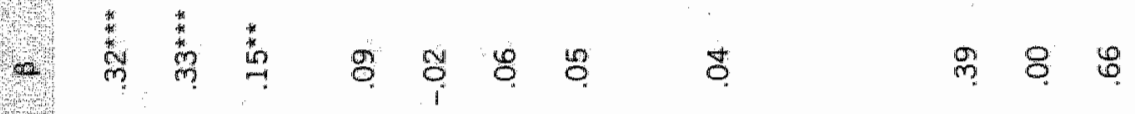

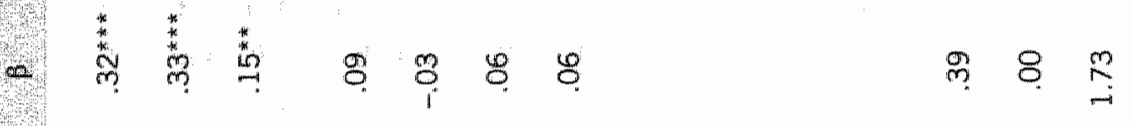

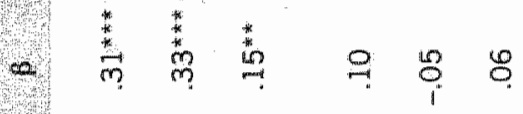
○)

象

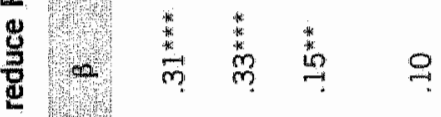

C c

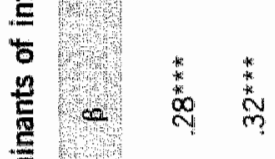

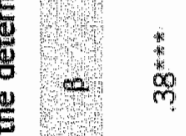

竞

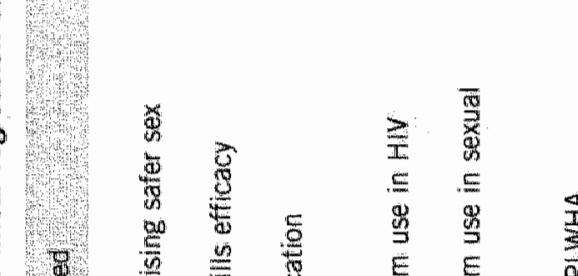

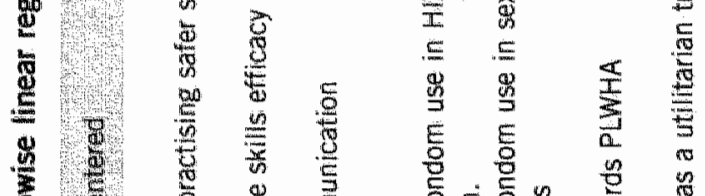

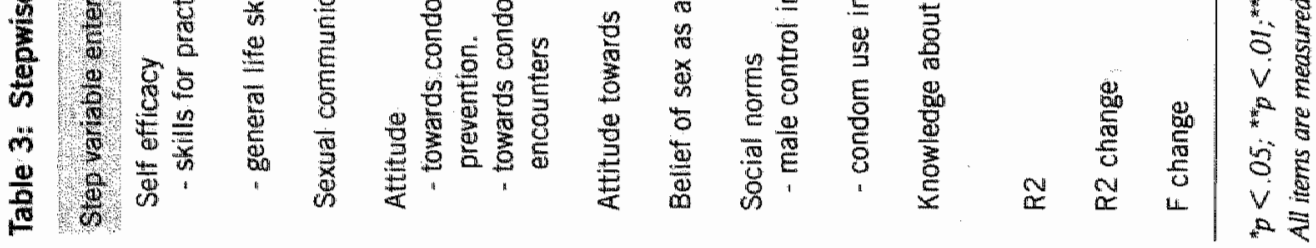


efficacy showed that the two groups of condom users differed significantly on these variables Wilks' Lambda $=.77, F(10,332)=9.74, p<.001$. Subsequent univariate ANOVAs showed that high intenders demonstrated higher selfefficacy on skills to practice safe sex and general life skills efficacy than low intenders. High as opposed to low intenders also demonstrated higher abilities on sexual communication with their sexual partners, a more positive attitude towards using condoms, and stronger belief of sex to be a non utilitarian transaction (see Table 4). There was no significant difference between high and low intenders on their knowledge about HIV transmission, attitude towards

Table 4: Multivariate analysis of Variance (MANOVA) for high intenders versus low intenders on psychosocial determinants

\begin{tabular}{|c|c|c|c|c|}
\hline Varables & $\begin{array}{l}\text { High intenders } \\
(N=191)\end{array}$ & $\begin{array}{l}\text { High intenders } \\
(N=154)\end{array}$ & F value & P value \\
\hline Self efficacy for practising safer sex & $4.58(0.68)$ & $3.89(0.90)$ & 64.37 & .000 \\
\hline General life skills efficacy & $4.33(0.57)$ & $3.91(0.78)$ & 33.22 & .000 \\
\hline Sexual communication & $4.56(0.62)$ & $4.22(0.86)$ & 18.59 & .000 \\
\hline $\begin{array}{l}\text { Attitude towards Condom use in } \\
\text { HIV prevention }\end{array}$ & $4.56(0.62)$ & $4.18(0.96)$ & 19.91 & .000 \\
\hline $\begin{array}{l}\text { Attitude towards condom use in } \\
\text { sexual encounters }\end{array}$ & $3.84(0.86)$ & $3.66(0.80)$ & 4.18 & .042 \\
\hline Attitude towards PLWA & $3.91(0.90)$ & $3.80(0.86)$ & 1.77 & .184 \\
\hline Sex as a utilitarian transaction & $1.71(0.54)$ & $1.89(0.61)$ & 8.18 & .004 \\
\hline $\begin{array}{l}\text { Social norm toward male control } \\
\text { in rellationships }\end{array}$ & $2.95(0.89)$ & $2.86(0.83)$ & .60 & .439 \\
\hline $\begin{array}{l}\text { Social norm towards condom use } \\
\text { in different relations }\end{array}$ & $2.91(1.29)$ & $2.94(1.22)$ & .09 & .765 \\
\hline $\begin{array}{l}\text { Knowledge about spread and } \\
\text { transmission of STDS and HIV/AIDS }\end{array}$ & $2.51(0.52)$ & $2.41(0.52)$ & 2.91 & .089 \\
\hline
\end{tabular}

All inems are measured on a 5 point scalle, accept for hrouldedge, which is measured on a 3 point scale.

PLWHA, perceived social norm about male control in relationships as well as perceived social norm about condom use in different sexual relationships.

\section{Differences between "Ever" and "Never" condom users}

In order to differentiate between reported past sexual behaviour and future intended behaviour we then explored the differences between those who reported to have used condoms ("ever users"; $N=195$ ) in varying consistency prior to entering prison and those who had never used condoms ("never users"; $N=149$ ). A MANOVA showed that 
the two groups of condom users differed significantly on the indices of knowledge, attitude, sexual communication, perceived social norms, self-efficacy, and intention, Wilks' Lambda $=90, F(11,329)=3.46, p<.001$. Subsequent univariate analyses showed that those who had reported using condoms previously demonstrated higher self-efficacy to practice safer sex and intention to reduce risky sexual behaviour than those who reported never using condoms before (see Table 5). The group of ever users as opposed to never users also demonstrated a more positive attitude towards condoms. No significant differences were found between both groups on general life skills efficacy, sexual communication, knowledge about HIV transmission, attitudes towards PLWHA, male control in relationships and condom use in different sexual relationships. The belief of sex being a utilitarian transaction was marginally significant $(p=.06)$, with never users holding this belief more than ever users of condoms.

Table 5: Multivariate analysis of Variance (MANOVA) for condom use amongst Ever Users and Never Users

\begin{tabular}{|c|c|c|c|c|}
\hline Varables & $\begin{array}{l}\text { Ever users } \\
(N=195)\end{array}$ & $\begin{array}{l}\text { High intenders } \\
(N=(49)\end{array}$ & F value & Pvalue \\
\hline Intention & $4.75(0.41)$ & 4.4910 .81 & 14.43 & .000 \\
\hline Skills for practising safer sex & $4.55(0.70)$ & $4.07(0.95)$ & 17.91 & .000 \\
\hline General life skills efficacy & $4.18(0.67)$ & $4.07(0.77)$ & 2.41 & .122 \\
\hline Sexual communication & $4.47(0.68)$ & $4.35(0.83)$ & 2.04 & .154 \\
\hline $\begin{array}{l}\text { Attitude towards Condom use in } \\
\text { HIV prevention }\end{array}$ & $4.53(0.67)$ & $4.22(0.93)$ & 13.17 & $.000^{*}$ \\
\hline $\begin{array}{l}\text { Attitude towards condom use in } \\
\text { sexual encounters }\end{array}$ & $3.85(0.80)$ & $3.65(0.87)$ & 4.78 & .029 \\
\hline Attitude towards PLWA & $3.84(0.90)$ & $3.64(0.87)$ & .20 & .655 \\
\hline Sex as utilitarian transaction & $1.74(0.55)$ & $1.86(0.60)$ & 3.68 & .056 \\
\hline $\begin{array}{l}\text { Social norm towards male control } \\
\text { in relationships }\end{array}$ & $2.94(0.86)$ & $2.87(0.88)$ & .51 & .474 \\
\hline $\begin{array}{l}\text { Social norm towards condom use } \\
\text { in different relations }\end{array}$ & $2.89(1.27)$ & $2.99(1.23)$ & .57 & .451 \\
\hline $\begin{array}{l}\text { Knowledge about spread and } \\
\text { trransmission of STDs and HIVIAIDS }\end{array}$ & $2.51(0.51)$ & $2.40(0.55)$ & 3.29 & .071 \\
\hline
\end{tabular}

All items ane measured on a 5 point scale, accept for knowtedge, which is measured on a 3 point scalle. 


\section{Discussion}

Sexual activity inside prison is a tricky subject to explore due to the secrecy and low levels of disclosure and openness on the subject amongst inmates, more especially to outsiders Mahon, 1996). With a special focus on soon to be released inmates, this study addressed risky sexual behaviour and condom use on a broader scale that applied to both inside and outside of prison behaviours and skills. Special interest was taken in identifying psychosocial correlates of their intended safe sex behaviour when they get out of prison.

The findings of this study demonstrated that among prison inmates self-efficacy in the form of skills to practice safer sex was the strongest predictor of intention to reduce risky sexual behaviour. The participants who were comfortable with insisting on using condoms as well as possessing the practical skills of correctly using condoms were more motivated to use condoms than those who were less confident in performing those tasks. Furthermore, general life skills efficacy and sexual communication in the form of negotiating condom use with your sexual partner were the next strongest significant predictors of the intention to change behaviour amongst inmates. These findings are in line with other studies (e.g., Sheeran, Abraham \& Orbell, 1999) that stress the importance of perceived and actual skills to practice the behaviour as well being able to communicate safer sex practices with a partner as strong predictors of engaging in behaviour.

Attitude towards condom use, attitudes towards PIWHA and the bellief of sex as a nonutilitarian transaction were also correlated positively to intention to reduce risky sexual behaviour upon release. However, in the final regression analysis these latter variables did not contribute significantly in explaining the intention to reduce risky sexual behaviour. These constructs are what Sheeran and colleagues (1999) refer to as the labelling stage of behaviour, meaning they form the initial preparation for performing a behaviour but do not necessarily lead to the actual performance (see also Adih 6 Alexander 1999; Bryan, Aiken, G West, 2004). The so-called commitment and enactment stages, relying on actuall skills and performance, guide the final stages of the behaviour change process.

Most of the participants faired well on their knowledge on transmission and prevention of HIV and STIs. However, those who demonstrated high intention to reduce risky sexual behaviour and those who reported ever using condoms did better than their counterparts, respectively low intenders and never condom users. Furthermore, there is still a very strong belief amongst prison inmates that using condoms shows that one does not trust their partner, as indicated by the large number of non condom users who quoted trusting their girl friends and wives as the main reason for not using condoms. This is further demonstrated by the prevailing belief that married couples do not need to use condoms and the general practice being selective use of condoms with casual sexual relations outside of the relationship or marriage. Even though this seemed to be a prevalling belief it was not a good indicator of whether inmates will use condoms or not when engaging in sexual activities.

Another competing dynamic in decisions on condom use are the traditional beliefs 
and methods of ensuring fidelity amongst partners using traditional potions as traps to catch cheating partners (Sifunda et al, 2005b). Inmates who held the beliefs that they were getting protection from traditional methods were not likely to actively engage in conventional safe sex practices due to this cultural dynamic.

It must be noted further that there was a sizable proportion of participants $(31 \%)$ who faired very badly on almost all the knowledge questions and this finding is similar to what ldemudia and Reddy (2002) found amongst inmates in Nigeria where almost $25 \%$ demonstrated extremely low knowledge on HIV and STI transmission and prevention. This is a very important finding as it clearly emphasise the need for basic dissemination of information as being crucial when designing programs for inmates. Prison inmates also held a few misconceptions in terms of transmission through non-sexual contact as some people believed that sharing kitchen utensils and toilets can lead to the transmission of HIV. This type of misconception can lead to a lot of stigma amongst people who are suspected of having HIV more especially in prison where there is a need to share space and equipment with other inmates.

When comparing those with high intention to reduce risky behaviour against those who reported low intention, the high intenders scored significantly higher than the low intenders on self-efficacy for practicing safer sex, general life skills, sexual communication and also demonstrated a more positive attitude towards condom use. Low intenders also demonstrated a stronger belief of sex being a utilitarian transaction, which could indicate a propensity to engage in transactional sex and thus not insist on condom usage. The participants who reported ever using condoms scored significantly higher on all the predictors of intention to reduce risky behaviour than those who reported never ever using condoms, thus confirming the importance of these determinants as focal point for future health education interventions.

To conclude, the area of prison health research is still a new terrain that has not been adequately explored in health research and therefore a lot of theories have not been adequately tested for their applicability in exploring behavioural determinants. Most of the research instruments being used are also in their early stages of development and therefore requires further testing for improved validity on capturing offender related data. The prevailing situation of low literacy amongst inmates also limits the amount of information that can be gathered as materials sometimes need to be designed with language equivalent to that of a primary school level scholar (Braithwaite, Stephens, Cornely, Arriola, \& Robillard, 2004). In South Africa and other developing countries a further complication will be the linguistic differences and dynamics that need to be taken into account when translating the research instruments. This study therefore contributes to a new pool of information of enquiry into health education programming for a diverse group of people with a history of criminal offenses.

Programmes aiming at changing risky behaviour amongst inmates could adapt and modify approaches used in other programmes for other population groups. However, it 
must be noted that belief contents and other factors may be unique to offenders that necessitate proper enquiry to be able to design appropriate and effective health education programmes targeting offenders such as peer led health education programmes (Devilly, Sorbello, Eccleston, \& Ward, 2005; Kingtree \& Phan, 2001; WHO, 2000). Studying determinants of risky sexual behaviour in these settings thus provides insight into offender specific issues, more especially in the South African correctional system which had largely been a closed system in the past. This research is crucial as it not only contributes to the health of the offenders but also indirectly to society outside the correctional system particularly in environments of high rates of inside-outside prison movement. 
64 


\section{The relationship between Alcohol and Drug Use and Sexual}

Behaviour amongst prison inmates in developing countries: The case of South Africa

Submitted as:

Sifunda, S., Reddy, S.P., Braithwaite, R.B., Stephens, T., Bhengu, S., Ruiter, R.A.C., \& Van Den Borne, 8. (2005). The Relationship between Alcohol and Drug Use and Sexual Behaviour amongst Prison: Inmates in Developing Countries: The Case of South Africa 


\section{ABSTRACT}

To examine a possible link between substance use and risky sexual behaviour a cross sectional study was conducted among 357 inmates across four South African prisons involved in a pre-release intervention programme for parolees. About $93 \%$ of the participants reported using alcohol and $52 \%$ used marijuana prior to imprisonment while $56 \%$ reported previous occurrence of STls. Logistic regression analyses explored the impact of substance use on intention to reduce risky sexual behaviour. Age and inconsistent use of condoms were positively associated with having an STI prior to incarceration, while reported alcohol and marijuana intake thad no effect. Never using condoms before was highly associated with lower intention to engage in preventive behaviours upon release. It can be concluded that inmates demonstrate high levels of substance use and engaging in risky sexual behaviours. Targeted pre-release substance abuse interventions are essential to reduce the burden of disease amongst offenders. 


\section{Introduction}

The link between substance use and risky sexual behaviours has been explored in a number of so called high risk individuals such as injecting drug users (Van Empelen, Schaalma, Kok, E Jansen, 2001), gays or men who have sex with men (MSM) (Hospers $\&$ Kok, 1995). Drug use has been shown to diminish the chances of preventive sexual behaviours, more especially the use of condoms and refraining from behaviours such as casual sex, multiple partners and other risky sexual behaviours (RSB) amongst users (Ross, Timpson, Williams, \& Bowen, 2003).

In prison populations, risky sexual behaviour (RSB) and alcohol and other drug use (AOD) are very common and the link between the two has been well documented (Braithwaite, Hammett, \& Mayberry, 1996; Kingtree \& Phan, 2001). Socio-economical and contextual issues contribute to the link between substance use and risky sexual behaviour amongst prison inmates (Adesanya, Ohaeri, Ogunlesi, Adamson, \& Odejide, 1997; Kingtree, Braithwaite, \& Woodring, 2000; Kingtree \& Phan, 2001). For example, prison populations tend to have higher reported use of alcohol and drugs than the general population together with a host of other high risk activities such as unprotected sexual activity and multiple sexual partners (Braithwaite et al, 1996). Transactional sex is a very common practice amongst prisoners occurring both in the prison and out of prison context where sexual favours are exchanged for some form of payment (Foreman, 1999). Due to the shortage of cigarettes, alcohol, and sanitary supplies some prisoners resort to prostitution; which is either voluntary or sometimes forced as a form of paying back previous favours from other inmates.

The use of substances thus exposes inmates to an increased danger of being exposed to life threatening diseases such as STls and HIV/AIDS. It is therefore vital for public health practitioners and correctional officials to fully understand the dynamics of substance use and its impact on RSB amongst offenders. However, most studies conducted on the link between substance use and risky sexual behaviours were conducted in Western populations where the drug use patterns differ from those in the developing world (Bellis, Weild, Mutton, Beeching \& Syed, 1997). Furthermore, only few studies investigated substance use in direct relation to unsafe sexual practice (Kingtree et al., 2000; Kingtree $\&$ Phan, 2001) as opposed to most studies that tend to emphasise on HIV transmission risk as a result of injecting drug intake methods such as needle sharing (Stephens, Braithwaite, \& Cozza, 1999; Van Empelen et al., 2001). The present study seeks to explore the role of alcohol and other substances in the context of prison inmates in the developing world, particularly in South Africa, and its potential impact on the broader HIV/AIDS and STI transmission issues.

\section{AOD use in prison}

Substance use amongst prisoners plays a big role in defining status roles and group affiliations for offenders both inside and outside of prison. Use of drugs is very widespread in prisons, but their availability is not usually guaranteed which makes access to drugs a sure way of 
maintaining some form of influence inside prison. Drugs are usually taken in groups as they create that feeling of camaraderie whether by sharing a joint of marijuana or an injection of hard drugs (Foreman 1999). In interviews done with inmates in Brazil it was found that injection of cocaine is usually chosen as opposed to sniffing, as it brings more effects and also lasts longer and this is due to its scarcity (cocaine) inside prison (Foreman 1999). This reality has serious implications when it comes to the transmission of HIV/AIDS as prisoners usually share needles that never get disinfected with proper sterilising equipment.

Substance use patterns vary according to geographical areas and economic conditions of countries as well as the race and gender of prisoners (Bryan, Aiken, \& West, 2004; Henderson, 1998). Therefore most countries device intervention protocols that are best suited for their prevailing conditions. For instance, in most western countries prison populations will report higher risk associated with injecting drug use (IDU) (Bellis et al, 1997; Mahon 1996). As most of the prison research data comes from western countries where the lifestyles are different to third world conditions there is a need to explore the drug use patterns in the context of the developing world. The differences in the prevailing socio-economic and cultural backgrounds necessitates proper enquiry into developing world specific drug use issues and its relation to risky sexual behaviour.

The situation in developing countries especially in Sub-Saharan Africa is different as patterns of drug use are different to those in developed countries and potential transmission of HIV is less likely to be through IDU practices in poorer countries. Research conducted amongst inmates in Nigeria indicated very low levels on the use of hard drugs in prisons, whereby marijuana was found to be the most popular and readily available substance inside prison (Adesanya et al., 1997). These differences between the patterns of risk amongst inmates found in different socio-economic and cultural backgrounds call for extensive research, which will provide relevant information for intervention programmes that, pertain to this kind of environments.

\section{The South African context}

The South African prison system is made up of about 241 prisons which house on average between 175000 and 180000 inmates (Department of Correctional Services, 2001) The prison population is made up mostly of male inmates between the age of 18 and 35 years of age, with a large majority of them being African black males $77.5 \%$ ) followed by coloured males $(19.8 \%)$. Both groups have the same reality of living in very poor communities with high unemployment and a high rate of drug abuse. The SA prison also provides a unique environment that resulted from the legacy of apartheid. Prison formed part of the oppressive machinery. This meant that prisons were made to be dumping grounds for all people deemed to be "undesirable" to the government of the time. Prisoner welfare issues were never a priority and the system was closed from any outside scrutiny including research on prison health issues. With the new dispensation in 1994 the Department of Correctional Services needed scientific data to support efforts 
aimed at mistakes from the past as well as managing present and future challenges such as HIV/AIDS within the prison population.

\section{The present study}

Research into the South African correctional system provides a new pool of information that pertains to sexual risk behaviour and drug use in correctional systems in Sub-Saharan African conditions where sexual transmission is the main pathway of HIV transmission as opposed to intravenous drug use. This study seeks to explore the drug use patterns amongst inmates in the context of a developing country. Furthermore, it looks at the contextual definitions and perceptions of substance use amongst incarcerated populations and its impacts on sexual risk-taking motivation after being released from prison.

\section{Method}

\section{Study design}

This cross-sectional descriptive study formed part of an ongoing bigger study that was aimed at developing health education intervention programmes for prison inmates in the KwaZulu-Natal (KZN) and Mpumalanga (MP) provinces of South Africa (see Sifunda et al., 2005a). The collected data formed the baseline information collected from the participating inmates prior to them receiving the health education intervention programme. The study received full ethical approval from the South African Medical Association Research Ethics Committee (SAMAREC).

\section{Participants and study setting}

The study sites consisted of four facilities in KZN and MP provinces. Two prisons were selected in KZN and another two in MP. The selected prisons were classified as medium sized medium security facilities. The sites were selected after taking into account the logistics of having to follow up the participants after being released from prison to go back to their communities, as the intervention was a long-term 12 months cohort study. The four selected prisons were housing a total number of about 3022 inmates. All participants were selected from the prison records of individuals who had been earmarked for release on parole or end of prison sentence. A total of 362 inmates were selected to participate in the intervention programme and thus provided the information for the baseline questionnaire. The participants consisted mainly of African Black men who were Nguni speakers. Most people who speak this group of languages are fluent in isiZulu, which is the most spoken dialect of all the Nguni languages and also South Africa's most spoken language across all racial groups. As the programme was designed for people who were about to leave prison, the inclusion criteria for participants was soon to be released inmates who were to get out of prison within 3 months after receiving the intervention programme. Of the total selected inmate participants a total of 357 consented to participating in the study. 


\section{Study instrument}

A questionnaire was designed based on existing approaches of studying substance use amongst inmates populations (Braithwaite, Stephens, Cornely, Arriola, \& Robillard, 2004), and information that was obtained through focus group interviews conducted during a preliminary qualitative study that was conducted in four prisons as a situational analysis of the South African prison health system (see Sifunda et al, 2005a) and the social construction and cultural meanings of STI and HIV/AIDS related terminology (see Sifunda, et al., 2005b). Following demographic variables such as province, age, ethnicity, level of education, employment history, maritall status, the questionnaire measured by means of self-reports past risky sexual behaviour and alcohol and other drug use prior to incarceration. Furthermore, the believed impact of alcohol and marijuana use on risky sexual behaviour was measured using 22 items. The questionnaire was prepared in English and translated from English to isiZulu. To ensure the accuracy of the translations, the isiZulu version of the questionnaire was back translated to English by a team of research assistants who were involved in the project as data collectors and health educators. The first author who is a first language isizulu speaker rechecked all the translations. The questionnaire was interviewer administered as most prison inmates had very low literacy levels.

\section{Measures and scale construction}

Alcohol and other drug use prior to incarceration. Alcohol use was measured using one item with a scale of 1 to $6(1=$ daily, 2 =more than once $a$ week, $3=$ less than once a week, $4=$ more than once $a$ month, $5=$ once a month, $6=$ never), where participants were asked how often did they drank alcohol before being imprisoned. The same scale was used to measure the intake of other drugs including marijuana, mandrax (methaqualone), inhalants such as glue, ecstasy, crack cocaine and cocaine. Participants were also asked about their lifetime history of ever injecting drugs as well as sharing needles prior to entering prison.

Past STI history and risky sexual behaviour. Previous engagement in sexual activities was measured using one item with a scale of 1 to $5(1=$ daily; $2=$ more than once a week; $3=$ once a week; $4=$ more than once $a$ month; and $5=$ once $a$ month), where participants were asked how often they had engaged in sex be fore being imprisoned. Condom use behaviour was then assessed on a 5 -points scale $(1=$ never, 2 =less than hatf the time, $3=$ about half the time, $4=$ more than half the time, $5=$ always). Reasons for not using condoms the last time they had unsafe sex was also measured on a 5-points scale $(1=$ did not have one, $2=$ was too excited, $3=$ parther refused, $4=$ did not want to use one, $5=$ other reasons). Sexual preference or orientation was ( 1 = sex with men, $2=$ sex with wornen, $3=$ sex with both) and participants were also asked about previous engagement in anal sex with men either voluntarily or involuntary while in prison. Lifetime reported occurrence of ever sexually transmitted infections was measured using a scale from 1 to $3\left(1=\right.$ Yes, $2=N_{0}, 3=$ Not Sure), which was recoded into $\mathrm{I}=$ yes vs. $0=$ no/ $/$ unsure. 
Perceived beliefs about effects of alcohol and marijuana use on preventive behaviour. Explorative factor analysis with oblique rotation was used to identify conceptually meaningful dimensions within the different groups of items in the questionnaire that were directed to the perceived link between alcohol and marijuana use and risky sexual behaviours. The resulting group of items were then subjected to reliability analysis to measure the internal consistency of the resulting scale. Using an internal reliability of Cronbach's alpha of .60 or higher, the scales described next emerged from the analyses.

Six items were used to measure the believed impact of alcohol use on sexual feelings and behaviour (Cronbach's alpha $=83$ ) and summarised into one index alcohol intake and preventative behaviours. The questions addressed issues such as "alcohol makes me less likely to take precautions when having sex", "drinking alcohol makes me do sexual things that I wouldn't do when sober", and "drinking alcohol makes it harder to say no to sexual advances". All these items used a 5-points scale ranging from 1 (surely not) to 5 (surely yes).

Eight items were used to assess the effect that smoking marijuana had on their ability to practice preventative behaviours when having sex (Cronbach's Alpha $=88$ ). These items were averaged into one index marijuana smaking and preventative behaviour. The questions addressed issues such as "smoking marijuana makes me less likely to use a condom when having sex", "after smoking marijuana I find it difficult to say no to sexual advances", and "smoking marijuana makes me do sexual things that I wouldn't do when not high". Again a 5-points scale was used to measure these items ranging from 1 "surely not) to 5 (surely yes).

Intention. The intention to reduce risky sexual behaviour upon release from prison was measured using five items with a scale ranging from 1 (surely not) to 5 (surely yes). These items assessed participants' intentions to perform activities that result in reduced risk behaviour. In particular, the items asked participants if upon release from prison they intended on using condoms and negotiating condom use with all sexual partners, asking sexual partners about past STI and sexual history, and asking partners about HIV status and testing, and lastly avoiding mixing sexual activity with substance use (Cronbach's alpha $=.82$ )

\section{Data analysis}

The data were analysed using the statistical software package SPSS, version 12.0 . Frequencies were calculated for each item in the questionnaire both at data cleaning and analysis stages. These included the demographic variables such as age, level of education, employment history, marital status, sexual history in last 6 months prior to imprisonment, previous infection with STIs and reported use of alcohol and marijuana before prison. Next reported lifetime occurrence of STI "ever had an STI" ( $\mathrm{N}=200$ ) versus "never had an STD" ( $N=155$ ) was subjected to a logistic regression to calculate adjusted odds ratios for demographics, reported past condom use, reported use of alcohol and reported marijuana intake prior to incarceration. The demographics, past STI history, condom use 
history, reported alcohol and marijuana use as well as the scales measuring the believed impact of alcohol and marijuana use on preventive behaviour were then subjected to a stepwise multiple regression with intention to reduce risky sexual behaviour upon release as the dependent variable

\section{Results}

\section{Demographics}

A total of 357 inmates participated in the study, with the mean age of inmates being 27 years (ranging from 17 years to 55 years). The participants had been incarcerated for an average period of about 2 years ranging from 6 months to 17 years. Most of the participating inmates were serving prison sentences for the first time in their lives $(65 \%)$ A total of $50 \%$ were unemployed at the time of arrest. More than half (55\%) either had an average of four years of formal education whereas $8 \%$ were completely illiterate. About $66 \%$ had been married before they entered prison. Of the participants about $84 \%$ were living in their own home or with their families before arrest and only $1.8 \%$ was living with their friends who were also involved in criminal activities.

\section{Alcohol and other drugs use prior to incarceration}

Of the participants in the study, $93 \%$ reported taking alcoholic drinks before getting into prison with $11 \%$ reported to have taken alcohol every day and $55 \%$ consumed alcohol more than once in a week. The use of marijuana prior to entering prison was reported by $52 \%$ of the respondents. Out of this group ( $N=187)$ about $70 \%$ reported that they smoked marijuana everyday. A total of $14 \%$ reported the use of Mandrax (methaqualonel either in pill form or mixing it with a marijuana joint. The use of recreational drugs such as ecstasy was not reported by any of the participants, nor was the use of hard drugs such as heroin and crack cocaine.

\section{Past STI history and risky sexual behaviour}

About $56 \%$ of the participants reported having at least one STI in the past. Almost all participants (99\%) stated sex with women (heterosexual) as their sexual preference with only one participant stating to prefer sex with other men. However, 22 participants (6\%) upon probing admitted to having engaged in anal sex either voluntarily or involuntarily while in prison. All participants reported engagement in sexual activity prior to entering prison. Self-reported condom use behaviour prior to prison was reported with $18 \%$ using condoms consistently, 39\% using condoms inconsistently, and $43 \%$ reporting to have never ever used condoms. Some of the reasons cited for not using condoms at the last occurrence of sex outside prison were "I did not have one" (20\%), "partner refused" (10\%), "I trust my partner/wife" (40\%), and "I was too excited to think of using a condom" (12\%). 


\section{Correlates of Ever Having an STI.}

As the participants had been in prison for varied periods before the study we used past history of SII occurrence as a measure of previous risky behaviour associated with the intake of alcohol and marijuana. Through the use of a logistic regression model that specified lifetime ST infection as a criterion, age, $O R$ ad $=1.05, p<001$, and inconsistent use of condoms, ORadi $=2.03, \mathrm{p}<.05$, were significantly linked to a previous reported occurrence of STIs amongst the participating inmates (see Table 1). Older participants had

Table 1: Odds ratios for ST history according to demographic variables and reported past substance use

\section{Ever had STts Never had STIS \\ $(N=200) \quad(N=155)$ \\ Adjusted odds ? P value \\ Ratios $(95 \% \mathrm{cl})$}

$1.05(1.01-1.09) \quad .00$

1. Age

2. Education level
a. No formal education
8.0
b. Primary
45.5
7.1
1
$.99(.38-2.60)$
.99
$1.19(.42-3.36)$
27.0
$89(.31-2.57)$
.74
d. High school
25.2
20.6

3. Income
a. Unemployed
b. Less than R10 000
c. R10 $000-819999$
d. Above R20 000

49.5

50.3

40.0

$.75(.46-1.28)$

5.2

$2.19(.88-5.44)$

13.0

4.5

4. Marital Status
a. Not Married
b. Married

61.4

70.1

29.9

1

$1.60(.96-2.67)$

5. Conviction history
a. First time offender
b. Repest offender

62.5

69.7

3.5

30.3

$\frac{1}{.80}(.48-1.32)$

6. Reported past condom use
a. Consistent
14.2
22.1
b. Inconsistent
43.1
33.1
c. Never
42.1
44.8

1

$2.03(1.04-3.96) \quad .03$

$1.19(.61-2.29)$

7. Reported alcohol use
a. No
11.8
b. Yes
88.2

20.0

80.0

$1.76(.88-3.54)$

.11

8. Reported Marijuana use
a. No
4.6
50.3
1
b. Yes
58.4
49.7
$1.64(.99-2.70)$
.05 
a slightly higher chance to report having an STI at some point prior to entering prison. Inconsistent use of condoms seemed to double the chance of having an STI prior to imprisonment compared to consistent and never use of a condom. Those who reported never use of condoms were not more likely to report a history of having STIs compared to those who reported consistent use of condoms in the past. Previous reported history of marijuana and alcohol use were positively associated with having an STI prior to incarceration, however this was only (borderline) significant for marijuana use.

\section{Correlates of intention to practice Safe Sex upon release}

In order to predict future behaviour upon release from prison, the intention to reduce risky sexual behaviour was regressed in a step-wise method on demographic variables (step 1) and reported condom use (dummy coded comparing the never users against the inconsistent and consistent users, and the inconsistent users against the other two categories), STI history, and alcohol and marijuana use prior to incarceration (step 2). The explained variance of the model was $7 \%$, which is rather low but somewhat higher than

Table 2: Stepwise multiple regression of the intention to practice safe sex on demographic variables (step 1), reported condom use, STI history, alcohol and marijuana use (step 2)"

Intention to practice safer sex

step]

Stepra

$\begin{array}{lrrrr}\text { Predictor or Statistic } & \text { B } & \text { SE B } & \text { B } & \text { SE B } \\ \text { Age } & -.00 & .01 & -.00 & .01 \\ \text { Education } & .07 & .04 & .04 & .04 \\ \text { Income } & .06 & .05 & .07 & .05 \\ \text { Marital status } & .10 & .07 & .05 & .07 \\ \text { Conviction history } & -.03 & .07 & -.03 & .07 \\ \text { Reported past condom use } & & & & .13 \\ \text { Inconsistent Vs Consistent and Never } & & & -.15 & .10 \\ \text { Mever Vs Consistert and Inconsistent } & & & -.05 & .06 \\ \text { Reported history of STIs } & & & .05 & .10 \\ \text { Alcohol use } & & & .01 & .07 \\ \text { Marijuana use } & & & 4.47 & .27 \\ \text { Regression constamt } & & & .07 & \\ \text { F }^{2} & .02 & & & \end{array}$

$a_{N}=320$

$b_{M(s) m}=36$ 
findings from other studies attempting to establish a link between substance use and risky behaviour (Ross et al, 2003). The reported use of both alcohol and marijuana prior to imprisonment was not significantly linked to intention to practice safer sex after being released from prison, neither were other variables (see Table 2 ).

Due to the fact that participants who did not smoke marijuana did not answer the questions measuring the believed impact of marijuana on risky sexual behaviour separate analyses had to be conducted for non-marijuana users and marijuana users to include measures of the perceived negative impact of marijuana and alcohol use on intention to practice safe sex. Among non-marijuana users a stepwise multiple regression model specified intention to reduce risky sexual behaviours upon release from prison as a criterion against demographic variables, reported condom use (dummy coded), STI history, alcohol use, and the beliefs of alcohol intake leading to increased risky behaviour (see Table 3). Maritall status and beliefs about the negative effects of alcohol on preventive behaviours were significantly linked to the intention to practice safe sex upon release. In the final

Table 3: Stepwise multiple regression of intention to practice safe sex on demographic variables (step 1), reported condom use, STI history, alcohol use (step 2), and beliefs about effects of alcohol use on preventive behaviours (step 3) among non-marijuana users"

Intention 10 practice safer sex

\section{Step 1}

Step 2
Step 3

\begin{tabular}{|c|c|c|c|c|c|c|}
\hline Predictor or Statistic & $\mathrm{B}$ & SE B & $B$ & SE B & $\mathrm{B}$ & SE B \\
\hline Age & .00 & .01 & .00 & .01 & .00 & .01 \\
\hline Education & .12 & .06 & .10 & .06 & .11 & .06 \\
\hline Income & -.07 & .07 & -.07 & .07 & -.09 & .07 \\
\hline Marital status & $40^{\text {* then }}$ & .13 & $.35^{*+*}$ & .14 & $.32^{* *}$ & .13 \\
\hline Conviction history & .14 & .13 & .14 & .13 & .16 & .12 \\
\hline $\begin{array}{l}\text { Reported past condom use } \\
\text { Inconsistent Vs Consistent and Never } \\
\text { Never Vs Consistent and Inconsistent }\end{array}$ & & & $\begin{array}{l}.16 \\
.02\end{array}$ & $\begin{array}{l}.16 \\
.16\end{array}$ & $\begin{array}{r}.08 \\
-.08\end{array}$ & $\begin{array}{l}.15 \\
.15\end{array}$ \\
\hline Reported history of STls & & & -.11 & .11 & -.07 & .10 \\
\hline Alcohol use & & & .25 & .20 & .11 & .19 \\
\hline $\begin{array}{l}\text { Beliefs on alcohol use and preventive } \\
\text { behaviour }\end{array}$ & & & & & $.16^{n+k}$ & .04 \\
\hline Regression constant & & & & & 3.59 & .39 \\
\hline $\mathrm{R}^{2}$ & .11 & & .16 & & .24 & \\
\hline
\end{tabular}

$a_{N}=120$

$b_{\text {sermer }}=.32$

"p $<.05 ; " p<0.01 ; * * *^{*} p<.001$ 
model, those who were married were more likely to practice safe sex in the final model. Furthermore, those who believed stronger that alcohol had a negative impact on practising safe sex had more positive intentions to reduce risky sexual behaviour. The explained. variance was $24 \%$.

For marijuana users a multiple regression was then performed regressing intention to reduce risky sexual behaviour against all the other variables including the perceived negative impact of marijuana smoking on preventive behaviour (see Table 4). In the final model, the perceived belief of alcohol and marijuana use on risky sexual behaviour were both significantly related to the participant's intention to practice safe sex when leaving prison. Furthermore, among marijuana smokers previous condom use, income and marital status was positively related to practicing safe sex upon release. The explained variance for the model was $19 \%$.

Table 4: Stepwise mulltiple regression of intention to practice safe sex on demographic variables (step 1), reported condom use, STI history, alcohol use (step 2), and beliefs about effects of substance use on preventive behaviours (step 3) among marijuana users

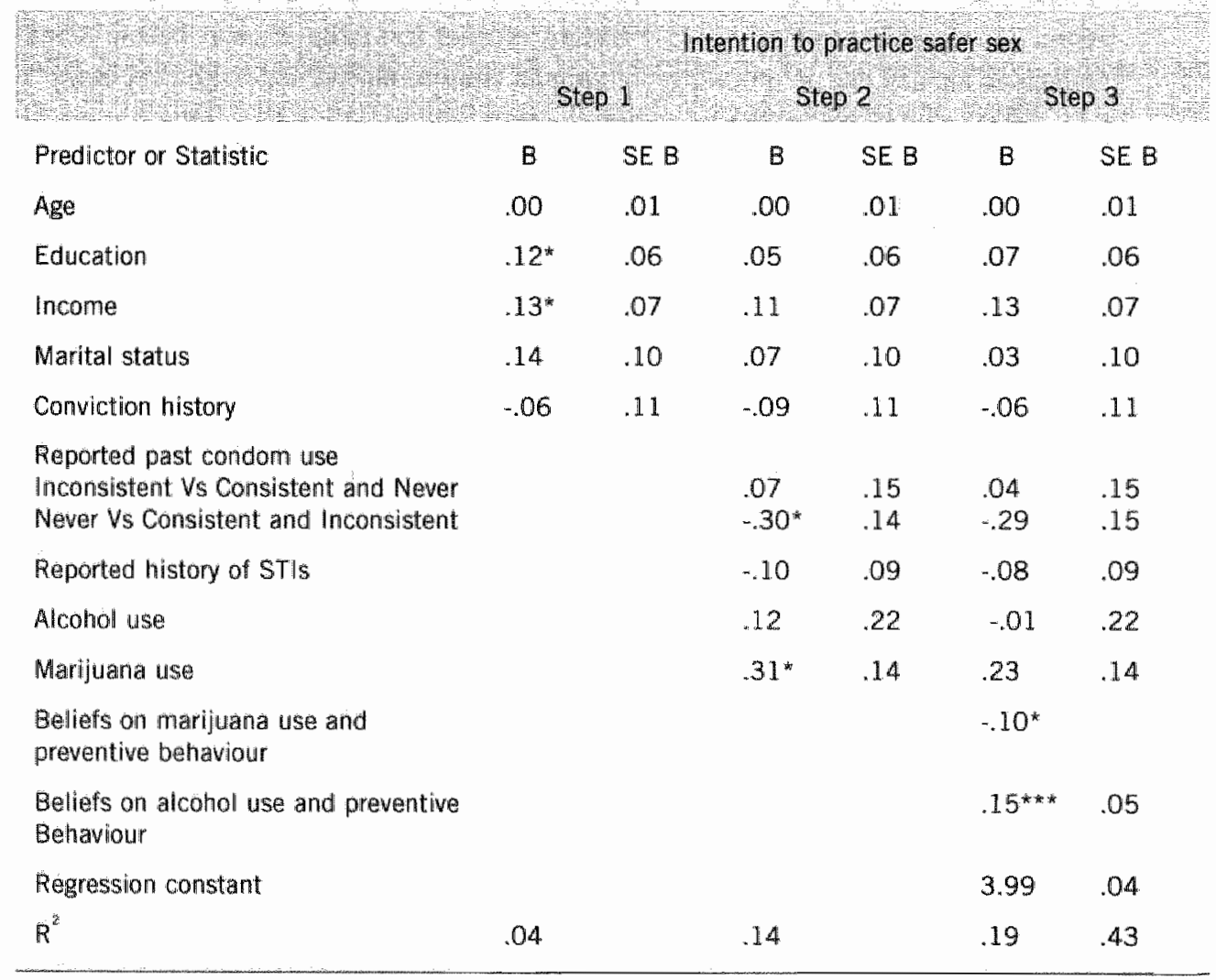

${ }^{\prime} N=185$

$b_{M}=43$

$* 0.05 ; * *_{p}^{*}<.01 * * * 0.001$ 


\section{Discussion}

More than half the participants in this study reported having had an STI prior to imprisonment. This rate is much higher than the rates reported in the genera:

South African population of around 15\% (Pham-Kanter, Steinberg \& Ballard , 1996), but simlar to other studies conducted amongst inmates in other countries (Braithwaite ot a., 2004; Morris, Baker, Valentine, G Pennisi, 1998) who generally show higher STI prevalence rates than the general population. Inmates largely belong to a section of the population that has high sensation seeking and risk taking behaviour, and committing a crime could be viewed as a manifestation of this characteristic. This reality has serious implications to HIV prevention amongst inmates, which ultimately impacts on their sexual partners and the broader community.

Alcohol and marijuana use amongst participants was found to be extremely high in line with other findings from Sub-Saharan Africa (Adesanya et al, 1997). Similar results are found on data from the Southern African Development Community (SADC) Epidemiological Network on Drug Use (SENDU), a drug survellance network on drug use patterns in 13 SADC countries, which shows that alcohol and marijuana are the drugs of choice in Southern Africa (Perry E Pludderman, 2004). The use of hard drugs such as heroin, crack and cocaine was almost non-existent amongst our study group, which could. due to the high costs of acquiring these drugs. Additionally, there might be other socioeconomic and cultural dynamics responsible for the lower use of hard drugs amongst non Caucasian population groups as demonstrated by findings from Western studies on drug use patterns (Morris et al., 1998; Resnicow, Soler, Braithwaite, Ahluwalia, E Butler, 2000 ). Marijuana, in contrast, seems to be very affordable and widely available both inside and outside of prison almost on a global scale.

The definition of 'drugs" also shows many variations within and across cultures. Marijuana is an accepted substance in most traditional settings in South Africa due to some traditional uses that are associated with the herb. The use of marijuana in prisons. seemed to be widely accepted as one of the perks that inmates need to be afforded in order to maintain order within everyday prison life and therefore widely accessible in most prison facilities (Adesanya et al, 1997; Long, Allwright, E Begley, 2004). Marijuana was also viewed as a prohibited substance and not a 'drug" amongst inmates, such that individuals who smoked marijuana would always say they do not take drugs when probed about drug use behaviour.

Most inmates generally associated alcohol intake with risky sexually behaviour much more than smoking marijuana. The general perception was that alcohol intake leads to increased yearning for sex and tends to lower inmates ability to think about protective actions. This is evident in the fact that those who reported having believes of alcohol affecting their ability to practice safer sex demonstrated a positive intention to reduce risky behaviour upon release. The belief on marijuana's impact on preventive behaviour was negatively associated with intention to reduce risky behaviour as smoking marijuana 
was not perceived as leading to increased sexual risk taking amongst inmates. Marijuana has also been reported in other studies to have no direct impact on risky behaviour amongst users who are above 18 years of age (Kingtree et al., 2000). Only adolescents who are below 16 years of age having shown increased sexual risk taking after smoking marijuana (Kingtree \& Phan 2001).

The study did not find any direct link between reported intake of alcohol, and marijuana use and any increase in risky behaviours, as has been the case with other studies (Castilla, Barrio, Jose Belza, \& De La Fuente, 1999). Nonetheless some studies have shown that drinkers acknowledge the reduced inhibition and increase in the likelihood of neglecting safety measures after drinking alcohol (Leigh \& Stall, 1993; Nadeau, Truchon, \& Biron, 2000). The causal relationship might be hard to prove but the association clearly exists, more especially amongst inmates who are likely to report more frequent and higher intake of substances than most people due to their lifestyles in general.

This study provides insight into a new area of research in South Africa, but a few potential limitations should be mentioned. Firstly, the study enrolled people who had been approved for parole and thus did not represent inmates who do not qualify for parole who may be different from the study group. Secondly, the instruments being used for data collection were newly developed tools whose validity has not been thoroughly tested over time. What made this issue even more complicated was the dynamic of having to translate study instruments into Zulu which brought linguistic and cultural complications to the study (see Sifunda et al., 2005b).

Another limitation was potential recall bias on the self reported history of substance abuse and sexual activity. As participants were preoccupied with challenges of returning back home, they might have tended to provide information that paints a socially desirable picture of themselves. This is likely due to the fact that most of the conditions attached to parole are against any form of substance use and other illegal activities. Furthermore the causal relationship between drug intake and RSB seems weak due to the fact that the participants had been in prison where there is lower access to drugs more especially alcohol. However, the study tried to elicit alcohol and drug related behaviour prior to incarceration which might thave been an indicator of how inmates were likely to behave upon release from prison. There is a need to conduct more research that will explore further, the dynamics of alcohol and substance use related risky behaviour amongst inmates.

Despite all these limitations the study provided valuable insight into the context of prison inmates and substance use. We were also able to gain new knowledge on the extent of drug use amongst prisoners in South Africa and its potential impact on the spread of HIV and AIDS which provided valuable information in designing a contextually relevant health education intervention for prison inmates. It can be concluded that the use of alcohol and other drugs is likely to result in increased risk taking amongst inmates and thus leading them to potential infection with STIs including HIV and AIDS. 


\section{Chapter 6}

\section{The effectiveness of a peer-led HIV/AIDS and STI Health}

\section{Education intervention for prison inmates in South Africa.}

Sifunda, S., Reddy, S.P., Braithwaite, R.B., Stephens, T., Bhengu, S., Ruiter, R.A.C., \& Van Den Borne, B. (2005). The Effectiveness of a Peer-led HIVIAIDS and STI Health Education Intervention for Prison Inmates in South Africa. 


\section{ABSTRACT}

This paper reports on the effectiveness of the first systematically developed health education intervention for the reduction of risky sexual behaviour among soon to be released prisoners in South Africa. Data from three out of four prisons were eligible for data analysis including 263 inmates. Using a nested experimental design, short-term evaluation while inmates were still in prison demonstrated that experimental groups showed higher knowledge of STls and had a more positive intention to reduce risky behaviour than the control group in two out of three prisons. Long-term assessment 3-6 months after release from prison indicated that experimental groups were more positive about sexual communication, selfefficacy and intention. Groups educated by a HIV negative educator performed marginally better than those in groups with a HIV positive peer educator. It is argued that peer-led health education programmes may be effective in reducing risky behaviour amongst soon to be released inmates. 


\section{Introduction}

Prison inmates are increasingly being recognised as a subgroup that faces a high risk of getting infected with the Human Immunodeficiency virus (HIV) as well as other sexually transmitted infections (STIs) (WHO, 2000). The prevalence rates of sexual related infections amongst inmates is reported to be up to 5 times higher than rates found in the general populations (Braithwaite, Hammett, \& Mayberry, 1996; Hammett, Harmon, \& Maruschak 1999). Furthermore, life in prison exposes inmates to a host of other problems ranging from poor hygienic conditions, overcrowding, to the threat of sexual abuse either through coercion or more often by force, often in relation to drug abuse and other prison related dynamics (Braithwaite et al., 1996; Edemudia \& Reddy 2002; Watson, Stimpson, \& Hostick 2004).

Prison inmates are a highly mobile population who often move in and out of prison as well as within different prisons (Grinstead, Zack, \& Faigeles, 2001). This means that people who commit offenses face a double risk of being infected with HIV and other STIs both from within and outside of prison. Watson and colleagues $(2004$, p. 125) note that "the health of prisoners as they return to the community may have consequences for the communities to which they return", and by and large the health problems of prisoners also reflect and magnify the problems of their communities of origin. Thus the perception that health and welfare issues of inmates only affects people behind the walls is both misinformed and very counterproductive to public health initiatives in the general community.

Prisoners may be difficult to reach after release due to unstable social and financial environments, such as a lack of permanent residence and unemployment. As a result, when they are released from prison, HIV prevention and risk reduction issues are unlikely to receive high priority (Grinstead et al., 2001). Therefore, the time spent in prison creates an opportunity for public health practitioners to design and implement health interventions that empower offenders while they in a captive state of prison life, and to prepare them for future life challenges outside of prison. (Braithwaite et al., 1996; Bryan, Ruiz, \& O'Neill, 2003; Crinstead, Zack, \& Faigeles, 1999).

There is a dearth of systematically developed health education interventions that specifically target prison inmates. Even in the more developed countries prison-based programmes have mainly been based on authorities reacting to prevalence data that relies heavily on demographic differences amongst prisoners (Bryan et al., 2003). This approach has led correctional based programmes to focus on addressing specific outbreaks of certain diseases as opposed to having a comprehensive systematic approach to disease prevention and management. For instance, most programmes usually focus on the treatment of substance abuse, TB and STI with no clear plan on how to incorporate long term prevention amongst inmates through appropriate health education interventions (lacob \& Stover 2000; Long, Allwright, \& Begly, 2004).

There is an overwhelming interest in the merits of developing health education 
interventions that are tailored for specific subpopulations (Reddy, Van den Borne, \& Yach, 1995). The prison population in South Africa as a subpopulation has received very little attention in the exploration of prison specific health behaviour determinants and thus systematically developed intervention programmes for inmates are not in place. The small trickle of studies in this area has come mainly from the USA (Bryan et al., 2003; Bryan, Aiken, \& West, 2004; Grinstead et al, 2001). In sub-Saharan Africa STI and AIDS prevention programmes in the prison setting are even non-existent.

\section{The South African Prison setting}

The South African prison system consists of 241 prisons which house an average about 175000 inmates (DCS, 2001). Prisons in South Africa are largely populated by African Black males who hail from extremely disadvantaged and depressed backgrounds due to the legacy of Apartheid. Additionally low literacy rates and higher tendency to engage in risky behaviours amongst offenders makes them an even more vulnerable group than males in the general population (DCS, 2001). The time spent in prison can therefore be one of the most crucial points of access for providing HIV/AIDS and STI prevention information especially in preparation for release and re-entry into the community of origin.

In keeping with HIV prevention, treatment and care policies of the South African government, the Department of Correctional Services has a policy of providing free access to condoms, for all inmates housed in the country's prisons. This is in line with the department of health's framework on HIV prevention for the general population of the country. Parallel to the availability of condoms, sex between men is still considered as 'sodomy' in prisons and likely to be subjected to some punitive measures (Sifunda et al., 2005a). Additionally, the association of sexual activities with gang practices also makes sex a closed subject in prison. These sensitive issues limit the use of condoms by inmates while incarcerated.

\section{The present study}

Most of the studies conducted on prevention initiatives in prisons have been done in western countries where the socio-cultural context is different to those of the developing world (Idemudia \& Reddy, 2002). Furthermore, prison interventions have also tended to focus on the time spent in prison and have overlooked the importance of providing skills that are applicable to both "inside" and "outside" for offenders. The present study aims to test the effectiveness of a systematically developed health education intervention targeting prison inmates on psychosocial determinants of reducing risky sexual behaviours, specifically taking into account the socio-economic and cultural contexts of inmates in South African prisons.

Following the process of planned behaviour change (Bartholomew, Parcel, Kok, \& Gottlieb, 2001), earlier identified correlates of risky sexual behaviour upon release (see 
Sifunda et al, 2005c) served as target points for the development of a health education intervention on HIV/AIDS and STI prevention administered to offenders before they rejoin the community. Specifically the present study deternined the effectiveness of a HIV/AIDS peer led health education intervention programme on knowledge about HIV transmission, attitude towards condom use and people living with HIV/AIDS, sexual communication, self efficacy to practice safe sex and the intention to reduce risky sexual behaviour upon release from prison. The study further explored the merits of engaging former prison inmates to act as peer educators who deliver the health intervention to other prison inmates, as they were viewed to be potentially more efficacious than ordinary health educators.

\section{Method}

\section{Study design and setting}

The study was conducted using a nested experimental design. Within each of four selected prisons there was both a control and an experimental group. Additionally in each prison, the experimental groups were divided between those that were instructed by a HIV positive peer educator and those that were instructed by a HIV negative peer educator. The study utilised a pre-test (T1), a post-test prior to release from prison (T2) and a 3 to 6 months community follow-up test (T3) as evaluation measurements for all the participating inmates. The study received full ethical approval from the South African Medical Association Research Ethics Committee (SAMAREC).

The study sites consisted of four prisons in the provinces of KwaZulu-Natal (KZN) and Mpumalanga (MP) provinces, referred to as KZN1, KZN2, MP1 and MP2 prisons respectively. The selected facilities were classified as medium sized correctional facilities. The sites were selected after taking into account the logistics of having to follow up the participants after being released from prison to go back to their communities, as the intervention was a long-term 12 months cohort study. The four selected prisons housed about 3022 inmates during the study period.

\section{Participants}

Participants qualified to enrol in the intervention study if they were within six months of being released, either on parole or due to completion of their sentence. Each institution was requested to provide the research team with a list of all their inmates who had been officially approved for parole during the period. All the selected inmates were then summoned to a briefing session where the study programme was explained. Participants who were interested were then invited to attend a second session where they were provided with consent procedures as wells forms to complete. They were requested to respond to the baseline questionnaire before the commencement of the intervention sessions. A total of 362 inmates were recruited to participate in the intervention 
programme of which 357 consented to participating in the study and thus provided the information for the baseline questionnaire. The participants consisted mainly of African Black men who were Nguni speakers. Most people who speak this group of languages are fluent in Zulu, which is the most widely spoken dialect of all the Nguni languages and also South Africa's most spoken language across all racial groups.

\section{Intervention curriculum}

The curriculum for the South African Intervention was adapted and developed based on the work of Braithwaite and colleagues (Braithwaite, Stephens, Comely, Arriola, \& Robillard, 2004) who had engaged in a similar project with offenders in the state of Georgia, USA. To capture the cultural and socio-economic context and prison experience of South Africa preliminary qualitative studies were conducted that served as an access point analyses of the South African Correctional system and provided vital information for tailoring the intervention to Black African male inmates. That is, focus groups were conducted among both inmates and correctional services personnel in four prisons in the two provinces (for a report on those data, see Sifunda et al., 2005a, 2005b). These prisons were similar to those selected for the intervention study. Owing to the major cultural, language and socio-economic differences between South Africa and the USA the curriculum had to undergo major changes resulting in a new intervention believed to be more appropriate and relevant to the South African context.

The final intervention programme, subsequently called "Ubudoda Abukhulelwa" was then translated into Zulu and piloted amongst Zulu speaking inmates. This was done based on the fact that Zulu was the most predominant language in the selected provinces. In each of the participating sites 12 sessions were provided over a period of six weeks, with each session lasting 1.5 hours for a total of 18 hours for the full intervention. The curriculum covered the following topics: (a) HIV and AIDS, (b) Sexually Transmitted infections, (c) Nutrition and TB prevention \& management, (d) Alcohol and other Drug Abuse, (e) Sexuality and Gangsterism, and (f) Manhood and General Life skills. All sessions were planned between 9.00 and 12.00 hours in the educational section of all the participating prisons.

Two health educators who had no prior history of incarceration conducted all the sessions for the control groups. Participants in the control arm of the experiment were shown a series of videos covering various health issues, such as cholera, malaria and TB. They also received copies of HIV and STls information, education and communication materials which are distributed to the general public as part of the governments prevention programme.

\footnotetext{
'Ubudoda abukhuletwa - is a Ngumi idiom that means that a man is never too young to contribule posintueby to his society. It is usually used to cormmend the performance of a responsible or heroic deed as well as to motivate and encourage men to pursue responsible or heroic actions.
} 


\section{Training of peer educators}

Four former inmates were recruited and underwent training as peer educators to conduct the training sessions in the prisons. Two of the peer educators were HIV positive and had to disclose their status to the participants in their intervention group. They had agreed to do this during their recruitment interview. The training process also provided another opportunity to fine tune the intervention. This enabled modifying and further adapting the grammar and terminology to reflect that of the culture created within the prisons, which is viewed as being important when dealing with inmates' populations. The peer educators also received refresher training and evaluation sessions periodically as the intervention stretched over a period of 2 years. All peer educators were selected from the same areas that the study was being conducted and they all spoke Zulu as their first language.

\section{Study instrument}

A questionnaire was designed based on the theory of planned behaviour (Ajzen, 1991) and the social cognitive theory (Bandura, 1986; Bandura, 1999), and information that was obtained through the focus group interviews (see Sifunda et al, 2005a, 2005b). Following demographic variables such as province, age, ethnicity, level of education, employment history, marital status, the questionnaire measured the knowledge and beliefs about causes and transmission of STls including HIV/AIDS, attitudes towards condom use and people living with HIV/AIDS, sexual communication, social norms about gender relations and sexual violence, self-efficacy and skills for practicing safer sex (see also Sifunda et al., 2005b).

The questionnaire was prepared in English and translated from English to Zulu. To ensure the accuracy of the translations, the Zulu version of the questionnaire was back translated to English by a team of research assistants who were involved in the project as data collectors and health educators independently. The first author who is a first language Zulu speaker rechecked all the translations. The questionnaire was interviewer administered as most prison inmates had very low literacy levels. Three sets of data were collected, respectively at baseline (T1), post intervention prior to release from prison (T2), and a community follow-up interview 3 to 6 months after release from prison (T3). Participants who were on parole were interviewed at the community corrections office when they came for their monthly signing visits, while those who were not on parole had to be traced by the team in their villages. Participants were compensated with $R 50$ (about $\$ 7.00)$ at $T 2$, which they received the day they left prison, and at community follow-up they were given R100 (about $\$ 14.00$ ).

\section{Measurements}

Explorative factor analysis was used to identify conceptually meaningful dimensions within the different groups of items. Principal components extraction and direct oblimin rotation were used for extracting factors and measuring inter-item correlations. Based on the pattern matrix and scree plots, factors were determined and for each factor items with 
item loadings of 0.4 or higher were selected. The resulting group of items were then subjected to reliability analysis to measure the internal consistency of the resulting scale. Scales were constructed that had a Cronbach's alpha ( $\alpha$ ) of .60 or higher. This procedure was done for the baseline data. Scales used at T2 and T3 were similar to those at baseline.

Knowledge about spread and transmission of HIV and AIDS and other STIs. Inmates" knowledge about the spread and transmission of HIV and other STIs was measured using the averaged scores of nine items $(\alpha=.91)$. Questions addressed issues such as: "You can get HIV by sharing needles", "You can get HIV by coming into contact with infected blood", "A person can get HIV by sharing a room or cell with an infected person". "HIV/AIDS is caused by condoms", and "HIV/AIDS is caused by witchcraft". The items were measured using a scale with three possible options (true, false, I don't know) that were recoded into $1=$ incorrect, $2=$ unsure, and $3=$ correct.

Attitudes. Participant's attitude towards condom use in preventing HIV was assessed using the averaged scores of three items $(\alpha=.76)$. Questions were "Condoms work well to prevent HIV and other STIs", "It is important to use a condom every time you have sex", and "Condoms allso prevent unwanted pregnancy" $11=$ strongly disagree, $5=$ strongly agree). Participants" attitude towards people living with HIV/AIDS was assessed using the averaged scores of eight items ( $\alpha=.75$ ) with an answering scales that ranged from 1 (I definitely would mind) to 5 (I definitely would not mind). Questioned covered issues like, "If your relative has HIV would you mind caring for them" and "Would you mind sharing a room with an HIV positive person".

Sex Communication. The averaged scores of five items were used to assess sexual communication of participants with their sex partners $(\alpha=89)$ on a scale from 1 (strongly disagree) to 5 (strongly agree) The questions addressed issues of negotiating condom use and being the first person to initiate discussion on safer sex practices. Sample items were: "It is okay for a woman to discuss HIV/AIDS issues with her partner" and "A man should be able to discuss with his partner about safe sex".

Self Efficacy. Participant's perceived skills for practicing safer sex (self-efficacy) was assessed using the averaged scores of nine items $(\alpha=.89)$, which measured participants' confidence in issues such as being able to put on a condom correctly, being able to put on a condom even if it is dark, being able to resist sexual intercourse without using a condom even if it was someone you have slept with before. All items were measured using scales ranging from 1 (surely not) to 5 (surely yes).

Intention. The intention to reduce risky sexual behaviour upon release from prison was measured using the averaged scores of five items with a scale ranging from 1 (surely not) to 5 (surely yes). These items assessed participants' intentions to perform activities that result in reduced risk behaviour in particular using condoms and negotiating condom use with all sexual partners, asking sexual partners about past STI and sexual history, and asking partners about HIV status and testing, and lastly avoiding mixing sexual activity with substance use $(\alpha=82)$. 


\section{Result}

In the early stages of the study there was a change of management at KZNI prison. This resulted in the sessions having to be moved out of the educational section to the custodial section of the prison. The new venue proved to be inappropriate and not conducive to teaching as it was next to the courtyard, and was also used as a recreational hall and dining hall for all the inmates. Due to this development all the sessions had to be shortened and the facility also did not have audio-visual equipment to show the educational materials that were part of the curriculum. For the purposes of testing the effectiveness of the programme we excluded the 94 participants from that prison in the analysis. The final number of participants in the analysis was 263 inmates. The control group had 63 participants, in the intervention groups 86 had a peer negative instructor and 107 had a peer positive educator.

\section{Characteristics of sample}

The mean age of inmates was 27 years ranging from 17 years to 55 years. The participants had been incarcerated for an average period of about two years ranging from 6 months to 17 years. Most of the participating inmates $(65 \%)$ were first time offenders. A total of $50 \%$ were unemployed at the time of arrest and after release from prison only $3 \Perp \%$ were employed at the time of follow-up interviews. Of the participants about $93 \%$ reported that they were living in their own home with their families, or living with relatives after being released from prison.

\section{Short term effects comparison between control and experimental group}

To explore the short term effects of the intervention univariate analyses of variance (ANOVA) were conducted to compare the intervention and control group on the psychosocial measures at T2. Prison site was included as an additional factor to control for differences across sites, resulting in a 2 (Intervention: Experimental vs. control) $\times 3$ (Prison Sites) between-subjects design, with the baseline measure of the corresponding outcome measure included as covariate (for the mean scores, see Table 1). The analyses showed significant interaction effects between Intervention and Prison on the measures of knowledge, $F(2,224)=4.32, p<.05$, and intention, $F(2,221)=4.63, p<.05$. Simple main effect analyses on knowledge showed that the effect of Intervention was significant in $\mathrm{KZN} 2$ prison, $F(1,228)=13.25, p<.001$, and MP2 prison $F(1,228)=5.64$, $p<.05$, with participants in the experimental group showing more knowledge than participants in the control group. On the intention measure an effect of Intervention was found in KZN2 prison, $F(1,225)=12.72, p<.001$, and MP2 prison, $F(1,225)=11.79$, $p<.001$, with people in the intervention groups showing a more positive intention to reduce risky sexual behaviour than people in the control groups. There were no significant effects of Intervention at MP1 prison on both knowledge and intention, 
Table 1: ANOVA for short term (T2) main effects comparison between control and experimental group, Means and $\mathrm{SD}(\mathrm{N}=263)$

Tron $\mathrm{KL} / 2$

Proderor

Mrowledge

$(N=231)$

Attitude towards condom use

$(N=231)$

Attitude towards PLWHA

$(N=227)$

Sexual communication

$(N=228)$

Self-efficacy

$(N=226)$

Intention

$(N=228)$

contral

$1.72 \mathrm{a}$

(0.12)

2.70

$(0,48)$

2.29

(0.63)

2.54

$(0,52)$

$2.21 \mathrm{a}$

$0.62)$

$2.54 \mathrm{~b}$

4.51

4.50

4.36

3.99

4.28

4.45

(0.75)

(10.94)

(0.76)

(1.0.2)

$(0.86)$

$(0.75)$

$\begin{array}{cccccc}2.73 & 2.75 & 2.55 & 2.74 & 2.68 & 2.78 \\ (0.36) & (0.45) & (0.30) & (0.43) & (0.61) & (0.47)\end{array}$

4.41

4.64

4.43

4.36

4.37

4.45

$(1.16)$

$10.80)$

$(0.69)$

0.711

(0.61)

(0.58)

4.74

4.68

$(0.35)$

$(0,45)$

\subsection{5}

4.39

4.68

4. 50

(0.50)

(0.69)

$(0.44)$

$(0.66)$

$4.12 \mathrm{a}$

(0.87)

$4.79 \mathrm{~b}$

4.51

4.56

$4.10_{a}$

(0.40)

(0.68)

$(0.74)$

4.65

(0.48)

Note. For each prison, means within a row that are printed in bold and do mot share subscripts differ significantb.

$F_{s}<1.16$, ns, neither were there effects of Intervention and Prison and their interactions on attitude towards condom use, attitude towards PLWHA, sexual communication, self efficacy for practising safe sex, $F s<2.90$, ns.

\section{Long term effects comparison between Control and Experimental Group}

Analyses were then conducted comparing the intervention and control groups at 3-6 months post release from prison (T3) with the baseline measure included as covariate (for the mean scores, see Table 2). A significant main effect of Intervention, which was not qualified by an interaction effect of Prison, was found on the measure of sexual communication, $F(1,131)=6.61, p<.01$. As predicted, the intervention group agreed more with statements supporting communication about sex with future partners $(M=4.68, S D=0.61)$ than the control group $(M=4.34, S D=0.84)$. Furthermore, there was a main effect of prison on attitude towards condom use, $F(2,133)=4.60, p<.05$, and attitude towards people living with HIV/AIDS. These effects were not qualified by an interaction with Intervention, $F_{S}<.51$, ns. Posthoc comparisons showed that the attitude towards condom use was more positive in $K Z N 2$ prison $(M=4.80, S D=0.58)$ than in MP1 prison $(M=4.26, S D=0.86 ; p<.01)$, whereas no significant differences were found comparing MP2 prison $(M=4.55, S D=0.75)$ to $K Z N 1$ and $M P 1$ prisons 
Table 2: ANOVA for long tem (T3) main effects comparson between contro and experimental growp, Means and SD $N=135)$

\begin{tabular}{|c|c|c|c|c|c|c|}
\hline & Priso & KxN2 & Fros & np & 2) & $1 \times 2$ \\
\hline Predretoc & Contral & Exp & ownto & $6 \times 0$ & Mormor & Ex] \\
\hline $\begin{array}{l}\text { Knowledge } \\
\mathrm{N}=142\end{array}$ & $\begin{array}{l}2.94 \\
10.09\end{array}$ & $\begin{array}{l}2.92 \\
10.13\end{array}$ & $\begin{array}{c}2.75 \\
(0.72)\end{array}$ & $\begin{array}{c}2.90 \\
1015\end{array}$ & $\begin{array}{l}2.83 \\
0.46\end{array}$ & $\begin{array}{l}2.91 \\
0.16\end{array}$ \\
\hline $\begin{array}{l}\text { Attitude towards condom use } \\
(N=140)\end{array}$ & $\begin{array}{l}4.69 \\
10.38\end{array}$ & $\begin{array}{l}4.82 \\
10.62\end{array}$ & $\begin{array}{c}4.22 \\
(0.74)\end{array}$ & $\begin{array}{l}4.28 \\
10.921\end{array}$ & $\begin{array}{l}4.30 \\
(1.2)\end{array}$ & $\begin{array}{c}4.66 \\
10.48\end{array}$ \\
\hline $\begin{array}{l}\text { Attitude kowards PLWHA } \\
C N=136\end{array}$ & $\begin{array}{l}4.66 \\
10.49\end{array}$ & $\begin{array}{c}4.51 \\
00.62)\end{array}$ & $\begin{array}{c}4.10 \\
(0.49)\end{array}$ & $\begin{array}{c}4.14 \\
(0.40)\end{array}$ & $\begin{array}{c}4,32 \\
(0.25)\end{array}$ & $\begin{array}{l}4.2^{3} \\
10.45\end{array}$ \\
\hline $\begin{array}{l}\text { Sexual communication } \\
W=138\end{array}$ & $\begin{array}{l}4.70 \mathrm{a} \\
(1.46)\end{array}$ & $\begin{array}{l}4.78 b \\
(0.37)\end{array}$ & $\begin{array}{l}4.32 \mathrm{a} \\
(0.28)\end{array}$ & $\begin{array}{l}4.56 \mathrm{~b} \\
(0.61)\end{array}$ & $\begin{array}{l}4.04 \mathrm{a} \\
(1.05)\end{array}$ & $\begin{array}{l}4.65 \mathrm{~b} \\
10.81)\end{array}$ \\
\hline $\begin{array}{l}\text { Self-efficacy } \\
(N=139)\end{array}$ & $\begin{array}{l}4.78 \\
(0.30)\end{array}$ & $\begin{array}{l}4.80 \\
(0.33)\end{array}$ & $\begin{array}{c}4.70 \\
(0.34)\end{array}$ & $\begin{array}{l}4.64 \\
(0.54\}\end{array}$ & $\begin{array}{l}4.71 \mathrm{a} \\
(1.59)\end{array}$ & $\begin{array}{l}4.78 \mathrm{~b} \\
(0.30)\end{array}$ \\
\hline $\begin{array}{l}\text { Intention } \\
(N=138)\end{array}$ & $\begin{array}{c}4.65 \\
(0.36)\end{array}$ & $\begin{array}{c}4.83 \\
(0.34)\end{array}$ & $\begin{array}{l}4.73 \\
10.46)\end{array}$ & $\begin{array}{c}4.63 \\
(0.65)\end{array}$ & $\begin{array}{l}4.07_{\mathrm{a}} \\
(1.15)\end{array}$ & $\begin{array}{r}4.80_{\mathrm{b}} \\
(0.47)\end{array}$ \\
\hline
\end{tabular}

Note. For each prison, means within a row that are printed in told and do not share subscripts differ significantly.

( $p^{3} s>$.37). With regard to attitude towards people with HIV/AIDS, attitudes were more positive for $K Z N 1(M=4.55, S D=0.59)$ and $M P 1(M=4.13, S D=0.43)$ prisons as compared to $M P 2$ prison $(M=4.27, S D=0.40 ; p$ 's $<05)$, whereas $M P 1$ and $M P 2$ prison did not differ significantly $(p=.66)$.

Significant interaction effects between Intervention and Prison were found on the measures of self-efficacy, $F(2,132)=10.42, p<.001$, and intention, $F(2,131)=5.87$, $p<.01$. Simple main effect analyses showed that the effect of Intervention was significant only for MP2 Prison on the measures of self-efficacy, $F(1,136)=17.50, p<.001$, and intention, $F(1,135)=11.07, p<.001$ (all other $F s<1.58$, ns). At MP2 site, participants in the experimental group had more positive self-efficacy beliefs and intention regarding practising safe sex. At follow-up, no significant differences were found for Intervention and Prison on participants" knowledge about HIV/STD transmission, $F_{\mathrm{S}}<.53$, ns.

\section{Effect of HIV Status of Instructor on the Experimental Group}

To explore the effect of the HIV status of the peer educator the experimental condition was divided into HIV negative HIV positive peer educators, with the control groups forming the third level. All outcome measures at T2 and T3 were then subjected to 3 (Peer educator: positive vs. negative vs. control) $\times 3$ (Prisons) univariate analyses of 
Table 3: Mean scores and SDs for effects of HIV status of instructor on intervention within the 3 prisons at $\mathrm{T} 2(\mathrm{~N}=263)$

Prison $18 \mathrm{ZN} 2$

Pison $\mathrm{NPI}$

Qontrol

Piedictor

Knowledge

\section{$1.72 \mathrm{a} \quad 2.90_{\mathrm{b}} \quad 2.60_{\mathrm{c}}$}

(0.12)

(0.16)

(0.56)

2.29

2.47

(0.63)

(0.54)

2.78

$(0.37)$

$2.21 \mathrm{a}$

(0.62)

$2.83 \mathrm{~b}$

(0.25)

$2.43_{\mathrm{b}}$

$(0.63)$

$\begin{array}{lccccccccc}\text { Attitude towards } & 4.51 & 4.43 & 4.50 & 4.36 & 3.97 & 4.11 & 4.29 & 4.33 & 4.49 \\ \text { condoms } & (0.75) & (1.06) & (0.91) & (0.70) & (1.03) & (1.02) & (0.86) & (1.11) & (0.60) \\ \text { Attitude towards } & 2.73 & 2.80 & 2.73 & 2.55 & 2.74 & 2.79 & 2.68 & 2.50 & 2.80 \\ \text { PLWA } & (0.36) & (0.53) & (0.42) & (0.30) & (0.44) & (0.43) & (0.61) & (0.43) & (0.45) \\ & & & & & & & & & \\ \text { Sexual } & 4.42 & 4.68 & 4.64 & 4.44 & 4.34 & 4.43 & 4.36 & 4.26 & 4.50 \\ \text { communication } & (1.16) & (0.53) & (0.92) & (0.69) & (0.75) & (0.58) & (0.61) & (0.75) & (0.52) \\ & & & & & & & & & \\ \text { Self-efficacy } & 4.74 & 4.80 & 4.61 & 4.45 & 4.39 & 4.34 & 3.68 & 4.20 & 4.54 \\ & (0.35) & (0.27) & (0.51) & (0.68) & (0.75) & (0.80) & (0.44) & (0.74) & (0.62) \\ & & & & & & & & & \\ \text { Intention } & 4.12 \mathrm{a} & 4.97 \mathrm{~b} & 4.71_{\mathrm{b}} & 4.51 & 4.58 & 4.45 & 4.10 \mathrm{a} & 4.27 \mathrm{~b} & 4.79_{\mathrm{b}} \\ & (0.87) & (0.07) & (0.57) & (0.46) & (0.68) & (0.67) & (0.74) & (0.79) & (0.47)\end{array}$

Note. For each prison, means within a row that are printed in bold and do not share subscripts differ significantly.

variance, with the baseline measure included as covariate. Only significant effects $(p<$ .05) involving Peer-educator will be reported. Tables 3 and 4 show the effect of each type of instructor within the different prisons on the variables at time $\mathrm{T} 2$ and $\mathrm{T} 3$, respectively.

At T2, significant interaction effects between Peer Educator and Prison were found on knowledge, $F(4,221)=4.29, p<.01$, and intention, $F(4,218)=4.08, p<.01$. Subsequent simple main effect analyses showed that the effects of Peer Educators on knowledge and intention were significant in KZN2 prison, $F(2,227)=7.84, p<.001$, and MP2 prison, $F(2,224)=5.03, p<.001$. On both measures posthoc comparisons showed that both the peer negative and peer positive instructors performed better than the control group $\left(p^{\prime} s<.05\right)$. No significant differences were found between the HIV negative and the HIV positive educators, except for the knowledge variable in $\operatorname{KZN2}$ prison $(p<, 01)$.

At T3, significant main effects of Peer Educator were found on attitude towards condom use, $F(2,130)=3.66, p<.05$, and sexual communication, $F(2,128)=4.50$, $p<.05$. Posthoc comparisons on these measures showed that the HIV negative peer educator intervention group had higher average scores than both the HIV positive peer educator group and the control group on both attitude towards condom use $(M=4.64$, $S D=0.60 ; M=4.56, S D=0.84 ; M=4.37, S D=0.82$, respectively) and sexual communication $M=4.76 ; S D=0.46 ; M=4.61, S D=0.70 ; M=4.34, S D=0.84$, 
Table 4: Mean scores and SDs for effects of HIV status of instructor on intervention within the 3 prisons at $T 3(\mathrm{~N}=135)$

Prison KZN2

Rredictor

\section{Knowledge}

Prison MP

Peer?
HWl

Peer Control

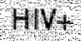

\section{rept} $1 \mathrm{~W}=$
Peer

HIVt
Rrison MP?

Pontro:

Peer Peer

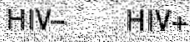

$\begin{array}{ccc}2.95 & 2.98 & 2.92 \\ (0.09) & (0.07) & (0.14)\end{array}$

2.75

2.90

2.94

$(0.72)$

(0.15)

(0.11)

$2.84 \quad 2.90$

2.92

2. Attitude towards condoms
$4.70_{\mathrm{a}} \quad 4.93_{\mathrm{b}} \quad 4.79 \mathrm{c}$

(.38) $(0.22) \quad(0.70)$

$4.22_{a} \quad 4.51_{b} \quad 3.43 c$

$(0.46)$

(0.20)

(0.15)

\section{Attitude towards} PLWA

$(0.73)$

$(0.70)$

(1.21)

4.31

$4.71_{b} \quad 4.53_{c}$

(1.12)

$(0.43)$

(0.51)

\section{$\begin{array}{lll}4.66 & 4.50 \quad 4.52\end{array}$ \\ $\begin{array}{lll}(0.49) & (0.72) & (0.60)\end{array}$}

\subsection{0}

4.16

4.10

4.32

4. 17

4.27

4. Sexual

communication
$4.70_{a} \quad 4.88_{b} \quad 4.76_{c}$

(0.49)

$(0.41)$

$(0.43)$

(0.25)

$(0.46) \quad(0.45)$

$\begin{array}{lll}(0.46) & (0.33) & (0.39)\end{array}$

$4.86_{\mathrm{a}} \quad 4.70_{\mathrm{b}} \quad 4.05_{\mathrm{c}}$

$4.04 \mathrm{a} \quad 4.80_{b} \quad 4.59_{c}$

$(0.28) \quad(0.50) \quad(0.72)$

(1.05)

$(0.42)$

$(0.93)$

\section{Skillls for \\ 4.77 \\ $4.79 \quad 4.80$ \\ practicing safe sex
$(0.30)$
(0.24)
$(0.36)$

$\begin{array}{ccc}4.69 & 4.76 & 4.22 \\ (0.34) & (0.38) & (0.81)\end{array}$

3.70

(1.59)

$4.79 \mathrm{~b}$

$4.78_{b}$

(0.29)

6. Intention
4.65
4.95
4.79
(0.36)
(0.13)
(0.38)
4.73
4.70
4.36
$\begin{array}{lll}(0.45) & (0.59) \quad(0.79)\end{array}$

$4.07_{a} \quad 4.73_{b}$

$4.83_{\mathrm{b}}$

$\begin{array}{lll}(1.15) & (0.41) \quad(0.33)\end{array}$

Note. For each prison, means within a row that are printed in bold and do not share subscripts differ significantly.

respectively). Additionally, we found main effects of Peer Educator on self-efficacy and intention that, however, were qualified by interaction effects with Prison, $F(4,129)=$ $6.57, p<.001$, and $F(4,128)=3.73, p<.01$, respectively. On these variables the effect of Peer Educator was significant only for MP2 prison on self efficacy, $F(2,135)=14.41$, $p<.001$, and intention, $F(2,134)=8.18, p<.0001$. Subsequent posthoc comparisons. showed that both the peer negative and peer positive instructors performed better than the control group ( $p^{\prime} s<.05$ ), but with no significant differences between the peer negative and peer positive instructor.

\section{Discussion}

The findings of this study indicate significant differences between the experimental and control groups on the variables that require development of certain practical skills involved in the practice of safer sex such as sexual communication and self-efficacy. Both groups showed reasonably high intention to reduce risky behaviour apon release from prison, but the intervention group likely due to their advantage of having additional skills acquired were able to follow through and demonstrate high intention to practice safer sex in the long term when they were back in their communities. The intervention showed no 
differences in variables that measure long term socially and culturally mediated variables such as social norms and attitude towards people living with HIV and AIDS.

Although both instructors showed positive results compared to the control group, the findings suggest that a HIV negative peer educator is likely to be a better choice of an agent for behaviour change in prison populations. Due to the stigma attached to spending time in prison, the additional stigma of being HV positive might make it difficult for prisoners to look up to someone who has that extra burden to deal with as a role model they can aspire to be like. The HIV negative peer educator who conducted the sessions in prison MP2 was a former inmate who had recently been released from the same prison and was still on parole while working on the project. This may have led him to being a more trustworthy and credible figure for the participants in those groups and thus likely to have been one of the reasons while prison MP2 showed a generally higher impact of the intervention than the other two facilities. Another important observation was that the peer educator in prison MP1 had graduated with his high school certificate while still in prison, and most participants might have been aware of that and therefore looked up to him even before he became part of the intervention team as a positive role model. Therefore it is likely that spending time in prison may make someone a suitable candidate to conduct a life skills programme in the prison context, however peer educators whose claim of prison experience is easily verifiable by the participants may lead to an even greater impact for prison based programmes. Devilly and colleagues (2005, p.237) observed that despite the paucity of evidence on prison based peer-led interventions, emerging research data suggests that "such programs are well tolerated, effective and possibly more cost effective than professionally led programmes".

Our findings indicate a clear pattern of generally less impact of the intervention in MP1 prison. This facility was the smallest facility which only had one lock up area and thus all study participants were leaving in the same quarters while bigger facilities had several living quarters where participants were housed. These highly increased chances for contamination between participants in a smaller facility like MPl, due to the close knit nature of the prison community. Efforts were made to build in some down time between the groups in order to allow participants to be released before the enrolment of the next experimental group in the project. Despite all these attempts the unpredictable nature of prison release procedures meant that some participants who were in a different condition were still around the facility when another group was already involved in the study. Additionally it soon came out that the programme became very popular amongst the facilities such that inmates who were due to be released started knowing about it and preparing for enrolment long before they met the conditions. Typical part of this preparation would be to find out what the programme participants were doing and start sharing the information such as folders and pamphlets from the sessions, which could potentially have lowered the effect of the intervention.

The study also highlights the different socio-cultural differences between inmates in the developing world and inmates in a first world setting in terms of the urgent issues that 
needs to be addressed in pre-release and community reintegration programming for inmates. While most inmates in the West are likely to face problems with accommodation and homelessness almost all the participants in our study went back to their families and relatives who accepted them back into the family (Sifunda et al., 2005c). Most studies in Western countries avoid doing longitudinal community follow up studies with ex inmates due to the dismal rates of tracing them up after release (Grinstead et al., 1999; Clark, et al. 2000) as most of them get lost from the system. However, the present study showed a significantly low attrition rate amongst the participants even when conducting community follow-ups for up to 6 months after they had been released from prison. This was achieved despite the fact that the communications infrastructure is also not that advanced as a majority of the participants did not have a street address or a telephone. Most family members usually commended the team during follow up visits based on the participants testimonials on how the intervention helped them with pre release preparation. The intervention was even of greater importance when taken into account the fact that the majority of the participants were first time offenders, who therefore stood a very high chance of being reformed to avoid future problems with the law and also protect themselves from potential health problems when they get out of prison.

There were several inherent limitations in the present study. Firstly the sampling was mainly guided by the parole approval system in the prison as participants were only people who had been granted parole: It is likely that inmates who did not qualify for parole might have been different from those who were eligible for participation in the study. In addition to that, the conditions attached to being released on parole are very strict which might led to participants giving responses that they perceive to be more social desirable in order to ensure that they safe guarded their parole conditions. Additional the financial incentive might also have led to some bias on the responses given by participants during follow up interviews, as participants might have felt they had to give 'good answers' in order to qualify for the incentive.

Secondly, the study focused on measuring behavioural intentions as opposed to actual reported behaviour which might have been a stronger indicator of the effect of the intervention. Prison parole conditions are very strict and inmates are supposed to adhere to all of them while they are still serving their sentence in the Community Corrections wing of DCS. Most of the behaviour related questions such as use of drugs and alcohol and other risk taking practices are part of the things that people on parole are not supposed to engage in. Upon realising this potential for under reporting of all this behaviours the intervention was then assessed mostly on psychosocial determinants with low reliance on actual behaviour as most people were not likely to declare that they are breaking parole rules. Nonetheless we feel that the intention measures provided a fair indicator of participants' behaviour.

Thirdly, the control group had to be given with general government issued information and communication materials, such as pamphlets, leaflets and posters. These 
materials are widely avallable in the public health service and to a lesser extent some were also found in the prison health facilities. Inmates being a subgroup that generally has poor access to information, we were ethically bound to ensure that the control group also recelves some minimal benefit for participating in the study. It is highly likely that participants in the control would have paid more attention to the information and enquired more clarifications from colleagues due to their increased awarenesis through participating in the study. Much as this materials were not similar to the intervention, they did cover a number of health issues that were formed the intervention curriculum, though in a less in-depth manner but could have still had an impact on their intended behaviour outcomes.

\section{Implications for practice}

This study was one of the few studies that explored the use of theoretical approaches in designing health education intervention targeting inmates and probably the only one conducted in the setting of Sub-Saharan prison conditions. As a relatively new area of theory application there is still a huge need to expand work in this area in order to establish the applicability of different behaviour theories in the context of a prison setting. Bryan and colleagues (2003) observed that even in a prison context in the US, there are still cultural and linguistic differences as evident in African-Americans showing less explained variance on a TPB model compared to Hispanics and Caucasians respectively. The additional issues of language and adaptation of terminology in South Africa when taken into consideration (Sifunda et al., 2005b), underscores the need for socio-culturally appropriate locally designed programs targeting inmates.

This study also highlights the need to explore further subgroup specific behaviour determinants that apply to inmates risk related behaviour. It is through using an integrated approach of combining traditional psychosocial constructs and the emerging inmate specific constructs that targeted interventions can become more effective. Researchers also need to pay more attention to language and numeracy skills when conducting prison based research and this is even more important for non English speaking populations. Messages for inmates need to be simple and focused to ensure that even people with low literacy are able to grasp all the program concepts. Due to the insular nature of most correctional facilities the best way to successful programs for inmates, will be achieved through forging long-term cooperative partnerships between the prisons and public health institutions. It is through these collaborative partnerships that all stakeholders can jointly map out priority areas and realistic interventions for incarcerated individuals. Internationally the need to apply systematic theory based program development for inmates is an area that needs to receive even more attention than it is currently getting. 
General discussion and conclusion 


\section{Introduction}

Prison research is an area that is increasingly gaining prominence amongst public health practitioners, mostly due to the realisation of the negative consequences in neglecting prison health issues. Inmates are a subpopulation group that is still grossly underserved with little evidence of properly designed prison based health interventions. The challenge for researchers has been to come up with new theories and insights into the field starting from an almost non-existent body of evidence. Depending at how one looks at it, this has been both a challenge and at the same time a golden opportunity for the few researchers embarking on prison based research to engage in an area where there is boundless possibilities to discover and shape the future directions in the development of appropriate health interventions for prison based populations.

There is a strong body of evidence from epidemiological data highlighting the multitude of challenges that are faced by inmate populations worldwide (Braithwaite, Hammett \& Mayberry, 1996). Most inmates are usually from poor socioeconomic backgrounds with very little or no access to appropriate health care services even in their communities. This creates a complex web of criminality, unemployment, substance use and other harmful behaviours that lead to poor health status amongst inmate populations. While this might seem as an inmate problem the reality is that prisons are not isolated islands or closed off systems despite the physical barrier of prison walls. Inmate health problems subsequently have an impact on the health of greater society as inmates are constantly moving in and out of prison and in the process interact with a large number of people such as their sexual partners, spouses and families when they get released from prison. It is therefore critical to utilise time spent in prison as a window of opportunity to provide critical life skills and health interventions to inmates in preparation for their release and enhancing better reintegration and coping skills when they get 'outside'.

This thesis outlines the development and evaluation of the first ever prison based health education intervention for soon to be released inmates in South Africa. We followed a systematic development approach utilising the combination of theories and empirical evidence on prison health issues locally and worldwide, and tested the final untervention in an experimental study design. Through the research conducted for this thesis many valuable lessons and insights have been gained on the process of conducting prison based research in the context of the developing world. The thesis has also highlighted a number of health and welfare issues that affects inmates in the South African context and therefore makes a contribution to the process of formulating a broad agenda that tackles prison health issues in a holistic manner. 


\section{Discussion of empirical studies}

\section{Structural and cultural context of the study setting}

The second chapter of the study describes the initial structural and situational analysis of prisons as a setting for the envisaged health promotion intervention. As the study was the first of its kind in South Africa, it was logical to conduct a comprehensive access point analysis into the prison health care system and structural characteristics of correctional facilities in the two provinces earmarked for the intervention. This provided a good measure of the right entry point into the correctional system in South Africa. The process followed provided the research team with insights and perceptions of health care delivery in prisons as experienced by correctional health workers and inmates as providers and end-users of the heaith services respectively.

Health promotion interventions emerged as an area of health care services that was not getting the necessary attention and seriousness it deserved. None of the facilities involved, had a program in place apart from infrequent invitations of health educators from the public health service to provide once off talks. Activities for the commemoration of "World AIDS Day" once a year were considered as the key aspect of providing health education, an approach that is unlikely to result in substantial change of behaviour amongst inmates. The poor focus on health education programs results in inmates missing an opportunity to gain critical health information while serving time in prison. Despite the departmental policy outlining health education as an key function for health workers there were no means to monitor whether health staff actually conducted health education programs in their facilities which would enable the provision of necessary support, where required. Furthermore no standardised health education materials existed within the department to facilitate easier provision of health education in prisons. Faced with a situation whereby correctional staff were not skilled in designing health interventions, prisons have been missing a golden opportunity of imparting critical health information and skills for disease prevention amongst inmates.

Understanding the prison structural environment and operating procedures helped in the logistical planning of how to implement a long term prison based program in a realistic manner focusing on the context of the prison setting. This information provided guidance for the selection of facilities to be involved in the intervention. For instance, all prisons are run on strict routines that have to be adhered to on a daily basis and more often there is minimal flexibility within the system. So if participants missed lunch because of attending the training sessions that would mean that they had to wait till the next scheduled meals. Program planning took into account all these dynamics and most arrangements were continuously renegotiated throughout the duration of the study. Another unique characteristic of prison based research is the fact that, much as prisons fall under the same jurisdiction, they in no way resemble a homogeneous grouping. Every single facility has got its own subculture and internal guidelines that evolved ower time and guide the common practices of both inmates and officials. 
As the study had a community follow-up aspect certain facilities, such as farm prisons would not have been suitable for inclusion in this type of study as they are usually in isolated locations housing long-term prisoners who come from all over the country. As prisoners from these facilities come from all over the current practice is to transfer them to smaller facilities closer to their communities in the last few months before parole. This information therefore helped us to focus on smaller facilities that house inmates from surrounding communities who were suitable candidates for participating in the intervention and allowed easier tracing and follow up when they returned to their communities.

Chapter 3 focuses on the cultural and linguistic considerations that needed to be taken into account as a build up to designing and implementation of a health education programme amongst Nguni speaking inmates. As part of developing and adapting western-based concepts into the South African context the understanding of illness meanings and indigenous interpretations of STI and AIDS related terminology was very critical. This was even a more pertinent issue when taking into consideration that most of the inmate population has got little or no formal education and thus all program materials had to be written in Ngunil languages and orally transmitted to the target group.

Focus group interviews with both prison warders and inmates provided some insights into the issue of everyday terminology and illness representations associated with STIs and HIV amongst Nguni speakers. Conventional biomedical terminology used in brochures and the like is hardly used by members of our target population. Most widely available government issued leaflets usually translate content directly from English versions to local languages without any consideration to ensure that health information is contextually equivalent to what the original materials are trying to convey. This approach is grossly flawed and as evident from the findings of this study, very unlikely to result in any meaningful gain of information and change in behaviour. The programme tested in this thesis was one of the first interventions that acknowledged the existence of non traditional STIs and allowed for participants to engage with prevention issues taking into account both cultural and mainstream evidence based strategies. It is important to note that our intervention did not attempt to provide any authoritative input into the cultural STI related issues and practices, but allowed participants to share and challenge these issues amongst themselves. It is through this kind of open minded approach to socio-cultural issues that researchers and health care workers can come to understand the use of the dual system of consulting both traditional and western remedies in the management of STIs amongst indigenous populations in South Africa.

The poor track record in the area of socio-cultural health research has largely been due to the prevailing reality where most researchers are not familiar with local languages, and thus rely on translators who have no training in the development of health education programs. The so called bilingual translators will typically lack the skills required to identify any loss of content and meaning that occurs during the translation of materials. 
Unfortunately the existence of socio-cultural dynamics and 絇ness interpretations in public health cannot be wished away or brushed aside as cultural barners. Capacity development initiatives amongst indigenous population groups, is the challenge that, if $_{\text {ingnored, will be }}$ detrimental to both researchers and the target populations, and will lead to continued implementation of contextually inapproprate programs that end up being ineffective.

\section{Determinants studies}

The fourth and fifth chapters presented data from a systematic exploration of health behaviour determinants amongst inmates, specifically psychosocial determinants and alcohol and other substance use. Bryan and colleagues (2004) suggests a two pronged approach in the exploration of subgroup specific determinants. The first stage involves exploring the applicability of general constructs from established models of health behaviour such as the health belief model (HBM), theory planned behaviour (TPB), social cognitive theory $(\mathrm{SCT}$ ) and other theories that have worked successfully in the general population. Second in this process is to explore subpopulation specific constructs that provide specific information about the target group. A combination of these two approaches is likely to provide a model that allows for the development of better tailored interventions. This study followed a similar approach whereby we were not only interested in identifying specific prison related subgroup constructs, but went further to explore the applicability of traditional theories in inmate populations in the context of a non-Western country.

The study demonstrated the applicability of both the SCT and TPB as an appropriate model of predicting sexual behavioural intentions amongst prison populations. The constructs of self efficacy, sexual communication, general life skills efficacy emerged as the most significant variables that would serve as an entry point for a health education intervention targeting inmates. This emphasised that inmates needed a programme that would equip them with sexual negotiation skills as well as practical skills related to risk reduction such as correct use of condoms. Communication skills are very critical amongst inmates as they not only improve health related behaviour, but also enhance general interpersonat skills, which can help them avoid engaging in violent behaviour. General life skills efficacy such as conflict resolution and negotiations were also strong predictors of positive intentions amongst inmates. These skills are essential to reduce general risk taking including engaging in criminal activities and other undesirable behaviours. However, it must be mentioned that constructs such as knowledge and attitude still received special emphasis in the intervention as the prison population tends to vary a lot depending on the educational levels as well as the length of incarceration. Participants who had spent long periods in prison tended to have very low knowledge levels and even their risk perception was different to younger inmates who had been in prison for shorter periods.

In addition we found unique constructs such as 'sex as a utilitarian transaction', which is a very prison specific construct emanating from the widespread use of sexual favours 
as a form of payment amongst inmates both inside and outside prison. We also found high social acceptability of marijuana smoking amonist inmates, which is believed to cause relaxation and remove any sexual urges. Alcohol on the other hand was perceived as a substance that heightens sexual urges and seen to increase risky behaviour and thus not a very popular substance amongst inmates while serving time in prison.

Alcohol and marijuana use is extremely common amongst inmate populations as evident in this study where a large majority $(94 \%)$ reported drinking alcohol and more than half the participants reported use of marijuana prior to entering prison. Inmates always carry one of the heaviest burden of alcohol and other substance use when compared to the general population (Adesanya et al 1997, Braithwaite et al., 1996). There seems to be a clear link to the cycle of criminal activities and substance use whereby inmates committed crimes more often when they are under the influence of mind altering substances. Conversely, dependence on illegal substances can lead to individuals committing criminal acts in order to get money to acquire drugs. This cycle is highly linked with general risk taking which extends to health related behaviours more especially, unprotected sex, sex under the influence as well as transactional sex.

The reported use of marijuana and alcohol was strongly linked with past history of having an STI prior to arrest, which suggested some link between substance use and risky behaviour. The belief of alcohol leading to risky sexual behaviour was strongly linked with risky sexual behaviour while on the other hand there is a strong belief amongst inmates that marijuana use did not result in risky sexual behaviour. Amongst inmates smoking marijuana is believed to actually do the opposite, of ensuring that smokers do not think about sex or have any sexual urges after smoking. This partially explains the widespread use and appeal of marijuana inside prisons as the drug is supposed to help one to pass the sentence quickly and also eliminate sexual feelings. If smoking the drug is associated with sex it would easily mean that those who smoke in prison would be admitting to homosexual behaviour as one would be expected to fuifill ones sexual urges after smoking. This belief of marijuana not having any effect on sexual risk behaviour is also found in research from other countries (Adesanya, 1997, Kingtree et al, 2001). It is evident from these findings that programs targeting marijuana use amongst inmates need to take this belief into account and try to outline other negative consequences of taking the drug, which might achieve more positive change amongst inmates.

\section{The peer-led health education intervention}

The few health interventions that have been conducted in prisons have largely focused on demographic variables such as race, gender, age and drug use history, which have served an important function in tailoring programs targeting these demographic differences (Belenko \& Peugh, 2004; Henderson, 1998; Jacob \& Stover, 2000). However, these types of studies have not been very useful in capturing the psychosocial differences thereby informing the content of systematically developed health education interventions. 
As the original intervention had been based on previous work on inmates in the USA, failure to follow a systematic approach when adapting the intervention would have led to the implementation of a program likely to be inappropriate for the South African context. There were a number of unique concepts that were added in our program in order to tailor the intervention on issues relevant to the SA correctional population. Therefore critical issues highlighted by the access point analysis (chapter 2), the terminology study (chapter 3) and the determinants studies (chapter 4) contributed greatly in informing the systematic development of the intervention. Topics such as manhood, cultural based roles and responsibilities, and raciall relations as well as personal skills assessment, emerged as strong themes for the intervention. It is important to note that in the past within the black community crime committed against white people was not viewed negatively due to apartheid legislation and therefore it was important to engage participants in this issue and explore the implications, especially in light of the changes in the country's politics.

The findings from the evaluation of the intervention demonstrate that it had little impact in the short term, with no significant differences between the control group and the experimental condition except for knowledge and intention. It is important to mention that the short term measurements were taken immediately after the programme was provided and whille all the participants were still in prison and therefore had not had an opportunity to apply any of the skills that the programme was targeting. Long term effects showed some differences as the experimental group demonstrated better practical skills for practicing safer sex and sexual negotiation skills as well as intention to reduce risky behaviour in their sexual encounters. These differences were obvious at this stage as inmates were now outside of prison and therefore had the opportunity to apply the acquired preventive skills.

The majority of participants in the study had previously been unemployed and even those who reported being employed prior to imprisonment were predominantly in low paying unskilled jobs with annual gross income of less than R10 000 (\$1500) (chapter 4). The low levels of education amongst the group might have also been partly responsible for this vicious cycle of poverty and crime. Upon release only $33 \%$ had managed to find employment at the time of conducting follow up interviews. The added stigma of being an ex-inmate coupled with lack of skills made it harder for ex-inmates to get employment, more especially in South Africa, where unemployment levels are extremely high in the non-skilled sector. There is a strong indication that most participants had been involved in criminal activities due to socio-economic reasons as the majority had been first-time offenders $(67 \%)$ who might have committed crimes to survive. Lack of skills and unemployment came out strongly in the qualitative studies and therefore job skills assessment had to be included as one of the themes covered in the intervention. This was probably the most pressing concern as inmates evidently faced a huge task of trying to get employment and avoid criminality in the backdrop of illiteracy, poverty and the stigma of having a criminal record. This issue often overshadowed the health related topics and 
clearly highlighted the need for a comprehensive skills development for inmates to enhance better community reintegration.

A very significant finding from the study was the fact that almost all the participants in the program returned home to live with their families and relatives after being released. Indications during follow up interviews and home visits with community corrections officers showed that most families were actively engaged in ensuring that parolees are following all the parole conditions. The prevatling family structure and strong social fibre in the South African context is an important factor that makes the rehabilitation and reintegration of inmates to be shared by a larger community network which offers more support and thus higher chances for successful rehabilitation and reintegration of offenders. Literature from most western countries indicates that in those societies most. offenders will largely go back to criminal and drug using circles after being released which exposes them to higher chances to commit another crime or violate parole conditions which lead to high levels of recidivism (Grinstead et al., 2001; Mahon, 1996). In the worst scenarios some ex inmates return to live on the streets if they are homeless, while in contrast the safer social and family networks in the South African context presents higher chances of better rehabilitation outcomes.

All the former inmates who were employed as peer educators to conduct the health education training sessions were still serving parole in the community corrections in their respective areas and therefore found the programme dealt with a lot of issues that they were personally dealing with. The peer educators had been recruited from the community corrections unit of DCS and therefore had firsthand knowledge of all the issues and challenges that are faced by inmates after release from prison more especially adhering to parole conditions and movement restrictions. The training sessions with the peer educators also provided an opportunity to refine the intervention in such a way that it would make the most sense and also avoid causing any controversy when implemented amongst inmates. Being involved in the project helped the peer educators in their own growth and rehabilitation and allowed them to provide a critical function of being role models as well as providing practical solutions and answers to a number of issues and concerns that the rest of the research team which had no prison experience would not have been able to address effectively.

The study demonstrated that using peer educators amongst prison populations is a very appropriate channel of programme delivery, due to the high level of credibility that an ex inmate would have amongst their peers. The use of both peer HIV-positive and peer HIV-negative educators helped to explore the issue of modelling even deeper and it is quite clear that inmates are not likely to look up to a peer positive role model. This would be quite understandable as the period of transition from prison to community life comes with a lot of anxiety for inmates and therefore individuals are likely to look up to people who are representing a picture of hope. Due to the high levels of stigma surrounding HIV infection inmates might not easily relate to an HIV positive peer 
educator. Another potential reason for this outcome might have been due to the fact that most of the material covered issues mostly to do with preventing oneself from getting infected, with less emphasis on behaviour related to people who were already infected. As none of the participants had been tested for their HIV status prior to enrolment it was difficult for peer positive educators to go more in-depth on positive living issues, as most participants were operating under the assumption that they were not infected.

\section{Methodological issues}

\section{Research design}

The need to adhere to strict ethical considerations led us to employ a nested design in the experimental study. The ideal design would have been to randomly assign a large number of different facilities between the different experimental conditions. Due to the fact that most prisoners are usually disenfranchised as it had been shown in the preliminary qualitative studies that they had low levels of HIV information, it would have been unethical to assign some institutions only to the control group and therefore every facility had to get all conditions of control, peer negative educator and peer positive educator. This type of study design created a situation where the chances for contamination between participants were extremely high due to the close knit nature of the prison community.

Efforts were made to build in some down time between the groups in order to allow participants to be released before the enrolment of the next experimental group in the project. Despite all these attempts the unpredictable nature of prison release procedures meant that some participants who were in a different condition were still around the facility when another group was already involved in the study. Additionally it soon emerged that the programme became very popular amongst the facility such that inmates who were due to be released started knowing about it and preparing for enrolment long before they met the conditions. Typical part of this preparation would be to find out what the programme participants were doing and start sharing the information such as folders and pamphlets from the sessions. This reality potentially lowered the effect of the intervention programme and in future studies with this type of design should be best avoided in prisons to ensure a more accurate assessment of programme impact.

\section{Measurements}

One major probable cause of the moderate impact outcomes in the study was likely to be due to the tools used in the assessments in the study. The study instruments mostly followed a Likert-type scale in the measurement of most variables. This is a widely used approach in social science research, but has significant limitations when applied in a non English language context more especially when translated into Nguni languages. It is difficult to assess the distinction in these languages between terms such as "agreeing" and 
"strongly agreeing", "disagree" and "strongly disagree" or "likely" and "most likely". One has to focus on tone and intonation to assess the subtle differences between the different responses. This challenge was overcome by employing well trained first language Nguni speakers to administer the questionnaire in a face to face situation.

Prison parole conditions are very strict and inmates are supposed to adhere to all of them while they are still serving their sentence in the Community Corrections wing of DCS. As the research team worked closely with the officers from the parole office and sometimes even had to share the same vehicles when tracing participants, it is highly likely that inmates would not report any information that they viewed as being a violation of their parole conditions. Most of the behaviour questions such as use of drugs and alcohol and other risk taking practices are part of the things that people on parole are not supposed to engage in. Upon realising this potential for under reporting of all this behaviours the intervention was then assessed mostly on psychosocial determinants with low reliance on actual behaviour as most people were not likely to declare that they are breaking parole rules.

\section{Challenges of conducting prison based intervention research}

This study clearly demonstrates that the prison is a very critical health care setting that needs even more research if public health goals are to be reached for both prisons and society at large. One important finding from this study was the fact that prison based studies are feasible despite all the challenges that makes engaging in this area to be viewed as a not so glamourous field for scientists. Because correctional facilities are highly controlled and closed systems researchers need to acknowledge that gaining access to prisons required a much deeper negotiation and understanding with prison officials at different levels of the line of command.

One major challenge in targeting soon to be released inmates in interventions is the issue of transfers to facilities nearer to the inmates ${ }^{t}$ communities. A sizable number of participants were lost to the programme due to being transferred to other prisons for the last few weeks before being released. The flow of information in prisons within departments is not very efficient such that even if a participant wanted to reverse a transfer in order to finish the intervention it was almost impossible to reverse a decision that had been authorised and needed to be executed by lower ranking officers. Space is also a controversial issue in prison as the entire facility is demarcated into all kinds of zones that are accessed based on certain privileges. Participants in the study could sometimes end up not attending the programme due to the intricate passage protocols that are applied to control movement. In certain times this would not be due to security concems, but based solely on territorial controls and power issues among staff members, which hinder programme implementation. However continuous negotiations and the development of trust between officials and the research team always seemed to lead to more acceptance and improved cooperation. 
Other major challenges are the logistics and the costs of conducting longitudinal studies with inmates. This is likely one of the main deterrent to researchers, as the process of conducting community follow up is very time and resource consuming especially in a country as vast as South Africa with many infrastructure shortages in tural areas. This problem can be solved by researchers working closely with the community corrections office as they are actively involved in tracing inmates on a daily basis. During the study there were plans to pilot an electronic monitoring device (EMD) system, which would make locating parolees easier for the community corrections department.

Low literacy levels amongst inmates provide a major challenge to researchers on how to ensure appropriate content during intervention planning. On the other hand the predominantly poor educational status of inmates builds the case for more targeted interventions as it is likely that interventions targeting the general population might be too complicated for the correctional setting. Prison inmates are likely to have low numeracy and grammar skills and therefore even though they might be adults, sometimes the content needs to be simplified enough, as most of them are unlikely to have gone beyond primary school education (Brathwaite et al., 2004). The most effective health education programs for inmates are likely to be programs that consist of simple and focused educational messages that do not depend on a high level of literacy (Seal, Margolis, Sosman, Kacanek, Binson \& Project START, 2003).

\section{Recommendations for future research}

Collaborative partnerships between prison facilities, research institutions and other community based service providers are probably the most effective solution in tackling the health and social welfare problems of inmates both inside and outside of the prison setting. These strategic partnerships are seen to be more effective due to their ability to provide complementing strengths between the partners and also lead to a stronger and wider network of partners working towards a common solution. Effective collaborations may lead to the development of multi-faceted pre release interventions targeting inmates that will deal with the major social welfare issues faced by inmates such as unemployment, job skills development and health behaviour change training. Part of the internal changes that took place during the duration of this study was the formation of a Research Unit within DCS head office in Pretoria. This was a very positive development that needs to be optimally utilised to strengthen research in prisons by providing proper training for staff as well as having the unit playing a lead role in setting up long term strategic partnerships with other organisations.

Discharge planning from prison facilities and appropriate reintegration training must receive stronger emphasis and should become more standardised as currently there is no clarity on what it entails. One of the reasons could be due to lack of meaningful partnerships between correctional facilities and service providers in the community such as the National Institute for Counselling and Rehabilitation of Offenders (NICRO). Most 
facilities will consider issuing inmates with pamphlets and address of a health care facility in their community as appropriate referral even for patients with critical conditions such as TB and STls. This can lead to inmates developing drug resistant strains of these conditions if they do not follow through with treatment due to the poor referral processes between prisons and the public health service. Inmates who had undergone some training through pre release programmes and received referral to an appropriate Community Based Organisation upon release for continuity of care, have been shown to demonstrate lower recidivism rates than inmates who did not participate in such programs (Flanagan, Kim, Zierler, \& Rich 1996, ).

Most inmates in the country are usually in prison as a result of committing petty socioeconomic crimes and therefore proper rehabilitation while in prison can reduce recidivism. Therefore investing in job skills development initiatives for inmates will be of major benefit to society at large. The current policy of optional participation in skills development result in missed opportunities as most inmates get to realise the disadvantages and consequences of having no marketable skills only when they are about to get released, which is usually too late: Furthermore the use of peer educators to administer interventions for inmates is an effective strategy that should be explored for possible large scale role over by the department as it has a strong role modelling and personal development aspect that benefits even the peer educators themselves (chapter 6).

There were strong indications that prison custodial staff would also need to get programmes that are tailored to improving their knowledge on health related issues, more especially on issues such as confidentiality of health information, stigma prevention and other issues involving their interaction with inmates on a daily basis (chapter 3). Health education interventions are undoubtedly of major benefit to inmates and the department needs to invest more time and resources in ensuring that this moves forward from just being a written policy to becoming a major part of health service provision in South African Prisons. Evidently the biggest challenges highlighted were staff shortages and inadequate training in health promotion for health care workers. The collaborative partnership approach provides opportunities for skills transfer for DCS staff provided by experts in the field from organisations such as the Medical Research Council and other organisations. 


\section{Conclusion}

Research in the correctional setting clearly requires a different approach and level of engagement when compared to conducting research in other settings. Prison based research requires sustained personal commitment and involvement, repeated attempts and continuous communication and negotiation with all stakeholders. This thesis demonstrates and hightights the importance and benefits of increasing public health efforts that comprehensively address health and welfare issues of inmates. Increasing the focus and resources targeting this critical area of public health enquiry is likely to lead to increased health benefits that far outweighs the challenges and even transcends beyond the prison walls. 


\section{References}

Abraham, C. (2004). Using theory in research. In C. Abraham, \& S. Michie (Eds), Healh psychology in practice (pp. 65-82). Malden, MA: Blackwell Publishers.

Adesanya, A. Ohaeri, JU. Ogunlesi, A.O. Adamson, T.A. \& Odejide, O.A. (1997). Psychoactive substance abuse among inmates of a Nigerian prison population. Drig Alcohol Dependency, 47, 39.44.

Adih, WK. \& Alexander, CS. (1999). Determinants of condom use to prevent HIV infection among. youth in Ghana. Joumal of Adolescent Health, 24, 63-72.

Ajzen, 1. (1991). The theory of planned behaviour. Onganisational Behaviour and Human Decision Procersas, $50,179-211$.

Albarracin, D. Johnson, B.T. Fishbein, M., Muellenteille, P.A. 2001\%. Theories of reasoned action and planned behaviour as models of condom use: A meta-analysis. Psydhological Bufletin "12, 142-161.

Bandura, A (1986). Social fotrdations of thought and action. A social cognitive theory. Englewood, NI: Prentice Hall.

Bandura, A. (1999). Self Efficacy: Towards a unifying theory of behavioural change. In Baumeister, R.F. (Ed.), The Self in Social Psychology (pp. 285-298). Philadelphia, PA, Psychology Press.

Bartholomew, L.K., Parcel, G.S., Kok, G. G Gottlieb, N.H. (2001). Intervention mapping: Designing theory and evidence-based health promotion programs. Mountain View, CA: Mayfield.

Becker, M.H. (1974). The Health belief model and personal health behaviour. Healh Education Monographs, 2, 324-508.

Belenko, S., \& Petugh, I. (2004). Estimating drug treatment needs among state prison inmates. Dnug and Alcohol Dependence, 77, 269-281.

Bellis, M.A., Weild, A.R. Mutton, J.K, Beeching IN., \& Syed, Q. (1997). Prevalence of HIV and injecting drug use in men entering Liverpool prison. British Medical Joumal, 315, 30-31.

Bosompra, K. (2001). Determinants of condom use intentions of university students in Ghana: An application of the theory of reasoned action. Social Science and Medicine, 52, 1057-1069.

Braithwaite, R., Stephens, T. Comely, R.C., Arriola, K, \& Robillard, A. (2004), The relationship among marijuana use, prior incarceration, and inmates self-reported HIV/AIDS risk behaviours. Addictive behaviours, $29,995-999$.

Brathwaite, RL. Hammet, TM. E Mayberry, R.M. 11996). Prisons and ADS. San Francisco: Jossey Bass, Inc.

Brummelhuis, H., E Herdt, G. (1995). Cuiture and Sexual Riste: Anthropoliogical Perspectives on AIDS, Cordon and Breach Publishers, Luxembourg.

Bryan, A., Aiken, LS., E West, S.G. (2004), HN/STD risk among incarcerated adolescents: Optimism about the future and self -esteem as predictors of condom use selfefficacy. lournal of Applied Social Psychology, 34, 912 - 936 .

Bryan, A., Ruiz, MS, \& ONeill, D. (2003). HV related behaviours among prison inmates: A theory of planned behaviour analysis. Joumal of Applied Sacial Psychology, 33, 2565-2586.

Bryan, A.D., Schindeldecker, M.S., E Aiken, L.S. (2001). Sexual self control and male condomuse outcome beliefs: Predicting heterosexual men's condom use fournal of Applied Social Psychology, 31, $1911-1938$.

Castilla, I., Barrio, $G$.. Jose Belza, M., \& De la Fuente, L. (1999). Drug and alcohol consumption and sexual risk behaviour among young adults: Results from a national survey. Drug and Alcohol Dependence, 56, 47-53.

Clark, N.J., Van Eck, RN., King, A., Glusman, B, McCain-Williams, A., Van Eck, S., E Beech, F. (2000). HIV/AIDS education among incarcerated youth. Joumal of Criminal Justice, 28,415-433.

Colvin, M. (1997). Sexually ,ransmitted diseases, South African health review, Health System Trust, Durban. 
Cummings, T.G., Eorley, C.G. (1997). Organisational development and change. Cincinnati, Ohio, South Western College publishing.

Department of Correctional Services (2001). Prisoners in custody. Statistics unit, Department of Correctional Services.

Department of Correctional Services (2003). Gearing towards rehabilitation: Policy document. Department of Correctional Services, Pretoria.

Department of Health. (2002). National HIV sero-prevalence survey of women attending public antenatal clinics in South Africa 2001. Pretoria.

Department of Health (2004). Camprehensive HIV and AIDS care, management and treatment for South Africa: Policy Doament, Pretoria.

Devilly, G.J., Sorbello, L., Eccleston, L, \& Ward, T. (2005). Prison-based peer education schemes. Aggression and Violent Behaviour, 10, 219-240.

Dolan, K., Wodak, A., E Penny, R. (1995). AIDS behind bars: Preventing HIV spread among incarcerated drug injectors. AIDS, 9, 825-832.

Farmer, $\mathrm{P}(1990)$. Sending sickness: Sorcery, politics and changing concepts of AIDS in rural Haiti. Medical Anthropology Quarterly, 4, 27.

Fisher, I.D., E Fisher, W.A. (1992). Changing AIDS-risk behaviour. Psychological Bulletin, 111, 455-474.

Fisher, J.D., Fisher, WA., Bryan A.D., E Misovich, S.J. (2002). Information-motivation-behavioural skills model-based. HIV risk behaviour change intervention for inner-city high school youth. Heallh Psychology, 21, 177-86.

Fleming, D.T, \& Wasserheit, J.N. (1999) From Epidemiological Synergy to Public Health Policy and Practice: The Contribution of Other Sexually Transmitted Diseases to Sexual Transmission of HIV Infection. Sexual Transmitted infections, 75, 3-17.

Foreman, M. (1999). AlDS and Mens: Taking Risks or Taking Responsibility? New York: St. Martin Press.

Glaser, J.B., \& Greifinger, R.B. (1993). Correctional Health Care: A Public Health Opportunity, Annals of Internal Medicine, 118, 139-145.

Green, E.C. (1992). The Antroppology of Sexually Transmitted Diseases in Liberia. Social Science and Medicine, 35, 1457-68.

Green, EC., Jurg. A., E Dgedge, A. (1993). Sexually-transmitted diseases, AIDS and traditional healers in Mozambique. Medical Anthropology, 15, 261-81.

Green, E.C., Zokwe, B. E Dupree, I.D. (1995) The experience of an AIDS Prevention Program Focused on South African Traditional Healers. Social Science and Medicine, 40, 503-515.

Green, LW. Groter, MW, (1999). Health Promotion Planming; An educational and Ecological Approach, 3nd Edition, Mountain View, Mayfield Publishing.

Grinstead O, Zack, B, Faiggeles, B. (2001). Reducing post-release risk behaviour among HIV seropositive prison inmate: The health promotion programme. Aids Education and Prevention, 13, 109-119.

Grinstead, O., Zack, B., Er Faugeles, B. (1999). Collaborative research to prevent HIV among prison inmates and their female partners. Health Education \& Behoviour, 26, 225. 238 .

Hammett, T.M. Gaiter, J.L. \& Crawford, C. (1998). Reaching seriously at-risk populations: health interventions in criminal justice settings, Health Education and Behaviour, 25, 99-120.

Hammett, T.M., Maruschak, Ls, \& Harmon, P. (1999). 1996-1997 update: HN/AIDS, STDs and TB in correctional factitives. Washington, DC: US Department of Justice.

Hammett, T.M., Harmon, M.P., \& Rhodes, W. (2002). The burden of infectious diseases among inmates of and release from US correctional facilities, 1997. American Journal of Public Health, 92, 1789-1794.

Helman, C.G. (2001). Culture Health and Ilthess, 4th Edition, Butterworth Heinemann, London. 
Hendesson, D1 1998. Drug abuse and incarcerated women: A research review foumal of Substance Abuse Treatment, $15,579587$.

Hospers, HI, \& KoK, G. 1995. Determinants of safe sex and risk-taking behavour among gay men: A review. ADS Education and Prewention, 7, 74-96.

Hospers, H.J. Debets, W. Ross, MW. B Kok, G. (1999) Evaluation of an HV prevention intervention for men who have sex with men at cruising areas in the Netherlands. ADS and Behaviour, 3, 359.366.

Hunter, S.M. \& Bhopal, R 2004$)$ Self Report in clinical and epidemiological studies in non-English speakers: the challenge of language and culture foumal of Epidemiology and Community Heath, 58,618 622.

Idemudia, SE, \& Reddy, S.P. (2002) Sexual Coercion of Young Offenders in Nigerian Prisons. Psychopathologie Africaine, 2, 221-234.

lacob, 1. \& Stover, H. (2000). The transfer of ham reduction strategies into prisons: needle exchange programmes in two German prisons. The International foumat of Dnig Polio, 11, $325-335$.

lames, S, Reddy, P., Ruiter, R.A.C., Taylor, M , Jinabhai, C.C., Van Empelen, P. E Van den Borne, B. (2005). The effects of a systematically developed photo-novella on knowledge, attitudes, communication and behavioural intentions with respect to sexually transmitted infections among secondary school leamers in South $\mathrm{Africa}_{r}$ Health Promotion International ${ }_{n} 20_{n}$ 157-165.

Krueger, R.A., (1988) Focus Groups; A Practical Guide for Applied Research, Newbury Park, CA, Sage Publications.

Kagawa-Singer, M. \& Kassim-Lakha, 5. (2003). A Strategy to Reduce Cross Cultural Miscommunication and Increase the Likelyhood of Improving Health Outcomes. Academic Medicine, 78, 577 - 587.

Kleinman, A. (1988). Rethinking Psychiatry: From Cutural Catgory to Personal Experience The Free Press, New York.

Kleinman, A. (1987). Anthropology and Psychiatry: The Role of Culture in Cross-Cultural Research on Illness. British joumal of Psychiatry, 151, 447-454.

Kingtree, J.B., Braithwaite, R., \& Woodring, T. 2000\%. Unprotected sex as function of alcohol and marijuana use among adolescent detainees. Journal of Adolescert Health, 27, 179-185.

Kingtree, J.B., G Phan, D.L. (2001\%. Marijuana use and HIV risk taking among adolescent offenders: The moderating effect of age. Joumal of Substance Abuse, 13, 59-71.

Kirby, D., G Diclemente, R.J. (1994). School based interventions to prevent unprotected sex and HIV among adolescents. In RJ DiClemente \& JL Peterson (Eds), Preventing AIDS: Theories and Methods of behavioural Interventions (pg $117: 139) \mathrm{NY}$, Plenum Press.

Kok, G, E Schaalma, H. (2004). Using theory in psychological interventions. In C. Abraham, \& S. Michie (Eds), Heallh psychology in practice (pp. 203-229). Malden, MA: Blackwell Publishers.

Leigh, B.C., G Stall, R. (1993). Substance use and risky sexual behaviour for exposure to HIV, American Psychologist, 48, 1035-1045.

Levy. M. (1997): Prison health services. British Medical fournal, 315, 1394-1395.

Long. I. Allwright, $S_{4}$ \& Begley, C. (2004). Prisoner's views of injecting drug use and tharm reduction in Irish prisons. The Iniernational foumal of Drug Policy, 15, $139-149$.

Mahon, N. (1996). New York inmates' HV risk behaviours: the implications for prevention policy and programs. Amterican Journal of Public Healthr 86, $1211-1215$.

Mallow, RM., Devieux, I.G., Jennings, T, Lucenko, B.A., \& Kalichman, S.C. (2001). Substance-abusing, adolescents at varying levels of HN risk: Psychosocial characteristics, drug use, and sexual behaviour: Journal of Substance Abuse, 13, 103-117.

Meyer-Weitz, A., Reddy, P., Weijts, W., Van den Bome, B., \& Kok, G. (1998). The Socio-Cultural context of STDs in South Africa: Implications for health education programmes. AlDS Care, 10, 39-55. 
Miller, IE, Guarnacia, P.), E Fasina; A. 2002). AlDS Knowledge Among Latinos: The Rolles of Language, Culture and Socio-economic Status. Joumal of Immigrant Health; 4, 63-72.

Mintzberg. H, 1993). Structure in fives, Englewood Cliff, N], Prentice Hall. Morris, RE, Baker, CI. Wallentine, M. Pennisi, A.j. (1998). Variations in HJV risk behaviours of incarcerated juveniles during a Four Year period: 1989-1992. Journal of Adolescent Health, 23, 39-48.

Nadeau, L., Truchon, M, \& Biron, C. (2000). High-risk behaviours in a context of substance abuse: A focus group approach, Joumal of Substonce Abuse Treatmen, 19, 319-328.

Patton, M.Q, (2002). Qualitative research and evaluation methods (3rd edition, pp. 339-447), Thousand Oaks, CA, Sage Publications.

Parker, C.R. (1995). The Social and Cultural construction of Sexual Risk, or How to Have (SEX) Research in an Epidemic; in Brummelhuis $\mathrm{H}$ E Herdt $\mathrm{C}_{\text {; }}$ Culloure and Sexual Rist: Anthropological Perspectries, Ansterdam; Gordon and Breach Publishers.

Perry, C.D.H., Er Pludderman, A. (2004). SENDU update, SADC epidemiology network on drug use. Medical Research Council, Cape Town, South Africa.

Peters, $\mathrm{V}_{,}$(2000), Kwalitan 5.0, Users Guide, Department of Research Methodology, Nijmegen, University of Nijmegen.

Pham-Kanter, G.B., Steinberg, M.H., B Ballard, R.C. (1996). Sexually Transmitted Diseases in South Africa, Genitourinary Medicine, $72,160-171$.

Poland, B.D., Green, L.W, E Rootman, I. (2001). Settings for health promotion: Linking theory and practice, California, Sage Publications.

Radley, A. (1994). Making sense of illness: The sacial psychology of health and disease. London, Sage Publications.

Rapposeli, K.K., Kennedy, M.G., Miles, R.J., Tinsely, M.J., Rauch, K.l., Austin, L., Dooley, S., ArandaNaranjo, B, E Moore RA, (2002). HIV/AIDS in Correctional Settings: A Salient Priority for the CDC and HRSA. A.IDS Education and Prevention, 14 (suppl B), 103-113.

Reddy, P., Meyer-Weitz, A., Van den Borne, B., Kok, G., G Weijts, W. (1998). The learning curve: Health education in STD clinics in South Africa. Social Science and Medicine, 47, 1445-1453.

Reddy, P., Van den Borne, B., \& Yach, D. (1995). Unravelling health promotion: in pursuit of more successful interventions. CHASA Jourval of Comprehensive Health, 6, 1110-114.

Rees, V., Saitz, R, Horton, N.I. \& Samet, ]. (2001). Association of alcohol consumption with HIV sex-and drug-risk behaviours among drug users, fournal of Substance Abuse Treatment, 21, 129 -134.

Resnicow, K, Soler, R., Braithwaite, R., Ahluwwallia, IS. \& Butler, C. (2000) "Cultural sensitivity in substance use prevention. Journal of Community Psychology, 28, 27/-290.

Ross, M.W., Timpson, S.C., Williams, M.L, \& Bowen, A.M. (2003). Situational correlates of condom se in a sample of African-American drug users who are primarily Crack Cocaine users. AVDS and Behoviour, $7,55 \cdot 60$.

Schaalma, H.P., A.braham, C. Gillmore, M.R., G Kok, G. (2004). Sex education as health promotion: What does it take? Archives of Sexual Behaviour, 33, 259-269.

Seal, W.D., Margolis; A.D., Sosman, I, Kacanek, D., Binson, D. and Project START (2003). HN and STD Risk Behaviour Among 18-to-25 Year -Old Men Released from US Prisons: Provider Perspectives. AIDS and Behaviour, 7, 131- 141.

Sheeran, P.; Abraham, C, \& Orbell, 5. (1999). Psychosocial correlates of heterosexual condom use: A metawanalysis. Psychological Bulletin, 125, 90-132.

Shisana O. \& Simbayi, L. (2002). Nelson Mandela HSRC study of HIV/AIDS: South African national HIV prevalence, behavioural risks and mass media household survey 2002. Pretoria: HSRC Press. 
Sifunda, S., Reddy, S.P., Braithwaite, R., Stephens, T., Bhengu, S. Ruiter, R.A.C, \& Van den Bome, B. 2005al. Access Point Analysis on the State of Health Care Services in South African Prisons: A qualitative exploration of Correctional Health Care Workers and Inmates' Perspectives in KwazulluNatal and Mpumalanga. Manuscript submitted for publication.

Siffunda, S., Reddy, S.P., Brathwaite, R, Stephens, $T_{n}$ Bhengu, S, Ruiter, R.A.C, \& Van den Bome, B. (2005b). Psychosocial Determinants of Risky Sexual Behaviour amongst South African Prison Inmates. Manuscript submitted for publication.

Sifunda, S., Reddy, S.P., Brathwaite, R, Stephens, T., Bhengu, S., Ruiter, R.A.C, G Van den Borne, B. (2005c). Social Construction and Cultural Meanings of STI and HIV/AIDS Related Terminology amongst Nguni Speaking. Prison Inmates in Four South African Correctional Facilities. Maruscript submitted for publication.

Sifunda, S., Reddy, S.P., Braithwaite, R., Stephens, T., Bhengu, S., Ruiter, R.A.C., \& Van den Borne, B. (2005d). The Effectiveness of a Peer-led HIV/AIDS and STI Health Education Intervention for Prison Inmates in South Africa. Manuscript submitted for publication.

Stephens, T. T., Braithwaite, R, G Cozza, S. (1999). Knowledge of prophylaxis therapy among HIVpositive prisoners. AIDS Care, 2, 547-554.

Stoller. N. (2003). Space, place and movement as aspects of health care in three women's prisons. Social Science and Medicine, 56, 2263-2275.

Toroyan, T., \& Reddy, P. (1998a). Participation of South African youth in the design and development of AlDS photocomics. International Qwarterly of Community Health Education, 17, 131-146.

Toroyan, T., \& Reddy, P. (1998b). Evaluation of a learner-produced photocomic in South Africa, International Quarterly of Community Health Education, 17.

Tumer, G. \& Shepherd, ]. (1999). A Method in Search of a Theory: Peer Education and Health Promotion. Health Education Research, 14, 235-247.

UNAIDS (2000). Report on the global HIV/AIDS epidentic June 2000. Joint United Nations Programme on HIV/AIDS, Genewa, Switzerland.

Van Empelen, P., Schaalma, H., Kok, G., \& Jansen, M.W.I. (2001). Predicting condom use with casual and steady sex partners among drug users. Health Education Research, 16, 293-305.

Van Heerden, 1., (1995). Issues affecting the reform of prison health care in South Africa. South African Medical Journal, $85,345-346$.

Wasserheit, IN.N. (1992). Epidemiological synergy. Interrelationships between human immunodeficiency virus infection and other sexually transmitted diseases, Sexually transmitted Diseases, $19,61-77$.

Watson. R., Stimpson, M., G Hostick, T. (2004). Prison health care: A review of literature, International Journal of Nursing Studies, 41, 119-128.

Winch, P.), Makemba, A.M., Kamazima, S.R., Lurie M., Lwihula, G.K.,Premii, Z, Minjas J.N. G. Shiff, C.J. (1996). Locall Terminology for Febrile Illness in Bagamoyo Districth, Tanzania and Its Impact on The Design of A Community-Based Malaria Prevention Programme. Social Science and Medicine, 42, 1057. 1067.

Wingood, G.M., Er DiClemente, R.J. (1998). The influence of psychosocial factots, alcohol, drug use of African-American Women's high-risk sexual behaviour. American Journal of Preventive Medicine, 15, 54 59.

WHO (2000). WHO guidelines on HIV infection and AIDS in prisons. UNAIDS Best Practice Collection. Geneva.

Woody, G.E, Donnell, D., Seage, R.G., Metzger, D., Marmor, M., Koblin, B.A., Buchbinder, S., Gross, M., Stone, B, \& Judson, FN. (1999). Non injection substance use correlates with risky sex among men having sex with men: data from HIVNET, Drug and Alcohol Dependence, 53, 197-205. 


\section{Summary}

This thesis describes the development and implementation of the first ever prison based peer-led health education intervention targeted at soon to be released prison inmates in South Africa. There is a strong body of evidence from epidemiological data highlighting the multitude of challenges that are faced by inmate populations worldwide. Most inmates are usually from poor socio-economic backgrounds, with very little or no access to appropriate health care services in their communities. The complex web of criminality, unemployment, substance use and other harmful behaviours leads to poor health status amongst offenders. Studies from western countries have indicated that inmate populations carry a very high burden of HIV and AIDS infections, with infection rates reported to be up to five times higher than in the general population.

Chapter 1 gives an outline of the thesis. First we describe the state of prison health issues. Prevailing problems in incarcerated populations such as risky sexual behaviour, substance use and access to health care services and health education programmes have been explored. We then explored the application of systematic intervention development models in the area of prison health research. Furthermore the history of prison institutions in South Africa is described, more importantly the paradigm shift in prisoner rehabilitation after the era of Apartheid. Lastly the chapter gives an overview of the project from a situational analysis through intervention development, implementation and evaluation of the health education intervention for soon to be released Nguni speaking prison inmates.

Chapter 2 describes the initial structural and situational analysis of prisons as a setting for the envisaged health promotion intervention. We conducted a comprehensive accesspoint analysis of the prison health care system and identified structural characteristics of the correctional facilities in the KwaZulu-Natal and Mpumalanga provinces. This provided a good understanding of the right entry points for involving key-persons and groups from the correctional system in South Africa in the development and implementation of the health education intervention. Health promotion interventions emerged as an area of health care services that were not getting the necessary attention. None of the facilities involved had in-house health education programs, apart from infrequent and irregular invitations to health educators of the public health service to provide once-off talks on some issues such as substance abuse and HIV and AIDS Prevention. This was mostly done on special occasions such as 'World AIDS day' commemoration. The poor focus on health education results in inmates missing an opportunity to gain critical health information while serving time in prison.

Chapter 3 describes the cultural and linguistic considerations that needed to be taken into account in the designing and implementation of a health education intervention amongst Nguni speaking inmates. As part of developing an effective health education intervention that is tailored to the South African prison context, the understanding of illness meanings and indigenous interpretations of Sexually Transmitted Infections (STIs) and AIDS related terminology of prison inmates and prison warders was very critical. 
Focus group interviews with both prison warders and inmates provided insights into the issue of everyday terminology and illness representations associated with STI and HIV amongst Nguni speakers. The programme that was tested in this study was one of the first interventions that acknowledged the existence of traditionat perceptions and interpretations of STls amongst Nguni Speakers. The intervention allowed participants to become involved in and become familiar with prevention issues taking into account the cultural context of disease, prevention and care while the intervention was developed according to mainstream, evidence based strategies.

Chapter 4 presents data from a systematic exploration of health behaviour determinants amongst inmates, specifically psychosocial determinants. The study demonstrated that both the social cognitive theory and theory of planned behaviour are appropriate models for predicting sexual behavioural intentions amongst prison

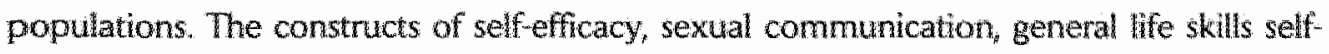
efficacy emerged as the most significant variables that would serve as an entry point for a health education intervention targeting inmates. The findings emphasised that inmates needed a programme that would equip them with sexual negotiation skills as well as practical skills related to risk reduction such as correct use of condoms. Communication skills are very critical for inmates as they not only improve health related behaviour, but also enhance general interpersonal skills, which can help them avoid engaging in violent behaviour. General life skills self-efficacy such as seffefficacy with respect to conflict resolution and negotiations were also strong predictors of positive behavioural intentions amongst inmates. These skills are essential to reduce general risk taking including engaging in criminal activities and other undesirable behaviours

Chapter 5 describes the extent of substance use amongst inmate populations. Alcohol and marijuana use is extremely common amongst inmates as was shown in this study where a maiority ( $55 \%$ ) reported drinking alcohol several times a week and also more than half the participants reported using marijuana prior to entering prison. The reported use of marijuana and alcohol was strongly linked with a past history of having a STI prior to arrest, which suggested some link between substance use and risky behaviour. The belief of alcohol leading to risky sexual behaviour was strongly associated with risky sexual behaviour while on the other hand there is a strong belief amongst inmates that marijuana use did not result in risky sexual behaviour. Amongst inmates smoking marijuana is believed to actually do the opposite, of ensuring that smokers do not think about sex or have any sexual urges after smoking. This partially explains the appeal and widespread use of marijuana inside prisons as the drug is supposed to help one to pass the sentence quickly and also eliminate sexual feelings

Chapter 6 outlines the findings from the evaluation of the intervention that demonstrate that it had little impact in the short-term, with no significant differences between the control group and the experimental condition except for knowledge (about HIV and AIDS and its prevention) and intention to reduce risky sexual behaviour, with a 
significantly higher increase in the experimental group as compared to the control group. Long-term effects showed some differences as the experimental group demonstrated better practical skills for practicing safer sex, better sexual negotiation skills and again a stronger intention to reduce risky behaviour in sexual encounters. There is a strong indication that most participants had been involved in criminal activities due to socioeconomic reasons. The majonty $(67 \%)$ had been first-time offenders while the main reasons for incarceration were petty theft, housebreaking and common assault which are not considered as serious crimes. Lack of professional skills and unemployment came out strongly in the qualitative studies and therefore job skills assessment had to be included as one of the themes covered in the intervention. A very significant finding from this study was the fact that almost all the participants in the program returned home to live with their families and relatives after being released. This also made it possible to approach the participants again for follow-up measurements after their release, which was a big problem in many previous prison studies in western countries. Follow-up interviews and home visits by community correction officers showed that most families were actively engaged in ensuring that parolees are following all the parole conditions.

The study demonstrates that using peer educators amongst prison populations is a very appropriate channel of program delivery, due to the high level of credibility that ex inmates have amongst their peers. The use of both peer HIV-positive and peer HIVnegative educators helped to explore the issue of modelling even deeper and it is quite clear that inmates are less likely to look up to a peer HIV-positive role model.

Finally Chapter 7 integrates the findings of the reported empirical studies and discusses the results and the implication for health education practice and suggests further exploration of health determinants and behaviour with regard to correctional populations. Furthermore the limitations of conducting research in a previously unexplored area of research as the correctional system are outlined. Additionally recommendations are presented for future research and expansion of the prison health agenda, more especially in the context of developing countries. 


\section{Samenvatting}

Deze dissertatie beschrijft de ontwikkeling en implementatie van de eerste planmatige gezondheisvoorlichtingsinterventie in Zuid Afrika die is gericht op gevangenen die binnen afzienbare tijd ontslagen worden en die werd uitgevoerd door ex-gevangenen (peers).

Epidemiologisch onderzoek bevestigt de veelheid van problemen waarmee gevangenen over de hele wereld geconfronteerd worden. De meeste gevangenen komen uit de lagere sociaal-economische klassen, met ook in hun woongemeenschappen weinig of geen toegang tot goede gezondheidszorg. Een complex samenspel van criminaliteit, werkloosheid, alcohol- en druggebruik leidt tot een slechte gezondheidstoestand van de gevangenen. Onderzoeken uit westerse landen hebben aangetoond dat mensen in gevangenissen veel vaker geïnfecteerd zijn met HIV en AIDS, met gerapporteerde infectiecijfers die 5 keer hoger zijn dan bij de doorsnee bevolking.

Hoofdstuk 1 geeft een overzicht van de dissertatie. Eerst geven wij een beschrijving van de gezondheidssituatie in gevangenissen. Veelvoorkomende problemen bij gevangenen zoals risicovol seksueel gedrag, alcohol- en druggebruik en toegang tot gezondheidszorg en gezondheidsvoorlichtingsprogramma's werden onderzocht. Vervolgens onderzochten wij de toepassing van planmatige interventie-ontwikkelingsmodellen op het gebied van onderzoek naar gezondheid in gevangenissen. Bovendien wordt de geschiedenis van het gevangeniswezen in Zuid-Afrika beschreven, waarbij de nadruk wordt gelegd op de paradigmaverschuiving naar de rehabilitatie van gevangenen na de periode van Apartheid. Tenslotte geeft het hoofdstuk een overzicht van het project van achtereenvolgens een analyse van de situatie, ontwikkeling van de interventie en de implementatie en evaluatie van de gezondheidsvoorlichtingsinterventie voor Nguni sprekende gevangenen die binnen afzienbare tijd ontslagen worden.

Hoofdstuk 2 beschrijft de initiële structurele en situationele analyse van gevangenissen als een setting voor de beoogde gezondheidsvoorlichtingsinterventie. Wii hebben een uitgebreide access-point analyse van het gezondheidssysteem in gevangenissen in Zuid. Afrika uitgevoerd en hebben structurele kenmerken van de gevangenissen in de provincies KwaZulu-Natal en Mpumalanga vastgesteld. Dit gaf ons een goed begrip van de mogelijkheden om sleutelpersonen en groepen van het Zuid-Afrikaanse gevangenissysteem te betrekken bij de ontwikkeling en implementatie van de gezondheidsvoorlichtingsinterventie. Uit het onderzoek bleek dat gezondheidsbevorderende interventies als onderdeel van de gezondheidszorg niet de nodige aandacht kregen. Geen van de betrokken instellingen had interne gezondheidsvoorlichtingsprogramma's, afgezien van zeldzame en onregelmatige uitnodigingen aan gezondheidsvoorlichters van de public health service om eenmalige praatjes te houden over onderwerpen als alcohot en druggebruik en HIV- en AIDSpreventie. Dit werd meestal gedaan bij speciale gelegenheden zoals Wereld AIDSdag. Het gevolg van de gebrekkige aandacht voor gezondheidsvoorlichting is dat gedetineerden de gelegenheid onthouden wordt om belangrijke gezondheidsinformatie tot zich te nemen terwil ze hun straf uitzitten. 
Hoofdstuk 3 beschrijft de culturele en taalkundige owerwegingen waarmee rekening gehouden moest worden bij het ontwerpen en implementeren van een gezondheidsvoorlichtingsinterventie onder Nguni sprekende gevangenen. Als onderdeel van het ontwikkelen van een effectieve gezondheidsvoorlichtingsinterventie die is toegesneden op de situatie in de Zuid-Afrikaanse gevangenissen, is het begrijpen van de betekenis die gevangenen en gevangenbewaarders aan ziekten toekennen, de inheemse interpretatie van seksueel overdraagbare aandoeningen (STIs) en de aan AIDS gerelateerde terminologie van gevangenen en gevangenbewaarders erg belangriik. Focusgroepinterview/s met zowel gevangenbewaarders als gevangenen die Nguni spreken, gaven inzicht in hoe zij praten over en welke ziektebeelden zij associëren met STls en HIV. Het programma dat in dit onderzoek werd uitgetest, was een van de eerste interventies die het bestaan erkende van traditionele percepties en interpretaties van STIs onder Nguni sprekers. De interventie gaf deelnemers de gelegenheid om betrokken te raken bij en vertrouwd te worden met onderwerpen met betrekking tot preventie die rekening houden met de culturele context van ziekte, preventie en zorg terwijl de interventie werd ontwikkeld volgens algemeen geaccepteerde, op onderzoek gebaseerde strategieën.

Hoofdstuk 4 beschrijft de resultaten van een systematische analyse van determinanten van gezondheidsgedrag van gevangenen, met de nadruk op psychosociale determinanten. De studie toont aan dat zowel de Sociaal Cognitieve Theorie als de Theorie van Gepland Gedrag geschikte modellen zijn om seksuele gedragsintenties onder gevangenen te voorspellen. De concepten self-efficacy, sexual communication en life skills self-efficacy kwamen naar voren als de belangrijkste variabelen die zouden kunnen dienen als een ingang voor een gezondheidswoorlichtingsinterventie gericht op gevangenen. De uitkomsten benadrukten dat gevangenen een programma nodig hadden dat hen zou uitrusten met zowel onderhandelingsvaardigheden met betrekking tot seks als praktische vaardigheden gericht op het verminderen van risico's, zoals het juiste gebruik van condooms. Communicatieve vaardigheden zijn erg belangrijk voor gevangenen omdat zij niet alleen het gezondheidsgedrag verbeteren maar ook hun algemene intermenselijke vaardigheden vergroten, wat hen kan helpen om betrokkenheid bij geweld te voorkomen. Algemene life skills self-efficacy, zoals self-efficacy met betrekking tot oplossen van conflicten en onderhandelen, waren ook sterke voorspellers van positieve gedragsintenties van gevangenen. Deze vaardigheden zijn essentieel om algemeen risicogedrag te verminderen, inclusief betrokkenheid bij criminele activiteiten en ander ongewenst gedrag.

Hoofdstuk 5 beschrijft de mate van alcohol-en druggebruik onder gevangenen. Uit dit onderzoek kwam naar voren dat alcohol- en marihuanagebruik zeer algemeen is onder gevangenen, waarbij een meerderheid (55\%) aangaf meerdere keren per week alcohol te hebben gedronken en eveneens meer dan de helft van de deelnemers aangaf marihuana te hebben gebruikt voordat ze de gevangenis ingingen. Het gerapporteerde gebruik van 
marihuana en alcohol was sterk gerelateerd aan het hebben gehad van een STI voorafgaand aan de arrestatie, hetgeen wijst op een mogelike relatie tussen alcohol en druggebruik en risicogedrag. De belief dat alcoholgebruik leidt tot risicovol seksueel gedrag was sterk geassocieerd met risicovol seksueel gedrag terwil aan de andere kant er onder de gevangenen een sterk belief is dat marihuanagebruk niet leidt tot risicovol seksueel gedrag. Gevangenen geloven dat het roken van manhuana het tegenovergestelde doet; het maakt dat rokers ervan niet denken aan seks of geen zin hebben in seks na het roken. Dit verklaart tot op zekere hoogte de aantrekkingskracht en het veelvoorkomend gebruik van marihuana in gevangenissen aangezien men denkt dat deze drug helpt om de straf sneller uit te zitten en de seksuele gevoelens uitschakelt.

Hoofdstuk 6 presenteert de uitkomsten van de evaluatie van de interventie en toont aan dat de interventie weinig invloed had op de korte termijn, met geen significante verschillen tussen de controlegroep en de experimentele groep, behalve dat bii de experimentele groep de kennis over HIV, AIDS en over preventie en de intentie om risicovol seksueel gedrag te verminderen, significant meer waren toegenomen. Op de lange termijn bleken er enige verschillen te zijn, waarbil de experimentele groep aangaf zowel over betere praktische vaardigheden voor het beoefenen van veiligere seks te beschikken als over betere onderhandelingsvaardigheden met betrekking tot seks en zij hadden nog steeds een sterkere intentie tot het vermijden wan risicovol seksueel gedrag.

Er zijn sterke aanwijzingen dat de meeste deelnemers betrokken zijn geweest bij criminele activiteiten vanwege sociaal-economische redenen. De meerderheid $(67 \%)$ had voor de eerste keer de wet overtreden, terwijl de belangrijkste redenen voor opsluiting kruimeldiefstallen, inbraken in huizen en gewone overvallen waren, die niet worden beschouwd als ernstige misdaden. Het gebrek aan professionele vaardigheden en werkloosheid kwamen sterk naar voren uit de kwalitatieve onclerzoeken en daarom moest beoordeling van de vaardigheden voor werk toegevoegd worden als een van de onderwerpen van de interventie. Een belangrijke uitkomst van dit onderzoek was het feit dat bijna alle deelnemers aan het programma na hun vrijlating uit de gevangenis teruggingen naar huis om weer bij hun familie te gäan wonen. Dit maakte het ook mogelijk om hen voor dit onderzoek opnieuw te benaderen voor na metingen na de in wrihheidstelling, wat een groot probleem is gebleken in veel studies onder gevangenen in westerse landen. Vervolginterviews en huisbezoek door community correction officers lieten zien dat de meeste famillies actief betrokken waren bij het ervoor zorgen dat de voorwaardelijk vrijgelatenen voldeden aan alle voorwaarden voor de voorwaardefijke invrijheidsstelling.

Het onderzoek toont aan dat het gebruiken van ex-gevangenen als voorlichters een erg geschikt middel is om een interventie bij gevangenen uit te voeren, vanwege de grote geloofwaardigheid van ex-gevangenen bij gewangenen. Het gebruiken van zowel HIVpositieve als HIV-negatieve ex-gevangenen als gezondheidsvoorlichters hielp om het onderwerp van modeling nog diepgaander te onderzoeken en het is duidelijk dat 
gevangenen minder geneigd zijn om op te kijken naar een HIV-positieve ex-gevangene als rolmodel.

Tenslotte worden in hoofdstuk 7 de resultaten van de empirische onderzoeken geintegreerd en worden de resultaten en implicaties voor de praktijk van de gezondheidsvoorlichting besproken en worden aanbevelingen gedaan voor verder onderzoek naar determinanten van gezondheid en gedrag met betrekking tot gevangenispopulaties. Daannaast worden de beperkingen bij het uitvoeren van onderzoek in een nog weinig bekend gebied van de wetenschap als het gevangeniswezen, geschetst. Bovendien worden aanbevelingen gedaan voor verder onderzoek en voor meer aandacht voor gezondheidsvraagstukken in gevangenissen, meer speciaal in de context van ontwikkelingslanden. 


\section{Acknowledgements}

To my supervisors, my family members (all over the world), my friends and colleagues.

KWANDZA KWALIWA BATSAKATSI

(Nguni proverb) 


\section{Curriculum Vitae}

Sibusiso 'uMabhoko ongashayeki' Sifunda was born on 13th June 1973 in Nkomazi in the Lowveld region of South Africa. At a very young age (thanks to the progressive policies of the National Partyl he became a guest of the government of Swaziland where he eventually completed his high school education Soon after high school he was awarded a merit scholarship to go and study in Canada and became a guest of the Canadian Government till 1995 when he returned to live in South Africa for the first time since the late seventies. Thanks to all the travel in his early years he can converse comfortably in over 10 languages. Upon return to SA he pursued BSc in physiotherapy at the University of Cape Town (UCT) where he was passionate about sports science and sports psychology. A former middle distance athlete and specialist in Russian/Ukrainian dancing he is still crazy about physical fitness and healthy lifestyles. Forever questioning life and evolving as a person he enrolled part-time in the first MPH class at UCT school of public health in 1999 and went on to become the first Black South African to be awarded an MPH by UCT. While working on his MPH Sibusiso was employed at the UCT faculty of health sciences as a Junior Research Fellow. In 2001 he joined the National Health Promotion R \& D Group at the Medical Research Council, where he became the Project Director for the first large-scale project focusing on prison health issues in South Africa. This project would eventually form the basis of his Doctoral studies with the department of Health Education and Promotion at the University of Maastricht. Since 2001 Sibusiso has been involved in several projects mostly focusing on substance use, STI, HIV and AIDS prevention. He is passionate about cultural and contextual relevance in the application of health behaviour theories and life skills intervention programmes. He is currently leading the process of setting up a new research programme on Mens' Health and Behaviour where he will act as the Programme Director. He still secretly dreams of becoming a Jazz pianist. 